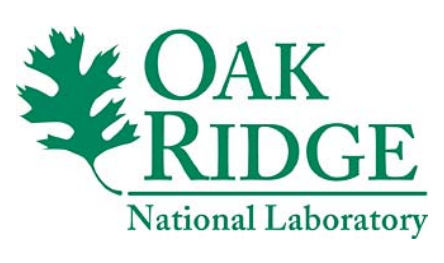

ORNL/TM-2008/174

\title{
Local Dynamic Reactive Power for Correction of System Voltage Problems
}

September 30, 2008

\author{
Prepared by \\ John D. Kueck \\ D. Tom Rizy \\ Fangxing (Fran) Li \\ Yan Xu \\ Huijuan Li \\ Sarina Adhikari \\ Philip Irminger
}

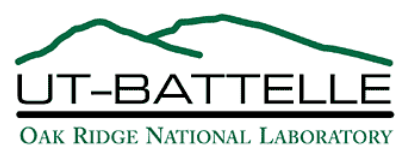




\title{
DOCUMENT AVAILABILITY
}

Reports produced after January 1, 1996, are generally available free via the U.S. Department of Energy (DOE) Information Bridge:

Web site: http://www.osti.gov/bridge

Reports produced before January 1, 1996, may be purchased by members of the public from the following source:

\author{
National Technical Information Service \\ 5285 Port Royal Road \\ Springfield, VA 22161 \\ Telephone: 703-605-6000 (1-800-553-6847) \\ TDD: 703-487-4639 \\ Fax: 703-605-6900 \\ E-mail: info@ntis.fedworld.gov \\ Web site: http://www.ntis.gov/support/ordernowabout.htm
}

Reports are available to DOE employees, DOE contractors, Energy Technology Data Exchange (ETDE) representatives, and International Nuclear Information System (INIS) representatives from the following source:

\author{
Office of Scientific and Technical Information \\ P.O. Box 62 \\ Oak Ridge, TN 37831 \\ Telephone: 865-576-8401 \\ Fax: 865-576-5728 \\ E-mail: reports@adonis.osti.gov \\ Web site: http://www.osti.gov/contact.html
}

This report was prepared as an account of work sponsored by an agency of the United States Government. Neither the United States government nor any agency thereof, nor any of their employees, makes any warranty, express or implied, or assumes any legal liability or responsibility for the accuracy, completeness, or usefulness of any information, apparatus, product, or process disclosed, or represents that its use would not infringe privately owned rights. Reference herein to any specific commercial product, process, or service by trade name, trademark, manufacturer, or otherwise, does not necessarily constitute or imply its endorsement, recommendation, or favoring by the United States Government or any agency thereof. The views and opinions of authors expressed herein do not necessarily state or reflect those of the United States Government or any agency thereof.

\footnotetext{
This work was sponsored by the Department of Energy's Office of Energy Efficiency and Renewable Energy, Distributed Energy Program. Prepared by Oak Ridge National Laboratory, P.O. Box 2008, Oak Ridge, Tennessee 378316285, managed by UT-Battelle, LLC, for the U.S. Department of Energy under contract DE-AC05-000R22725.
} 
Energy and Transportation Science Division

\title{
Local Dynamic Reactive Power for Correction of System Voltage Problems
}

\author{
John D. Kueck ${ }^{*}$ \\ D. Tom Rizy \\ Fangxing (Fran) $\mathrm{Li}^{\dagger}$ \\ Yan $\mathrm{Xu}^{\ddagger}$ \\ Huijuan $\mathrm{Li}^{\S}$ \\ Sarina Adhikari ${ }^{\S}$ \\ Philip Irminger ${ }^{* *}$
}

Date Published: September 30, 2008

\author{
Prepared by \\ OAK RIDGE NATIONAL LABORATORY \\ Oak Ridge, Tennessee 37831-6283 \\ managed by \\ UT-BATTELLE, LLC \\ for the \\ U.S. DEPARTMENT OF ENERGY \\ under contract DE-AC05-00OR22725
}

\footnotetext{
* Power and Energy Systems Group at Oak Ridge National Laboratory

${ }^{\dagger}$ Professor of Electrical Engineering at University of Tennessee-Knoxville

* Post-doc working under Oak Ridge Institute for Science and Education (ORISE) program

$\S$ Ph.d. candidate working for Dr. Fran Li at the University of Tennessee-Knoxville

** Higher Education Research Experience (HERE) student working under ORISE program
} 



\begin{abstract}
Electricity distribution systems are experiencing outages due to a phenomenon known as local voltage collapse. Local voltage collapse is occurring in part because modern air-conditioner compressor motors are much more susceptible to stalling during a voltage dip than older motors. These motors can stall in less than three cycles $(0.05 \mathrm{~s})$ when a fault, for example, on the subtransmission system, causes voltage to sag to 70 to $60 \%$ of nominal. The reasons for this susceptibility are discussed in the report. During the local voltage collapse, voltages are depressed for a period of perhaps 1 or 2 minutes. There is a concern that these local events are interacting together over larger areas and may present a challenge to system reliability. An effective method of preventing local voltage collapse is the use of voltage regulation from distributed energy resources (DER) that can supply or absorb reactive power. DER, when properly controlled, can provide a rapid correction to voltage dips and prevent motor stall.
\end{abstract}

This report discusses the phenomenon and causes of local voltage collapse as well as the control methodology that the authors have developed to counter voltage sag. The problem is growing because of the use of low-inertia, high-efficiency $\mathrm{A} / \mathrm{C}$ compressor motors and because the use of electric air-conditioning is growing and becoming a larger percentage of system load. A method for local dynamic voltage regulation is discussed which uses reactive power injection or absorption from local DER. This method is independent and rapid and will not interfere with conventional utility system voltage control. The results of simulations of this method are provided. The method has also been tested at the ORNL's Distributed Energy Communications and Control (DECC) Laboratory using its research inverter and synchronous condenser. These systems at the DECC Lab are interconnected with an actual distribution system, the ORNL distribution system, which is fed from the Tennessee Valley Authority's $161 \mathrm{kV}$ subtransmission backbone. The test results are also provided and discussed. The simulations and testing show that local voltage control from DER can prevent local voltage collapse. Our inverter-based DER can start to respond in $100 \mu \mathrm{s}$ or less to the start of a transient voltage change; our rotating-based DER is slower but still can start to respond in milliseconds. The results also show that the control can reach a new steady-state operating (reference) point so quickly, within 0.5 seconds, that it does not interfere with conventional utility methods. With regard to air-conditioning stall, although the $0.5 \mathrm{~s}$ steady-state response may not be fast enough, our controls will result in immediate response by the DER. With enough reactive power output from multiple DER, they could keep the voltage raised high enough and long enough to prevent stalling. As indicated in the report, not all air-conditioner compressors will begin to stall at once; therefore, DER should be able to at least mitigate a complete stalling of the air-conditioners even if the voltage sags below the stall voltage for some units. 
System Voltage Problems 


\section{Contents}

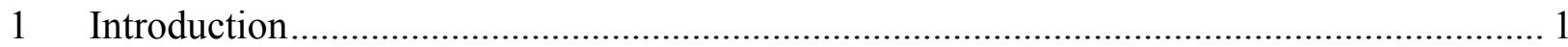

1.1 Effect of reactive power on blackout events …….................................................... 1

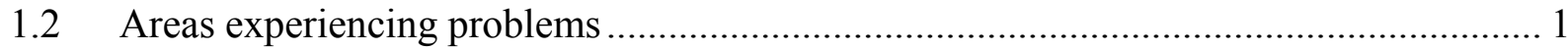

1.3 Problem providing/transmitting reactive power......................................................... 2

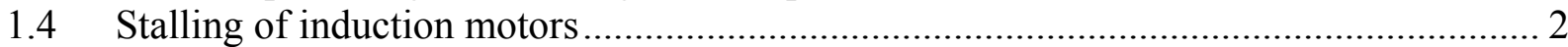

2 Voltage Effect on Motor Load and Power System Response................................................ 3

$2.1 \quad$ Effect of voltage on motor torque and stalling............................................................... 3

2.2 Existing tools and models to study the problem and determine a solution ....................... 4

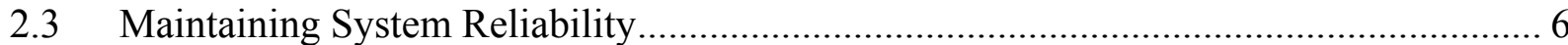

3 Power System dynamic behavior of Loads with voltage and temperature ............................ 7

3.1 Power system dynamic behavior with voltage, temperature effect: Load models and growing air-conditioning load...................................................................................... 7

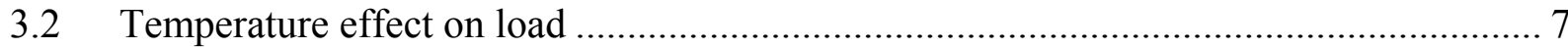

3.3 Reduction in Margin to Voltage Collapse ................................................................... 9

4 Problematic and unique features of energy-efficient motors, especially air-conditioning

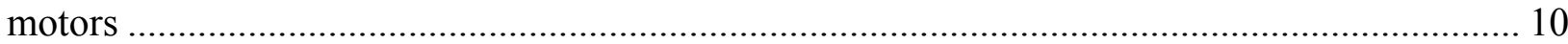

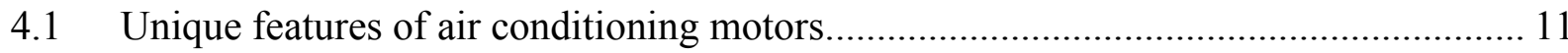

5 Optimum voltage for air-conditioning efficiency ………................................................... 14

5.1 Conventional voltage ranges required by standard .................................................. 14

5.2 Regulating Local Voltage to Improve Efficiency ................................................... 15

6 Commonly suggested voltage solutions and their drawbacks ............................................. 16

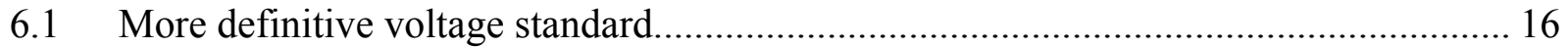

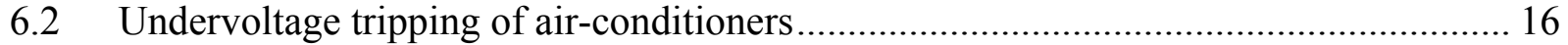

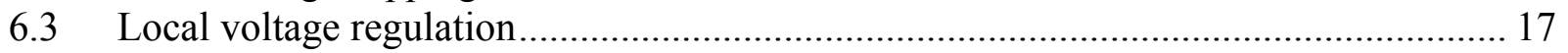

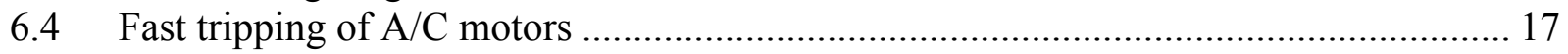

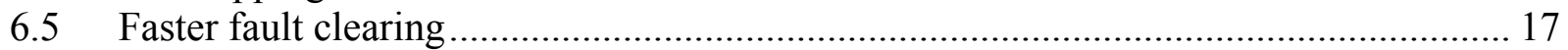

$7 \quad$ Challenges to Local Voltage Regulation ............................................................................ 17

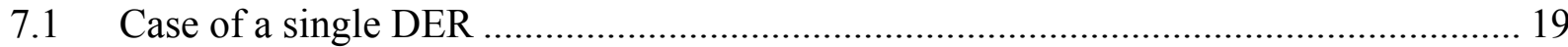

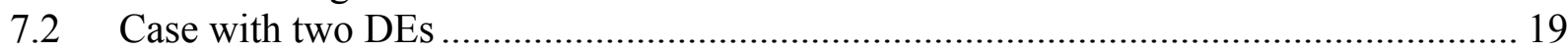

8 The Local Dynamic Reactive Resource Solution ............................................................... 21

$8.1 \quad$ Local dynamic reactive resources ………………................................................... 22

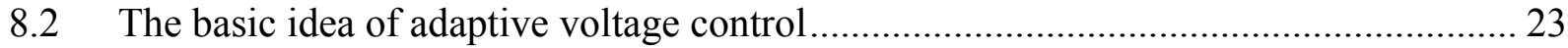

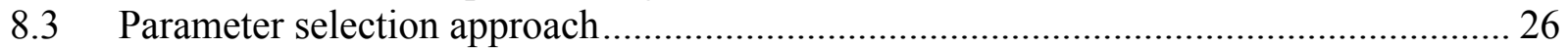

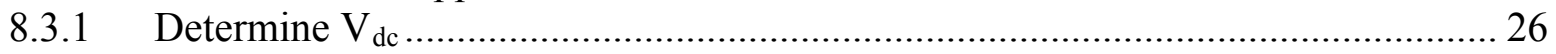

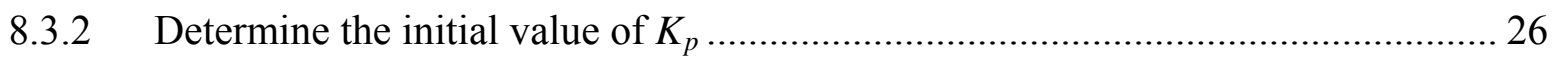

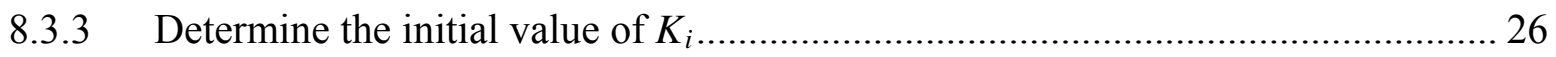

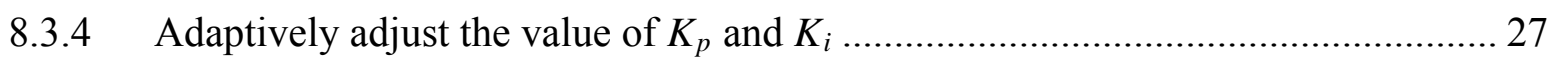

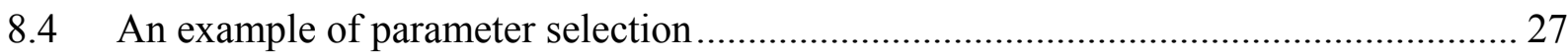

9 Adaptive Voltage Regulation Method and Simulation Results .............................................2 29

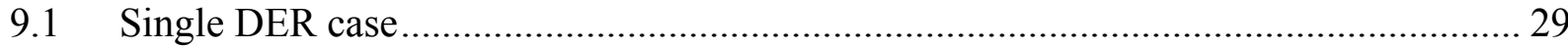

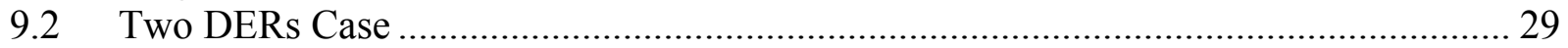




\section{Contents (cont.)}

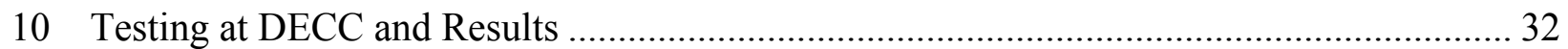

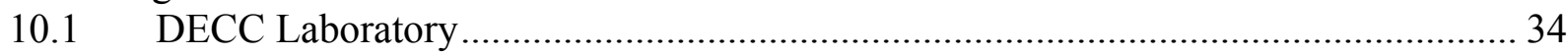

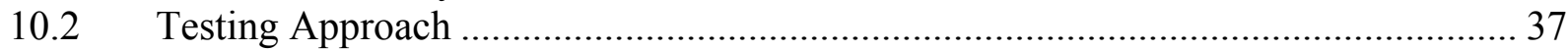

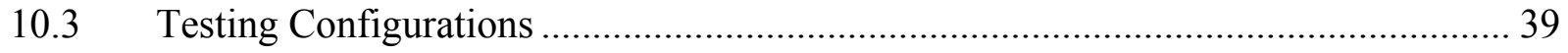

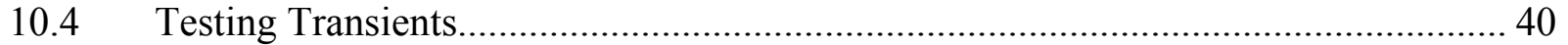

10.5 Test Schedule and Data Collected ..................................................................... 45

10.6 Control Algorithms and Testing Results ............................................................. 45

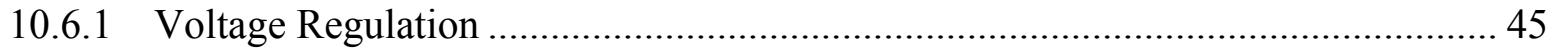

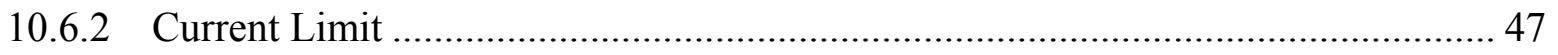

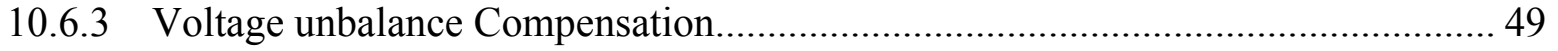

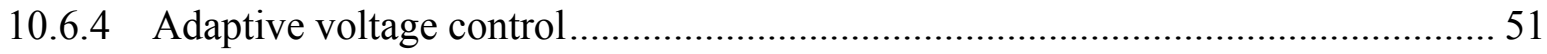

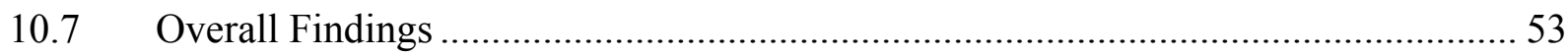

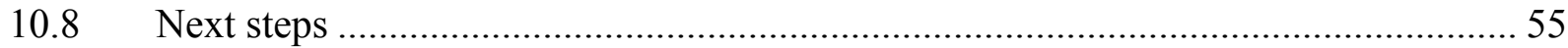

11 Simulations of system dynamic local voltage regulation using system load model............ 55

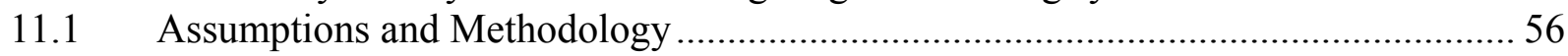

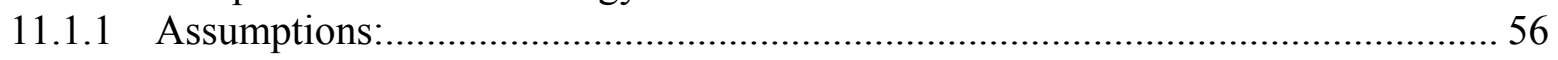

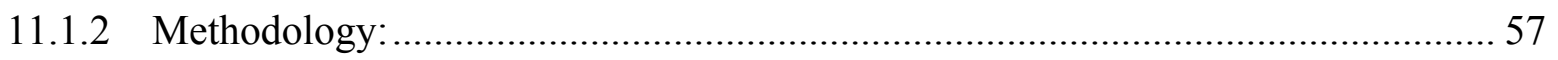

11.2 Simulation Results..................................................................................... 57

11.2.1 Case A: Verification of motor load characteristic during a subtransmission fault

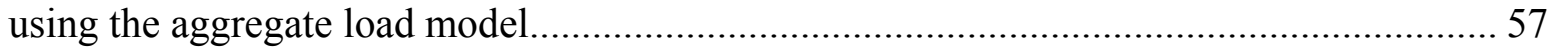

11.2.2 Case B: System with $240 \mathrm{~V}$ distribution feeder................................................ 59

11.2.3 Case C: System with 10 MVA loads in a $13.8 \mathrm{kV}$ feeder................................... 63

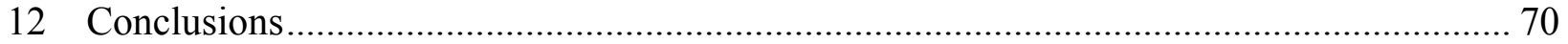




\section{Figures}

Figure 1-1. Transmission line absorption of reactive power. 2

Figure 3-1. Increase in running power (steady-state) of single-phase A/C compressor .................9

Figure 4-1. Compressor motor from a 3.5-ton $\mathrm{A} / \mathrm{C} ; \mathrm{H}=0.03$ to 0.05 seconds. ${ }^{\mathrm{b}}$...........................11

Figure 4-2. Voltage zones (normal, stall and drop-out) for $\mathrm{A} / \mathrm{C}$ operation. .................................12

Figure 4-3. Rapid stall of $\mathrm{A} / \mathrm{C}$ motor at $53 \%$ undervoltage in three cycles at $80^{\circ} \mathrm{F}$ and thermal

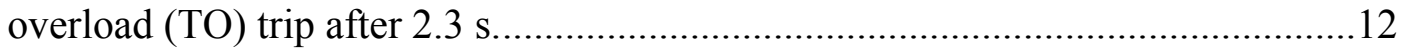

Figure 4-4. NEMA induction motor rotor bar designs. ......................................................... 13

Figure 4-5. Rotor bars from older and newer energy-efficient air-conditioning compressor

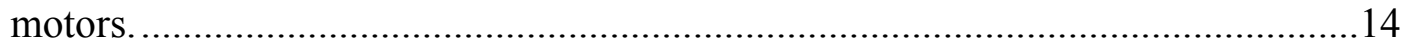

Figure 7-1. An illustrative diagram of a sample distribution system.........................................18

Figure 7-2. Single line diagram of the distribution system with DE. .........................................19

Figure 7-3. Voltage regulation with different $K_{p}, K_{i}$ — one DE case....................................20

Figure 7-4. Voltage regulation with different $K_{P}, K_{I}$-two DEs case. .......................................21

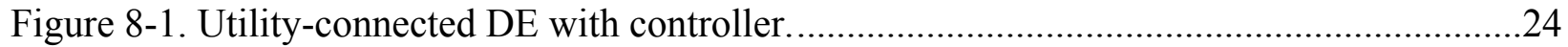

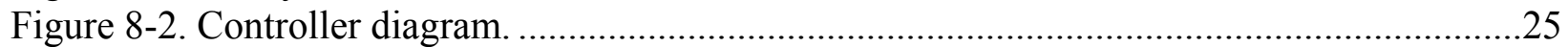

Figure 8-3 Desired response and actual response of the controller. .........................................25

Figure 8-4. Adaptive controller diagram. .......................................................................26

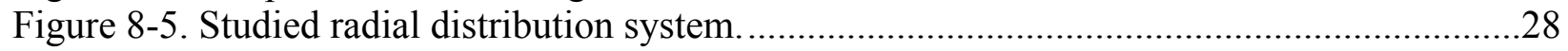

Figure 9-1. Voltage regulation with adaptive adjustment of $K_{p}$ and $K_{i}$................................30

Figure 9-2. Comparing ideal voltage error and the actual voltage error...................................30

Figure 9-3. Voltage regulation with initial $K_{p}$ and $K_{i}$. .....................................................30

Figure 9-4. Voltage regulation with adaptive adjustment of $K_{p}$ and $K_{i}$ at bus 2 .....................31

Figure 9-5. Comparing ideal voltage error and the actual voltage error at bus 2......................31

Figure 9-6. Voltage regulation with adaptive adjustment of $K_{p}$ and $K_{i}$ at bus 5.....................31

Figure 9-7. Comparing ideal voltage error and the actual voltage error at bus 5......................31

Figure 10-1. Inverter, synchronous condenser, and microturbine ...........................................34

Figure 10-2. Electrical configuration (diagram) of the DECC laboratory and equipment............35

Figure 10-3. Parallel (normal) configuration of circuits 2 and 4 forDECC testing......................40

Figure 10-4. Voltage transient due to balanced motor start...................................................41

Figure 10-5. Voltage transient due to single-phase motor start...........................................42

Figure 10-6. Load step transient with the addition of $20 \mathrm{~kW}, 37.5 \mathrm{kVar}$ load. ........................42

Figure 10-7. Load step transient with the removal of $20 \mathrm{~kW}, 37.5 \mathrm{kVar}$ load. .........................43

Figure 10-8. Synchronous motor (250 hp) startup and resulting voltage transient on SC power panel.

Figure 10-9. Synchronous motor $(250 \mathrm{hp})$ startup transient and resulting voltage sag on inverter power panel when the SC and inverter are connected in series................44

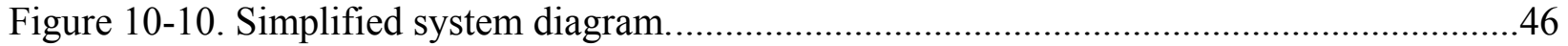

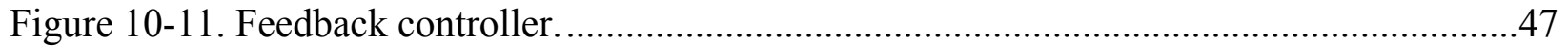

Figure 10-12. Voltage regulation with a sudden load change. ...............................................48

Figure 10-13. Control diagram of current limit for voltage regulation controller.......................49

Figure 10-14. Testing results of current limit for voltage regulation controller..........................50

Figure 10-15. Testing results of unbalanced voltage compensation controller..........................51

Figure 10-16. Testing results of voltage regulation for load change. .....................................52 


\section{Figures (cont.)}

Figure 10-17 Testing results of adaptive voltage regulation for load change............................ 53

Figure 11-1. Overall methodology of load modeling. .......................................................... 57

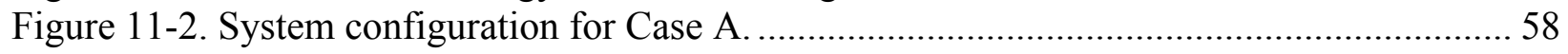

Figure 11-3. Voltage profile of bus $115 \mathrm{kV}$ without modeling of stalled case............................ 59

Figure 11-4. Voltage profile at the $115 \mathrm{kV}$ bus after using composite load model and

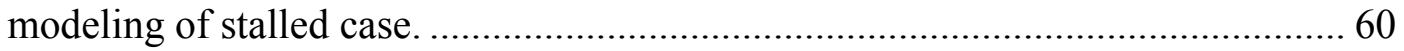

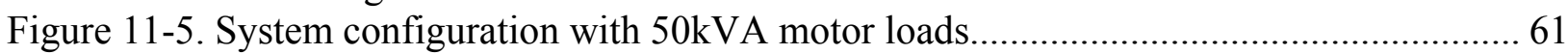

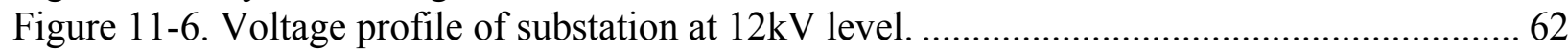

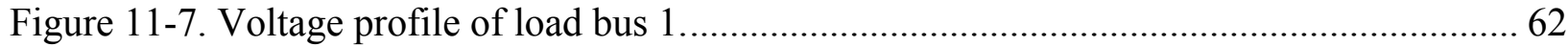

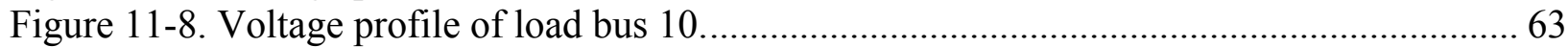

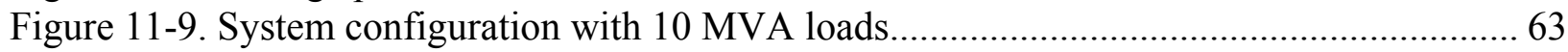

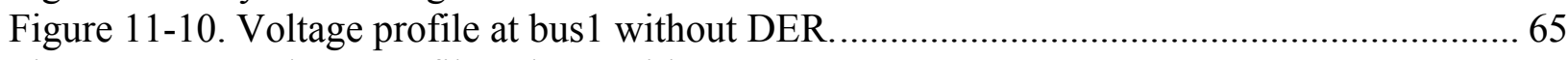

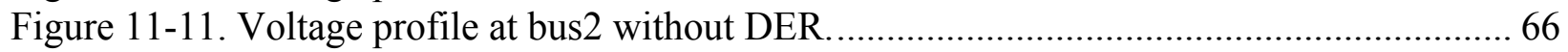

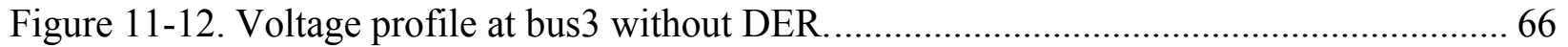

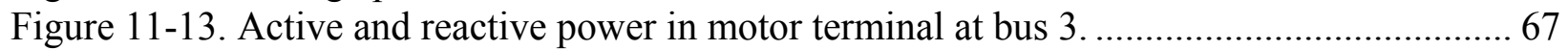

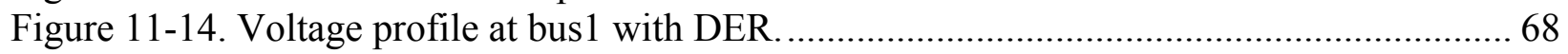

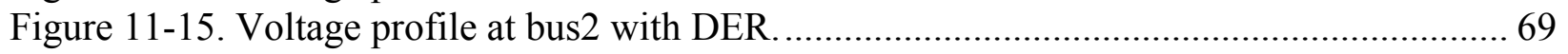

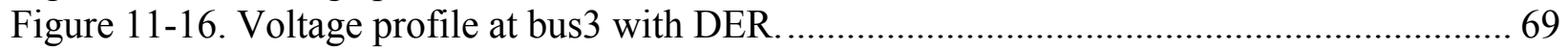

Figure 11-17. Reactive power injection from DER at bus 3 ............................................ 70 


\section{Tables}

Table 4-1. NEMA Motors.

13

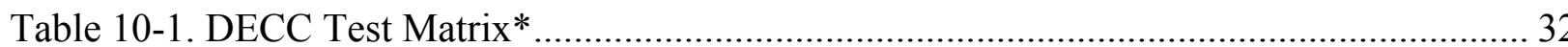

Table 10-2. Switching for the Three Different Circuit Configurations.

Table 10-3. Degree of Voltage Sag and Unbalance and Duration of the Different Motor Start Transients.

Table 10-4. Schedule for Testing of DE Control at the DECC Laboratory............................... 46

Table 10-5. Response times for adaptive voltage regulation................................................ 53

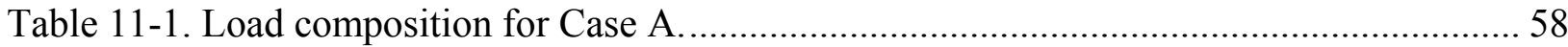

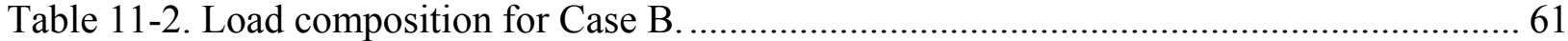

Table 11-3. Controller gain values for adaptive control of DER for Case C.............................6 64

Table 11-4. Load composition for Case C....................................................................... 64 
System Voltage Problems 


\section{Glossary}

A Amperes, a measure of current flow

ac Alternating current

$\mathrm{A} / \mathrm{C} \quad$ Air conditioner

Adc Direct current (dc) amperes due to direct current

$\mathrm{A}_{\mathrm{rms}} \quad$ Amperes RMS

CFL Compact fluorescent light

DC Direct current

DE Distributed energy or distributed generation

DECC Distributed Energy Communications and Controls

DER Distributed energy resource/resources

ETDS Extended Term Dynamic Simulation

$\mathrm{H} \quad$ Motor interia

hp Horsepower-745.7 watts

HPDM Heat Pump Design Model

$\mathrm{Hz} \quad$ Hertz - cycles per second; units of system frequency

IBGT Insulated-gate bipolar transistor

$\mathrm{I}^{2} \mathrm{R} \quad$ Voltage drop due to conductor resistance which is current squared times resistance

$\mathrm{K}_{\mathrm{i}} \quad$ Integral gain for PI controller

$\mathrm{K}_{\mathrm{p}} \quad$ Proportional gain for PI controller

$\mathrm{kV} \quad$ kilovolts or one-thousand volts

kVA kilovolt-ampere, measure of overall power capacity (apparent power)

kVAR kilovolt-ampere reactive, measure of reactive power

$\mathrm{kW} \quad$ kilowatts or one-thousand watts, measure of real power

Hs microseconds

MTG Micro-turbine generator

NEMA National Electrical Manufacturers Association

ORNL Oak Ridge National Laboratory

PCC Point of common coupling as defined in IEEE Std. 1547

PE Power electronics

PF Power factor-real power divided by apparent power

PI Proportional-integral, e.g., a PI controller

pu per unit

PV Photovoltaic, e.g., PV arrays

PWM Pulse-width modulation - modulation of duty cycle to control the amount of power

rms Root-means squared

$\mathrm{s} \quad$ second; there are 60 cycles in a second for a $60 \mathrm{~Hz}$ power system

SC Synchronous condenser (unloaded, overexcited synchronous motor)

SCE Southern California Edison Company 


\section{Glossary (cont.)}

SEER Seasonal Energy Efficiency Ratio

SVC Static var compensator

TO Thermal overload

TVA Tennessee Valley Authority

UV Undervoltage

V Voltage

VA Volt-ampere

$\mathrm{V}_{\mathrm{ac}} \quad$ ac voltage

$\mathrm{V}_{\mathrm{c}} \quad$ Inverter compensation voltage

$\mathrm{V}_{\mathrm{dc}} \quad$ dc Voltage

$\mathrm{V}_{\text {rms }} \quad$ Volts rms

Vt Terminal voltage at the PCC

W Watt -1 joule per second, a measure of real power 


\section{INTRODUCTION}

\subsection{Effect of reactive power on blackout events}

Reactive power supply is the key controller of voltage in alternating current (ac) power systems. The supply of reactive power, as with capacitive loads, will cause voltage to rise. Conversely, the absorption of reactive power, as with inductive loads, will cause voltage to drop. Dynamic sources of reactive power can rapidly change the amount of reactive power supplied or absorbed. Generators and solid-state devices such as static var compensators (SVCs) are the most common dynamic sources of reactive power. When a generator has additional reactive capacity that it can supply immediately when needed, it is said to be holding reactive reserves.

During a period of system stress, excess current flows to the load, the excess flow causes more reactive power absorption on the transmission lines, and voltage sometimes droops. Reactive reserves must be available to support voltage during system contingencies. At the beginning of the Northeast blackout of August 14, 2003, for example, all the reactive reserves in northern Ohio were exhausted, and voltage continued to fall and became unstable. Reactive power supplied locally has more impact than reactive power supplied from distant generators. Reactive power supplied from distant generators must flow on transmission lines, where it is absorbed (see Figure 1-1). Reactive power supplied locally could be a major player in improving system reliability as well as improving system efficiency by reducing congestion.

\subsection{Areas experiencing problems}

There are presently large-scale areas of "voltage susceptibility" that are known to have inadequate reactive reserves. On August 14, 2003, one such area was the Cleveland - -Akron, Ohio area. Other areas of voltage susceptibility that exist today are primarily located in urban centers. A relatively new phenomenon, micro-voltage collapse, is characterized by voltage instability occurring on individual distribution circuits. This instability is due to the fact that reactive power absorption can increase suddenly when large numbers of motors stall, e.g., during a subtransmission fault. This can pull down local voltage even though the subtransmission voltage may be marginally adequate. Induction motor stall reduces the motor power factor and increases current flow to the motor by about a factor of 6 and thus the current flow on the distribution circuit substantially. Motor stall in air-conditioning compressors is now much more rapid as a result of the extremely low inertia of energy-efficient motors. Distribution circuits that have a large percentage of air-conditioning load, such as those in Southern California, Arizona, and Florida, are susceptible. Ten years ago, $25 \%$ was considered a large percentage of airconditioning load. Today, there is anecdotal information of air-conditioning load reaching 70\% and published reports of up to 50\%. These levels of air-conditioning motor load truly present a concern, because if several circuits stall at the same time, the resulting level of inductive current flow may cascade into a wider-scale voltage collapse. 


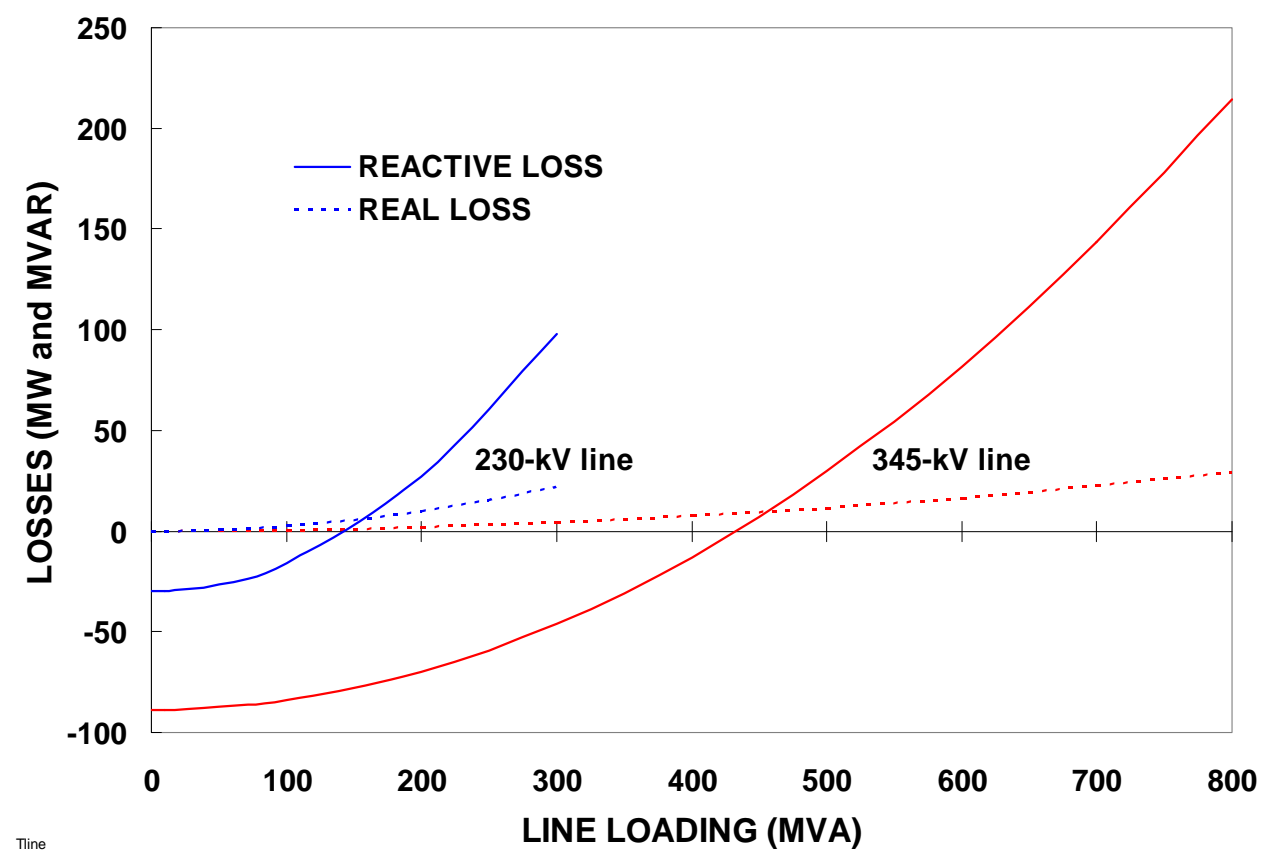

Figure 1-1. Transmission line absorption of reactive power.

\subsection{Problem providing/transmitting reactive power}

Transmission lines are inherently inductive (see Figure 1-1). The reactive power that is absorbed by transmission lines is equal to the square of the current flow multiplied by the inductive reactance. This means when a small amount of current is flowing, a very small amount of reactive power is absorbed. To make matters more complicated, transmission lines are also capacitive. The capacitance provides a supply of reactive power which is proportional to the square of voltage. Thus, at very light current flows, the line is capacitive. As current flow increases, at some point the capacitance balances the inductance and, at high current flows, the line becomes inductive. The characteristic impedance of a transmission line is expressed in terms of the surge impedance loading (SIL), or natural loading, which is the loading at which reactive power is neither produced nor absorbed. Loaded below its SIL, a line supplies reactive power to the system, tending to raise system voltages. Above the SIL, the line absorbs reactive power, tending to depress the voltage. This natural phenomenon makes it very difficult to supply reactive power across a transmission line to help support voltage. At high flows, the line absorbs the reactive power, depressing voltages even more. The old adage is "Reactive Power Does Not Travel Well."

Newer loads - such as high-efficiency motors, compact fluorescent light (CFL) bulbs, and adjustable speed drives - are helpful in providing more energy efficient loads that use less active power but problematic in terms of their reactive power use as is discussed later.

\subsection{Stalling of induction motors}

Induction motors typically have a full-load power factor of around 0.8 and a stalled- or lockedrotor power factor of less than 0.5 . This low locked-rotor power factor tends to depress local 
voltage when a large motor is started or when large numbers of small motors are stalled. An important change seen in the last few years is that high-efficiency motors are much more likely to stall because of their lower inertia and lower torque. Large groups of energy efficient motors used in air-conditioning compressors are now stalling together causing "microvoltage collapse". There is a concern that these microvoltage collapse events will begin to "lump" or interact together and cause large-scale voltage collapse. Other new energy-efficient loads also present problems. CFLs have a power factor of $0.5{ }^{\text {a }}$ In some states, legislation is being considered to ban the sale of conventional incandescent bulbs, which have a power factor of 1.0; in that case, all the new "more efficient" lighting load would have a power factor of 0.5 . Another developing problem is the use of adjustable speed drives for motors. In the past, when voltage drooped, induction motors slowed down slightly, and the motor load often decreased with the cube of the speed change. This had a "healing" effect for the system when an abnormal event occurred. When voltage drooped, load also dropped, offsetting the voltage decrease. This load drop was a critical part of reliable system operation. Today, when voltage drops, adjustable speed drives still supply the same voltage and frequency to the motor and thus eliminate some of the inherent load response.

\section{VOLTAGE EFFECT ON MOTOR LOAD AND POWER SYSTEM RESPONSE}

\subsection{Effect of voltage on motor torque and stalling.}

For the sake of completeness, this report will first discuss the effect of air-conditioner motor stall, as a stalled motor consumes six times as much electrical load, in general, as a running motor. Torque is the rotational force applied by the motor shaft to turn the compressor. Airconditioning compressors sometimes require high torque to start. Unfortunately, the torque delivered by an induction motor decreases with the square of the voltage. At $80 \%$ voltage, the motor will be delivering $64 \%$ of its rated torque. If the motor cannot produce enough torque to turn the compressor, it will stall or stop turning.

Voltages on the electric power system sometimes droop for an instant when there is a fault (short circuit) on the system. On a hot day, when the system is under heavy load and voltage has sagged to perhaps $90 \%$ of nominal, a fault may pull the voltage down to $75 \%$ or lower and a motor or motors may stall. Once a motor has stalled, it is not likely to start again until the voltage recovers. An air-conditioner motor needs its highest torque when it is starting the compressor. If the voltage at the motor terminal is not high enough, the motor may not be able to turn the shaft, and the motor may continue to stall.

At the precise instant of starting when the motor is not moving, the torque is called locked rotor torque. If the motor starts to turn the compressor shaft, the motor current immediately decreases as the motor begins to accelerate. If the motor does not have enough torque to turn the shaft, the motor will stall and continue to draw locked-rotor current. The locked rotor current is about six times greater than the normal full-load current. As the motor draws locked-rotor current, it heats up rapidly. The motor will eventually be tripped by a thermal overload (TO) protective device.

\footnotetext{
${ }^{\text {a }}$ Standard CFL bulbs have a power factor this poor; a premium, more costly CLF bulb that has a built-in capacitor can bring the power factor up to 0.9 .
} 
Voltage collapse occurs when power systems are under stress and there is not adequate dynamic reactive reserve to support voltage. As load increases, voltage sags and local voltage support is provided by capacitors. The ability of capacitors to supply reactive power decreases with the square of voltage. When voltage sags to $90 \%$ of rated voltage, capacitors provide only $81 \%$ of their rated reactive power. In addition, induction motors slow down and become more inductive, absorbing more reactive power and depressing voltage further. As voltage decreases, the effect builds on itself exponentially until finally the voltage collapses.

An interesting local phenomenon is now occurring on circuits with heavy air-conditioning loads. If a fault on the subtransmission system or some other contingency briefly depresses voltage, the air- conditioning motors may stall rapidly. Tests have shown that they can stall in as little as 3 to 5 cycles [1]. Local areas of voltage collapse are occurring as a result of air-conditioning compressor motor stall, sometimes on just one distribution circuit.

Local solution vs. transmission solution: The local solution is to use local dynamic reactive reserves operating to meet a voltage schedule to rapidly correct voltage so that the voltage does not drop and cause motor stall. The distribution system solution is to build a very stiff system with heavier conductors, shorter feeders, lower inductance and lower resistance so that the voltage does not sag as much when carrying high current levels. The distribution system solution is quite expensive compared with the local (equipment-level) solution.

\subsection{Existing tools and models to study the problem and determine a solution}

Distributed energy (DE) systems, such as reciprocating gensets, microturbines and fuel cells, provide a means to generate electric power closer to the end-user load more cleanly and efficiently. This is especially true if DE is combined with the recovery of waste heat generated by the prime mover. The prime movers that generate dc will use inverters to generate ac and interface with the distribution system. With the right controls, these DE systems can control not only real power $(\mathrm{kW})$ but also reactive power ( $\mathrm{kVar})$, which can dynamically regulate local voltage near the end-user load.

Traditional power system analysis methods are at best three-phase unbalanced powerflow analysis models based on Newton-Raphson and/or Gauss-Seidel iterative methods to calculate the bus voltages from quadratic algebraic equations. Most transmission system analysis tools, such as GE's PSLF, use only balanced models and network data. The methods are designed from steady-state operational and planning studies of various states and contingencies. They are inadequate for studying dynamic regulation of voltage by reactive-power-producing DE resources (DER), such as inverter-based microturbines or fuel cells. (Note that PSLF is now being expanded to model a composite load that includes small, single phase, motor loads.)

Several important limitations constrain the usefulness of traditional models for analyzing systems that include DER:

- A power flow analysis program that provides only balanced analysis will not be able to realistically analyze the impact of DE connection and penetration in the distribution system. 
It is expected that DE will continue to be placed by end-users in the distribution and transmission systems as the interest in locally generated power grows, especially any that can be generated using renewable resources such as wind turbines and photovoltaic (PV) arrays. Another issue is analyzing the benefit of regulating local voltage using DE. The traditional load flow models can analyze the steady-state benefits of DE such as capacity relief, loss reduction and to some degree voltage stability only by running numerous cases at lower and lower voltage to see when the power flow no longer converges to determine the margin to voltage collapse.

- Traditional tools lack the capability to link transmission network and distribution system models. Normally, transmission systems are modeled with a balanced power flow program, whereas a distribution system is modeled with either a balanced or unbalanced power flow program. Furthermore, the transmission system is normally modeled separately from the distribution system. In a transmission system model, the distribution system loads can be lumped (by equivalence) into a few large loads since the primary interest is the transmission system. Conversely, the distribution system model does not normally include the transmission system network in any great detail. In fact, normally only the substation voltage and transformer impedance is modeled on the load side of an infinite bus.

- Existing models cannot dynamically access the impact of DE controls on improving distribution and transmission system operation. These traditional analysis models do not have the capability to model the controls developed by the authors for providing autonomous and adaptive local voltage control. In order to adequately model these near-real-time controls, their impact on voltage regulation and their interaction with system-level voltage control of capacitor and line regulators, a much more flexible mathematical analysis tool such as Matlab/Simulink must be used. Unlike traditional modeling, Matlab/Simulink provides the ability to simulate the dynamic control logic of the DE inverter controllers. Typically, distribution utilities use commercial programs such as EMTP or ATP.

- Models are needed that can predict the behavior of air conditioners (A/Cs) during abnormal voltage events. Traditional power flow analysis methods normally treat loads as constant power or what is called a ZIP load, which is a combination of constant impedance (Z), constant current (I) and constant power (P). In the case of constant power, the model will continue to use the same power regardless of the voltage level (i.e., at lower voltage, it will draw more current). More recently, a composite load model that uses a motor load in parallel with the ZIP load has been used. Actual data have shown motor loads to be important to match load performance during an abnormal event, such as a fault, which is a more nonlinear load. The low-inertia compressor motors of high-efficiency A/Cs make them much more susceptible to stalling (rotor lockup) when the voltage drops below $70 \%$ or $60 \%$ of nominal. Therefore, it is extremely inaccurate to model the A/C's performance during a stall with the standard motor model. A more accurate representation for the stalled compressor is to model it with a constant impedance model instead.

In testing conducted by Southern California Edison (SCE), high-efficiency A/Cs with seasonal energy-efficiency ratios (SEERs) ranging from 10 to 13 were tested and found to stall at low voltage. Currently, only high-efficiency A/Cs and heat pumps with SEERs of 13 and higher are 
available making the stall of $\mathrm{A} / \mathrm{C}$ compressor motors more likely. The stalling can occur within three cycles (or $0.05 \mathrm{~s}$ ) of a single-phase or three-phase fault, requiring a time-based instead of a steady-state analysis based on algebraic equations and lumped parameter models. On a small scale, a mathematical program such as Matlab/Simulink can be used to model both the characteristics of the inverter-based DE controller and the response characteristics of system voltage regulation and loads such as high-efficiency A/Cs. A large-scale analysis using the same mathematical modeling program requires creating an equivalent model of the distribution and transmission system to keep the analysis and models manageable. Such as effort should be reasonable since the focus is on the specific performance of the DE controller and benefit of regulating voltage dynamically for various abnormal events such as $\mathrm{A} / \mathrm{C}$ stalling.

\subsection{Maintaining System Reliability}

To maintain the reliability of the electric power system at an acceptable level, risks to voltage stability must be controlled. The loading of major transmission corridors is often limited by stability concerns in the West (it is thermally limited in the east).

Stability is often dominated by the percentage of motor load. Reference [1] describes a study of voltage sensitivity in which the percentage of motor load modeled was based on actual detailed surveys on a substation-by-substation basis. The detailed surveys showed that roughly $52 \%$ of the total system load was motor loads. When this $52 \%$ was reduced to the $20 \%$ often used by the Western Electricity Coordinating Council (WECC), the voltage instability disappeared. The authors of reference [1] state that "The dynamics of voltage recovery and stability is highly influenced by the characteristic and fraction of motor load in the system." It is the belief of the authors of this report that the amount of motor load in the system today is being significantly underestimated because high-SEER air-conditioning compressors have a much higher load during hot weather than their low-efficiency predecessors, especially at stall conditions. This load is not used in system models because modelers are not aware of this feature of high-SEER air-conditioning, although SCE detected similar stalling performance effects with units from SEER 10 to 13. This challenge is going to become much more pronounced in California in the future as regulations require that only high-SEER air conditioning be installed. (This issue is discussed further in Section 3.2.)

Another study of air-conditioning motor stall [2] shows the response of the sample system after a 5-cycle fault. According to these authors, "With 2.5\% prone to stall motor load, the time for the voltage to recover to $80 \%$ of nominal is $0.88 \mathrm{~s}$, compared with $0.36 \mathrm{~s}$ without stalled motor load. At $5 \%$ prone to stall motor load, the final voltage only reaches about $74 \%$ of nominal. At $10 \%$ prone to stall motor load, the system goes into voltage collapse." Reference [2] also points out that the motor power factor under stalled conditions is significant in determining the total system reactive power demand, and that a lower power factor of 0.45 may be more appropriate for the prone-to-stall motors.

In addition, distribution systems are rarely balanced, as we are finding out in our testing. The Oak Ridge National Laboratory (ORNL) local voltage regulation method can provide balance compensation which greatly improves motor lifetime and efficiency. 


\section{POWER SYSTEM DYNAMIC BEHAVIOR OF LOADS WITH VOLTAGE AND TEMPERATURE}

\subsection{Power system dynamic behavior with voltage, temperature effect: Load models and growing air-conditioning load}

Extended-term dynamic simulation (ETDS) provides insight into the dynamic behavior of a power system. ETDS will show whether voltage problems are driven by slow or fast voltage dynamics, for example, whether there are coordination problems with capacitor bank switching and under voltage load shedding schemes. It also will provide guidance for fine tuning controls of SVCs, synchronous condensers (SCs), etc., so that voltage excursions can be regulated. As we will see, it is much easier to nip a voltage excursion in the bud than it is to deal with it after it has resulted in voltage collapse.

A typical load model may show motor load to be about $50 \%$ of peak system load. The motor load will often be a combination of industrial, residential and commercial motors. The remaining load may be about 20\% constant power load (electronics, motor drives, etc.), $10 \%$ discharge lighting (CFLs) and 20\% constant impedance load (incandescent lighting, ranges, irons, etc.). Each of these loads displays a fairly predictable response to voltage changes. Discharge lighting will typically extinguish when voltage drops below 70 to $80 \%$. Adjustable speed drives and computers tend to temporarily shut down when voltages drop below $90 \%$. Constant impedance loads draw less power as voltage drops. Large industrial motors and commercial motors have contactors, or electromagnetic contacts, that open when voltage drops to about $75 \%$. Small motors, such as those used in air-conditioning, do not have electromagnetic contacts, when voltage sags to $70 \%$ or less, these motors may stall, drawing large levels of current from the power system. They will continue to draw large levels of current until they trip on TO protection, which may take $10 \mathrm{~s}$ or even minutes. ETDS studies have shown that the amount of motor load has a significant impact on voltage stability. Small motors that do not disconnect but rather stall at low voltage are the most problematic. Even worse, low-inertia motors are quicker to stall and drag down system voltage. New, high-efficiency A/C motors have remarkably low inertia [1].

\subsection{Temperature effect on load}

When an $\mathrm{A} / \mathrm{C}$ unit must operate at higher ambient temperatures, the result is higher refrigerant pressures. Higher pressure increases the mechanical torque load for air-conditioning compressors [3] and the higher load means the A/C motor will draw more power. A sampling of test data for air conditioners operating at high ambient temperatures has been obtained. Newer, high-SEER $\mathrm{A} / \mathrm{Cs}$ are more effective at air-conditioning at an extremely high temperature range than are the older units, which tend to drop off in capacity (or unload) more at higher temperatures. This fact is probably only important to utilities in areas that experience temperatures over $110^{\circ} \mathrm{F}$. Compared with many of the older units, new high-efficiency A/Cs can use significantly more power in extremely hot weather $\left(115^{\circ} \mathrm{F}\right)$ than they use at $85^{\circ} \mathrm{F}$. For example, one utility found a SEER 10 unit to consume $23 \%$ more real power at $115^{\circ} \mathrm{F}$ than at $80^{\circ} \mathrm{F}$ whereas a SEER 13 unit consumes 55\% more real power at the higher temperature [5]. In addition, the SEER 10 sees no change in reactive power over this temperature range, whereas the SEER 13 sees a 31\% increase. This is not to imply that the higher efficiency A/C units (SEER 13) generally draw more power 
at $115^{\circ} \mathrm{F}$ than the older SEER 10 units, rather, their peak power draw is higher relative to the values drawn at the average cooling mode ambient.

ORNL developed and maintains the Heat Pump Design Model (HPDM), a detailed mathematical model that can be configured to model any $\mathrm{A} / \mathrm{C}$ or heat pump [4]. The model confirms that newer high-efficiency $\mathrm{A} / \mathrm{Cs}$ have a greater rate of power increase during extremely hot weather than do older $\mathrm{A} / \mathrm{C}$ models. There are three reasons for this result:

- The new scroll compressors maintain air-conditioning capacity better than older reciprocating compressors over high-temperature conditions. Reciprocating compressor capacity drops off more as ambient temperatures increase.

- The new environmentally safe refrigerant 410A loses efficiency at high ambient temperatures compared with the R22 refrigerant still in use in older models.

- New high-efficiency models typically have an expansion valve that automatically adjusts pressure for higher temperature so that the refrigerant is condensing properly. Older models typically have a fixed orifice expansion device that does not adjust with higher temperature and thus unloads the system more at higher ambient temperatures.

Unfortunately, very little testing on this effect has been found. SCE found in one case that the change in power per degree Fahrenheit was 74\% higher for a SEER 12 roof top A/C as than for a SEER 10 model ([5], page 32).

SCE prepared a second Air Conditioner Test Report [5] which found that the increase in running power to a residential SEER $13 \mathrm{~A} / \mathrm{C}$ could be about $29 \%$ higher than the increase for a SEER 10 A/C. Figure 3-1 shows the increase in power over temperature for the ten units that were tested.

When electrical load is composed of a larger percentage of high efficiency units, the load demand will increase more on an extremely hot day than conventional load models would predict. This is because (1) system analyses do not assume enough motor load (typically they assume 20\%), and (2) current power system modeling tools do not have an accurate load model of the high-efficiency A/Cs for both normal and abnormal voltage conditions. The lowest efficiency $\mathrm{A} / \mathrm{C}$ that can be purchased now is a SEER 13. As more and more high-efficiency air conditioning is installed, existing utility load models may not reflect this large change in load with temperature, and surprising load levels may occur on hot days. That current models do not properly show the delayed voltage recovery when $\mathrm{A} / \mathrm{Cs}$ stall during low-voltage events such as a single-phase fault is the reason for the concern. 


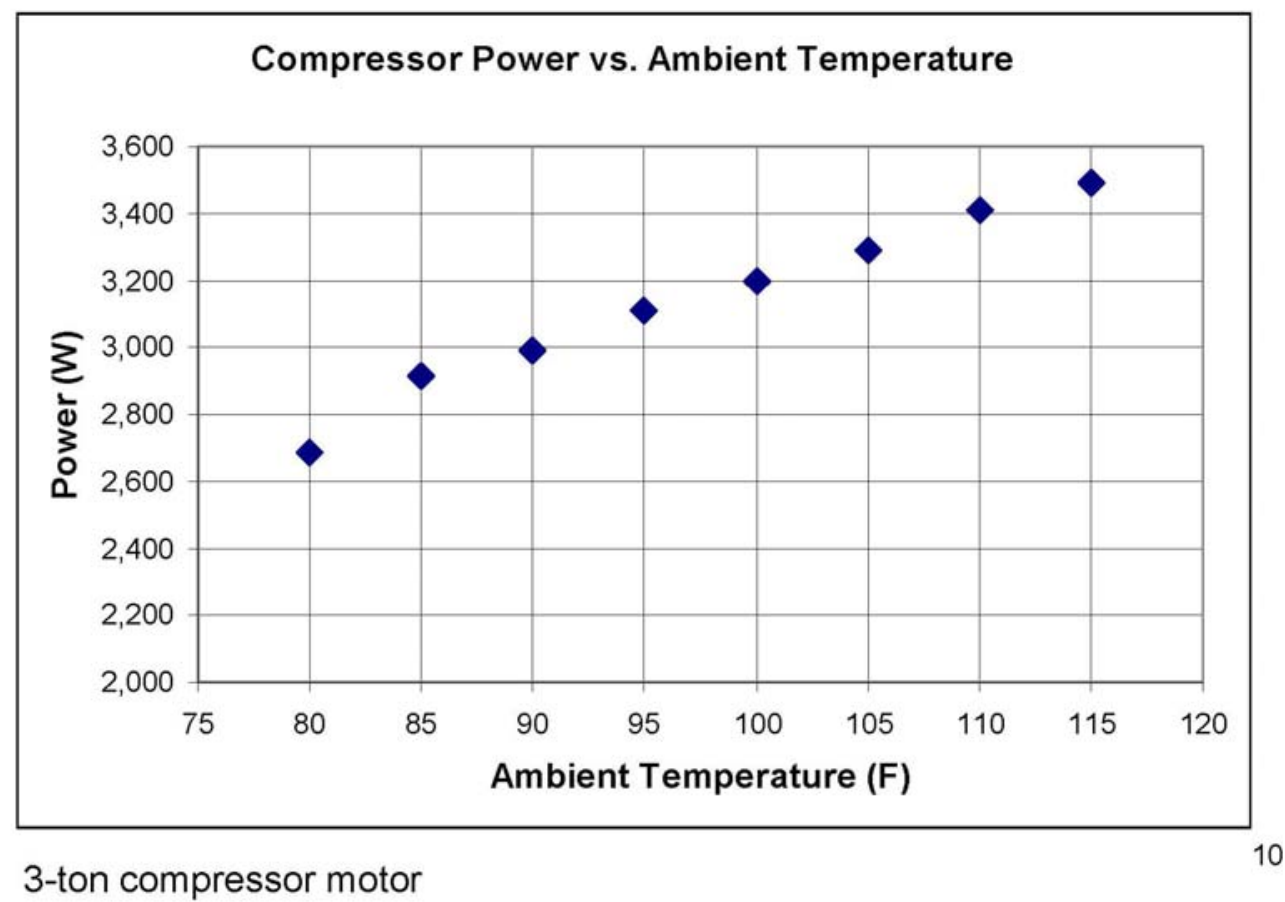

Figure 3-1. Increase in running power (steady-state) of single-phase $\mathrm{A} / \mathrm{C}$ compressor motor with increasing temperature for the SEER 10 to 13 units of reference [5].

\subsection{Reduction in Margin to Voltage Collapse}

Load modelers say that 27 to $50 \%$ of the total electrical load is air-conditioning on a hot day. This discussion will assume 27\%. According to reference [5], SEER 13 A/C increases in load $74 \%$ more than a SEER 10 unit on a hot day; this discussion will assume a conservative 29\% increase. If $27 \%$ of the electrical load increases by $29 \%$, the total load grows by a factor of 1.078 on a $115^{\circ} \mathrm{F}$ day. Why is this a problem? When power system engineers perform studies to ensure that a system stays stable on hot, high-load days, one of the concerns they study is voltage collapse. They determine what the margin is to voltage collapse with certain levels of power flowing in the system. They typically like to have a 5\% buffer over the predicted load level. If the load is a little higher than the prediction, perhaps $4 \%$, they will still have adequate margin to voltage collapse. The rule is that the system must be able to withstand a single contingency such as a loss of generator or loss of transmission line and remain stable. This is known as the $n-1$ ( $n$ minus one) criterion. At some future date, when half of the air-conditioning load consists of high-efficiency units, the load prediction models may be low by about $7 \%$, or more, on very hot days. This unplanned change in load level may encroach on the voltage stability margins. If the margin is "eaten up" by an unexpected load increase, then a single contingency may result in system collapse.

\footnotetext{
${ }^{\mathrm{b}}$ From a presentation by Dmitry Kosterev of Bonneville Power Administration, at DOE Air Conditioner Motor Stall Workshop, April 2008.
} 


\section{PROBLEMATIC AND UNIQUE FEATURES OF ENERGY-EFFICIENT MOTORS, ESPECIALLY AIR-CONDITIONING MOTORS}

Energy-efficient induction motors typically have lower power factors under stalled conditions because the stator is wired with larger conductor wires to reduce $\mathrm{I}^{2} \mathrm{R}$ losses. When the rotor is locked, the current flow in the stator is more inductive [1]. This lower power factor means that significantly more current is flowing when the motor is stalled and that the reactive support must be much higher. As an example, the National Electrical Manufacturers Association (NEMA) Design E (Energy Efficient) motor has a locked-rotor current that is 55\% greater than for a conventional NEMA design B motor [6]. Because of problems with application, Design E motors have been dropped from the NEMA standard and are no longer made. The concern with power factor also applies to normal running conditions. The document Energy Conservation Standards Rulemaking Framework for Small Electric Motors [7] describes the approaches the U.S. Department of Energy (DOE) anticipates using to prepare energy conservation standards for small electric motors. Page 13 of that document states

In addition to the internal losses discussed above, small motors with low power factors can induce extra energy losses in the power distribution system that supplies electricity to the motor. These increased currents cause additional losses in the power distribution system...

It is encouraging that this statement is in the framework document for small electric motors. We hope that power factor, both normal and locked rotor, may someday be covered by standards for $\mathrm{A} / \mathrm{C}$ compressor motors.

Unfortunately, small electric motors do not lend themselves to efficiency standardization. This is partially because of the large number of winding and circuit arrangements including: shaded pole, split phase, capacitor start induction run, capacitor start capacitor run and permanent split capacitor. In addition, the various small motor types have greatly different torque characteristics and power factor, both starting and running. This disparity in motors also applies to small motors in air-conditioning equipment. One expert has stated "When a motor must be replaced, it's a lot easier for a large three phase unit than a little split capacitor motor, because of the wide variation in 48 or 56 frame construction. There's less standardization. Even NEMA's standard lead coloring - nobody follows it." [8]. In Canada there is a small motor efficiency standard, $\mathrm{C} 747^{\mathrm{c}}$, that covers the efficiency of various types of small motors. Critics of the Canadian standard point out that comparisons of efficiency tests among manufacturers result in a wide spread in nominal efficiency [8]. For the purposes of this report, the concern is not that the motor efficiency is not accurately identified but that the motor load characteristics are changing dramatically in a direction that is problematic for the power system.

There are several techniques for designing a high-efficiency motor. They include a longer core length, deeper and wider slots, larger end rings, and a reduced air gap [9]. Each of these design measures has its drawbacks; one of the most common drawbacks in designing a high-efficiency motor is a reduction in starting torque, or the ability to turn the compressor shaft. Using larger

\footnotetext{
c "Energy Efficiency Test Methods for Single- and Three-Phase Small Motors," CAN/CSA-C747-94 (R2005), Canadian Standards Association, 1994.
} 
rotor bars to lower $\mathrm{I}^{2} \mathrm{R}$ loss in the rotor can reduce stall torque [10]. Increasing magnetic flux density by reducing the effective turns in the stator winding increases inrush current and lowers the power factor. Sometimes high-efficiency motors are designed with long, narrow rotors to reduce cooling losses; this can result in lower inertia. The reduced starting torque is especially a concern at reduced voltages, as is discussed later.

\subsection{Unique features of air conditioning motors}

High-inertia induction motors tend to maintain their speed during short periods of voltage dip. They are in a class of motors known as "robust" motors [2]. Robust motors are typically heavier and have a larger rotor diameter, a greater rotational inertia, and a higher starting torque. Robust motors are a different type from the high-efficiency motors now being used in high-efficiency appliances.

High-efficiency motors used in $\mathrm{A} / \mathrm{Cs}$ are now being manufactured with extremely low inertia (typically represented by the symbol " $\mathrm{H}$ " in units of seconds). Starting torque has apparently been such a concern that it was addressed with a design change. A test of motor inertia found it (H) to be as low as 0.03 seconds, as shown in Figure 4-1.

\section{E.g. 3.5-ton compressor motor: Weight: $4.6 \mathrm{~kg}$}

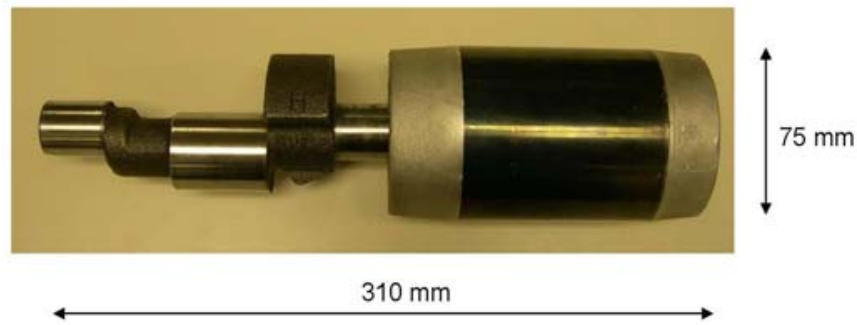

Figure 4-1. Compressor motor from a 3.5-ton $A / C ; H=0.03$ to 0.05 seconds.

New A/Cs manufactured after January 2006 must be SEER 13 or higher to meet DOE Standards [7]. The energy-efficient motors being designed to meet this standard have surprisingly high stall voltages when they are used to power compressors with high backpressure during hot weather (Figure 4-2). Testing has found that $\mathrm{A} / \mathrm{C}$ motors can stall at voltages as high as $73 \%$. In addition, testing by SCE has shown that the motors can stall quickly because they have lower inertia and are connected to a low inertia-scroll compressor.

Figure 4-3 provides details regarding an $\mathrm{A} / \mathrm{C}$ motor that stalled in three cycles after the voltage dropped, going from full load current to locked-rotor current. Some authors point out that motor loads that are prone to stall have a lower power factor of 0.45 , which contributes to the system being pushed much closer to voltage collapse during system events such as faults or line outages [1]. 


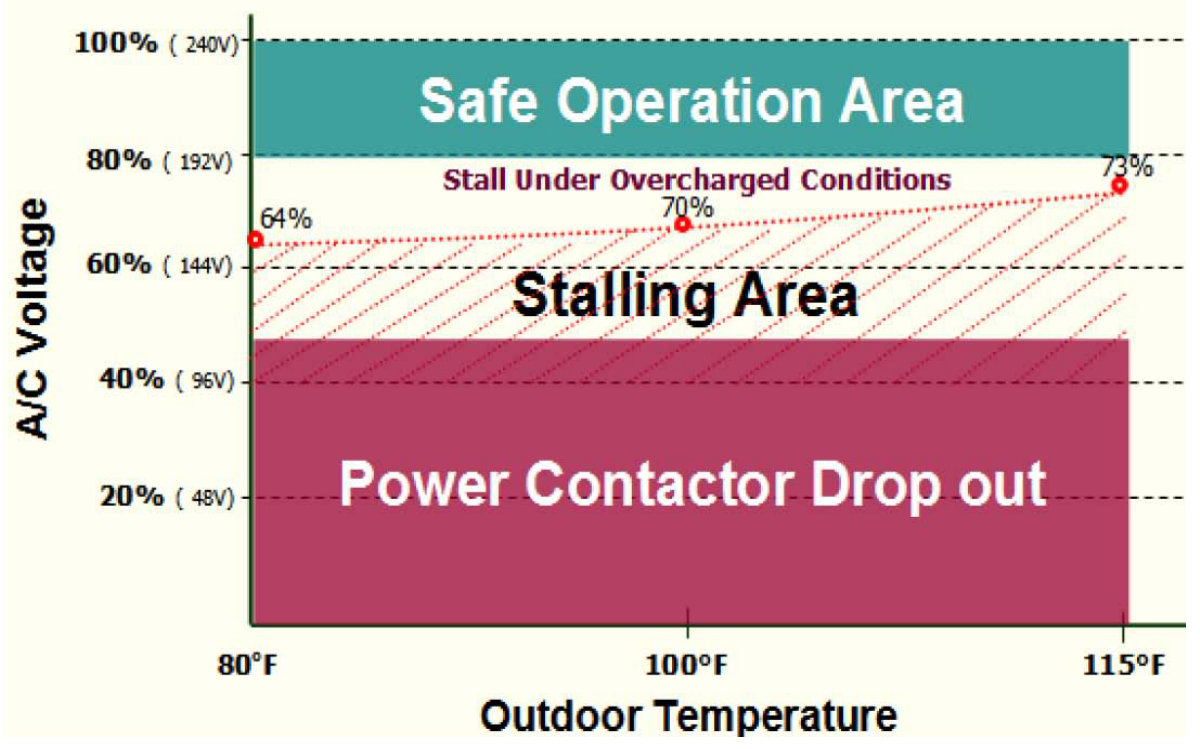

Figure 4-2. Voltage zones (normal, stall and drop-out) for A/C operation. ${ }^{\mathrm{d}}$

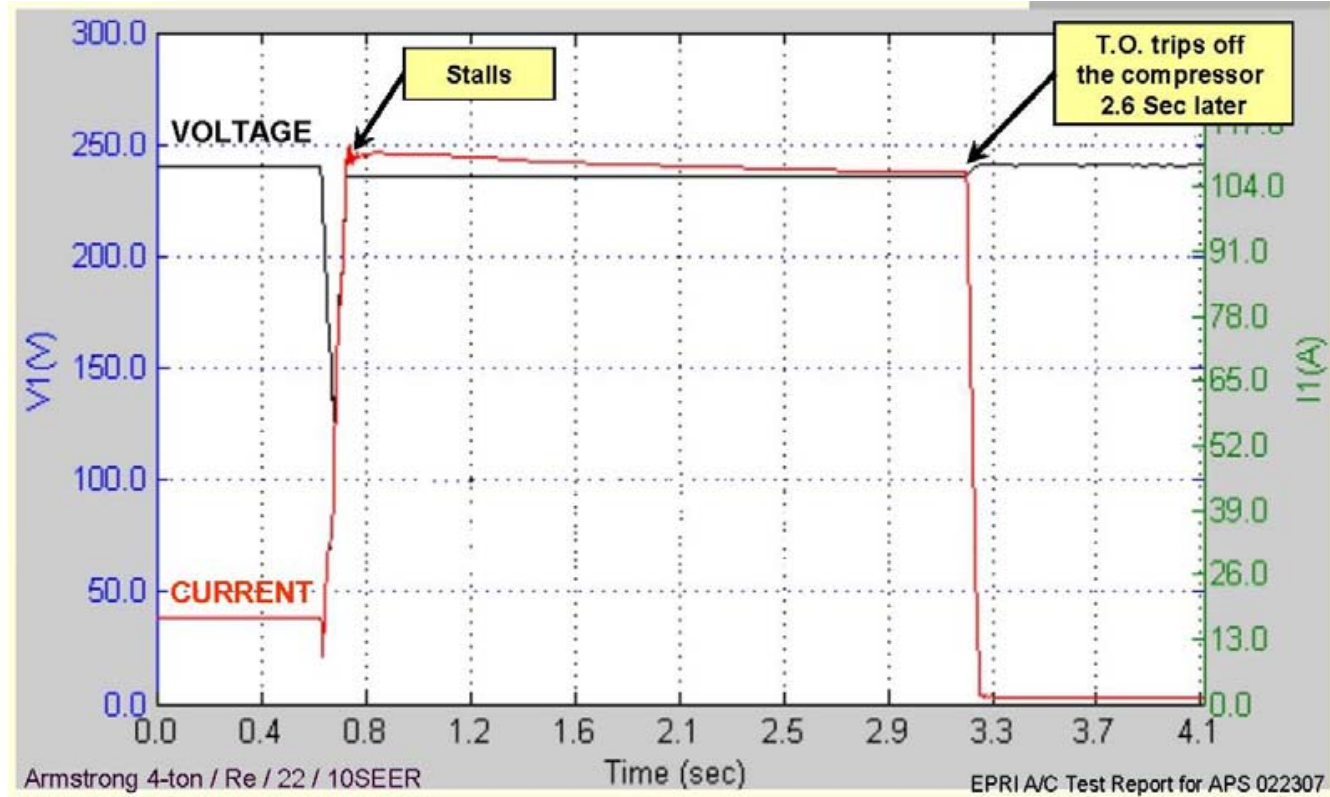

Figure 4-3. Rapid stall of $\mathrm{A} / \mathrm{C}$ motor at $53 \%$ undervoltage in three cycles at $80^{\circ} \mathrm{F}$ and thermal overload (TO) trip after $2.3 \mathrm{~s}$.

It would be impractical here to provide a thorough discussion of how an induction motor works and is designed, but we will attempt to describe briefly the importance of the shape of the rotor bar. The rotor bars are placed in rows along the circumference of the rotor, and rotor current flows through them. The current flowing in these bars sets up the magnetic field of the rotor. The

\footnotetext{
${ }^{\mathrm{d}}$ Figure from presentation by Richard Bravo of Southern California Edison, at DOE Air Conditioner Motor Stall Workshop, April 2008.
} 
rotor bar shape is one of the major design features in a motor that determines a motor's torque characteristics. The current in the rotor bar crowds toward the top of the bar when the motor is started. As the motor accelerates, the current flow penetrates deeper down into the bar. The shape of the rotor bar can thus be designed to provide features such as high starting torque or high efficiency. To provide high torque, the top of the rotor bar is sometimes narrowed so that the resistance is increased. This higher resistance provides a higher starting torque. To provide a higher-efficiency motor, the bar is made wider at the expense of starting torque. Figure 4-4 shows various rotor bar shapes.

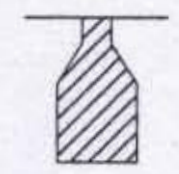

A

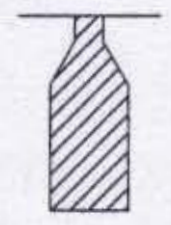

B

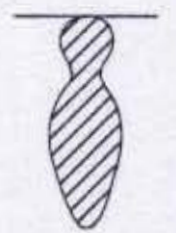

C

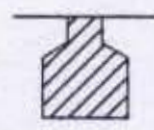

D

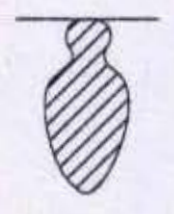

E

Figure 4-4. NEMA induction motor rotor bar designs. ${ }^{e}$

Table 4-1 gives a description of NEMA A to E motors. Note that because of starting problems, the NEMA E motor is no longer manufactured. Instead, a high-efficiency version of NEMA B is manufactured. The rotor bar shapes shown in Figure 4-4 are for machined copper bars, which tend to be more complex than simple cast aluminum bars. The rotor bars shown in Figure 4-5 from air conditioning compressor motors are cast aluminum bars.

Table 4-1. NEMA motors.

\begin{tabular}{|l|l|}
\hline NEMA & \multicolumn{1}{c|}{ Description } \\
\hline A & $\begin{array}{l}\text { For all purpose applications, normal starting torque and current, high breakdown } \\
\text { torque, low full load slip. }\end{array}$ \\
\hline B & Similar to A, except lower starting current. \\
\hline C & High-starting torque, low-starting current. \\
\hline D & Unusually high-starting torque, low-starting current. \\
\hline E & Low-starting torque, high efficiency. \\
\hline
\end{tabular}

From this study, the authors have disassembled four A/Cs and removed the compressor motor and rotor laminations to expose the cross section of the rotor bar. Figure 4-5 shows the rotor bars from a 29 year old compressor motor (pre SEER) and from newer SEER 10, 12 and 14 compressor motors. There is no obvious difference between the 29 year old motor rotor bar shape and the SEER 10 and 12 rotor bars. They are typical in shape for general purpose cast aluminum bars. However, the SEER 14 rotor bar unmistakably shows the characteristics of a high-efficiency rotor - a wider, shallower slot shape. This motor appears to be designed for higher efficiency and lower starting torque.

\footnotetext{
${ }^{\mathrm{e}}$ Figure 4.12 NEMA cage rotor designs, Electric Machines by Charles A. Gross Electric Machines, ISBN: 9780849385810, Pub Date: 10/20/2006, CRCPress.
} 


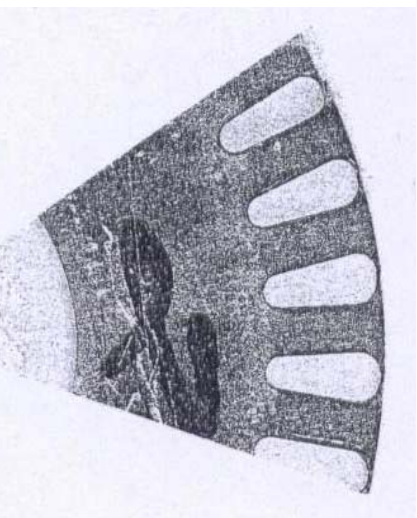

(a) 29-year old compressor motor.

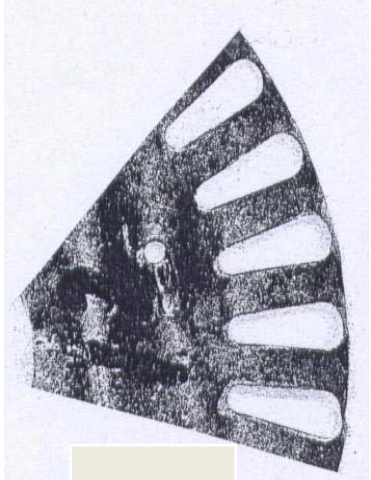

(c) SEER-12 compressor motor.

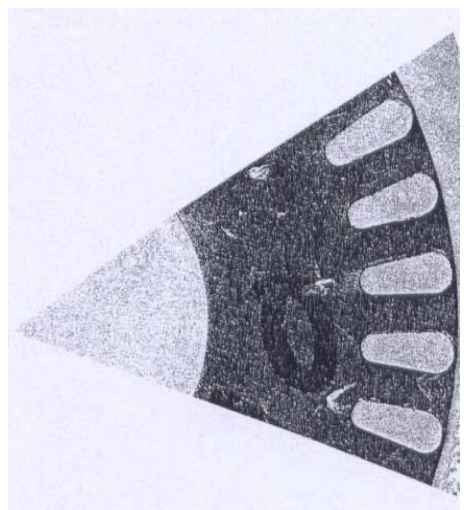

(b) SEER 10 compressor motor.

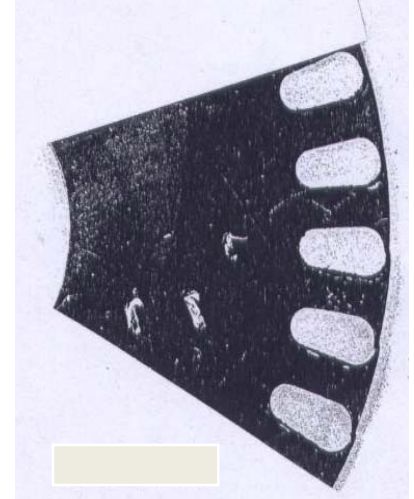

(d) SEER-14 compressor motor

Figure 4-5. Rotor bars from older and newer energy-efficient air-conditioning compressor motors.

New A/Cs manufactured after January 2006 must be SEER 13 or higher. To achieve these high levels of efficiency, compressor manufacturers have apparently switched to high-efficiency, lowtorque motor designs. It is reasonable to assume that the issues of low starting torque, low stall voltage, and low stall power factor are likely to continue and perhaps worsen and increase in importance.

\section{OPTIMUM VOLTAGE FOR AIR-CONDITIONING EFFICIENCY}

\subsection{Conventional voltage ranges required by standard}

The American National Standards Institute's Standard for Electric Power Systems and Equipment-Voltage Ratings (60 Hertz) [11] provides a voltage range for satisfactory performance (Range A) and a secondary range for acceptable performance (Range B). This allows voltage to go from 240 down to $216 \mathrm{~V}$ (Range A) or $90 \%$ and $208 \mathrm{~V}$ (Range B) or $87 \%$. On $208 \mathrm{~V}$ systems, voltage is allowed to go to $187 \mathrm{~V}$ (Range A) and $180 \mathrm{~V}$ (Range B).

According to this standard for Range A, electric supply systems shall be designed and operated so that most service voltages will be within the limits specified for Range A. The occurrence of 
service voltages outside of these limits should be infrequent. Utilization equipment shall be designed and rated to give fully satisfactory performance throughout this range.

Range B includes voltages above and below Range A limits that necessarily result from practical design and operating conditions on supply or user systems, or both. Although such conditions are a part of practical operation, they shall be limited in extent, frequency, and duration. When they occur, corrective measures shall be undertaken within a reasonable time to improve voltages to meet Range A requirements.

The B voltage range, although it does have specific voltage limits, has no specific time limits for duration or frequency limits specifying how often it may happen. Voltage in this range may be allowed to occur many times during the summer on high-load days; it will cause the air conditioning load level to be much higher because of the inefficiency of operation at $87 \%$ voltage.

Because there are no time limits or frequency limits this standard is effectively meaningless. During a hot afternoon, when the system is under stress, voltages may well be expected to be in range $\mathrm{B}$ for several hours because prompt corrective action does not have to be taken until the voltage goes beyond the range $\mathrm{B}$ limit [11]

Reference [12] also gives a minimum utilization voltage of $208 \mathrm{~V}$ (Range B) for an equipment voltage rating of $230 \mathrm{~V}$ or $208 / 230 \mathrm{~V}$. The standard states

It must be recognized that, because of conditions beyond the control of the supplier or user, or both, there will be infrequent and limited periods when sustained voltages outside of Range B limits will occur. Utilization equipment may not operate satisfactorily under these conditions, and protective devices may operate to protect the equipment.

The compelling conclusion here is that existing utility voltage range standards are ambiguous, the time the voltage can be in an abnormal range (Range B) is not defined, and the time the voltage can go beyond the abnormal range (outside of Range B) is not defined. Likewise, the standard for air-conditioning equipment simply quotes the power system standard and says that the equipment may not work and protective devices may operate, but it specifies no clear time ranges. This lack of specificity in the standard certainly contributes to operational problems both in the power system and in air-conditioning equipment. As it is now, $\mathrm{A} / \mathrm{C}$ units do not shut down the motor stall until the thermal switch is activated when the motor reaches the set-point temperature designed to prevent damage from motor overheating. There is no over/undervoltage relay to trip out the $\mathrm{A} / \mathrm{C}$ unit based on a voltage above Range $\mathrm{B}$ or lower than Range $\mathrm{B}$.

\subsection{Regulating Local Voltage to Improve Efficiency}

Tests by manufacturers have shown that compressor motor efficiency drops off more quickly when the motor is operated at reduced voltage, such as $187 \mathrm{~V}$, during heavily loaded conditions [3]. At lightly loaded conditions, efficiency is actually better at a reduced voltage of $187 \mathrm{~V}$. This is not unusual for induction motors. They typically have a higher efficiency at low voltage when operated with a light load but at a heavy load, they require a higher voltage to maintain 
efficiency. Test data shown in reference [5] indicate that at standard operational conditions, efficiency could actually be improved by $5 \%$ by raising the voltage from 187 to $230 \mathrm{~V}$. Precise voltage control depending on load is something that can be accomplished with adjustable speed drives, but has seldom been practiced on utility distribution systems ${ }^{\mathrm{f}}$. Previous studies have focused on how voltage reduction can improve energy efficiency, which depends on the makeup of loads in the system. With loads that are primarily resistance, voltage reduction does reduce the energy consumption of the loads - for example, by $0.65 \%$ for every $1 \%$ reduction in voltage - and thus gives the appearance of energy efficiency improvement. In fact, during periods of heavy load, voltage is usually depressed, not elevated. It is an unusual concept, though, to increase voltage during periods of heavy load (i.e., hot weather) to improve motor load and distribution system efficiency. This is something that could be done with local voltage regulation. This practice not only would improve efficiency but also would reduce transmission congestion and improve the margin-to-voltage collapse.

Reference [11] also gives a minimum utilization voltage of 208 V. Similar to the ANSI standard, for this Range B voltage, the utility is to take corrective measures within a reasonable time to improve voltages to meet Range A requirements.

\section{COMMONLY SUGGESTED VOLTAGE SOLUTIONS AND THEIR DRAWBACKS}

\subsection{More definitive voltage standard}

A more definitive voltage standard is needed to specify the upper/lower limits and time duration for normal and abnormal (beyond normal) voltages for air-conditioning equipment. A voltage standard that includes maximum times of low-voltage operation would allow manufacturers to design equipment capable of reliable operation under expected abnormal conditions, for the duration of the condition. The standard would also allow manufacturers to design equipment that trips off during expected transients, instead of stalling and relying on the thermal relay to trip the unit. The drawback is that today's distribution systems are not designed to provide such tight voltage regulation. The voltage limits have been set by standards, but the definition of acceptable durations and frequencies would be essentially impossible because of the range of distribution system types, operation methods and stress factors across the nation.

\subsection{Undervoltage tripping of air-conditioners}

Another solution is to incorporate an undervoltage trip capability in new and retrofitted existing $\mathrm{A} / \mathrm{C}$ units. A specified undervoltage which would cause the $\mathrm{A} / \mathrm{C}$ to trip would not be difficult to implement, especially if manufacturers have information on when the motor will stall. (Reference [5] discusses an issue involving stalled air conditioner motors as the root cause of delayed voltage recovery. It suggests that air-conditioning units should be equipped with an undervoltage relay and time-delay recloser.) A trip capability would provide a significant advantage to the utility by removing stalled motors from the system, and the trip would protect the motor and enhance motor lifetime by greatly reducing operation in a stalled condition. The

\footnotetext{
f "Distribution Efficiency Initiative, http://www.nwalliance.org/ourwork/projectsummary.aspx?ID=75.
} 
recloser would ensure that the unit stays out long enough for the low-voltage condition to pass; it also could ensure that there is diversity in how the $\mathrm{A} / \mathrm{C}$ units reconnect to the power system to prevent both a sudden inrush by multiple units and a significant drop in voltage as the $\mathrm{A} / \mathrm{C}$ motors restart. The drawback is that the undervoltage trip must occur quickly. A/C motors have been found in tests to stall in as little as three cycles. Conventional undervoltage devices may not act quickly enough to prevent motor stall. They would also be expensive to add.

\subsection{Local voltage regulation}

Local voltage regulation, which refers to the ability of the end-user to meet a schedule supplied by the utility, is another possible solution. If the customer were equipped with DER that could dynamically supply reactive power to regulate voltage, local voltage could be regulated to hold it in a band that meets the design B voltage specification. As an option to maximize efficiency, local voltage could be controlled to a level that would provide the best $\mathrm{A} / \mathrm{C}$ efficiency based on temperature. This approach would also increase the margin-to-voltage collapse and improve grid and distribution system efficiency. The challenge is that only a few progressive utilities are presently interested in having customers provide local voltage regulation in accordance with a schedule, but we anticipate that this will change in the future. Another drawback is that the resource must have adequate capacity. In the future, we anticipate that inverters such as those used in PV systems may be supplied with a larger VA capacity so they can provide reactive power from DE systems.

\subsection{Fast tripping of A/C motors}

Use of a fast trip device to trip stalled loads to prevent voltage collapse is another approach. Recently, there has been some discussion on modifying the air- conditioning manufacturer standard (Air-Conditioning, Heating and Refrigeration Institute) to include a requirement that the unit trip immediately on stall rather than waiting 2 or 3 minutes for a TO to trip.

\subsection{Faster fault clearing}

Longer fault duration of 0.5 to $2.5 \mathrm{~s}$ in duration would extend the stalling to many more motors. When fault clearing was improved to eight cycles $(0.13 \mathrm{~s})$, most of the voltages in a simulation recovered in $10 \mathrm{~s}$, and several cases showed immediate recovery [2].

\section{CHALLENGES TO LOCAL VOLTAGE REGULATION}

It is critical to maintain an acceptable voltage range at distribution substations (where the voltage is stepped down from subtransmission level to distribution level) in order to provide acceptable voltages to end-user loads on distribution feeders and circuits. Voltage regulation via central generator plants and the use of voltage regulation, such as load-tap-changing (LTCs) and capacitors, in the substations ensures this requirement will be met. Distribution engineers dispatch capacitor banks at distribution substations through manual operation or remotely controlled devices. Also, fixed and switchable (e.g., controlled by voltage) capacitor banks and line voltage regulators are used along distribution feeders to provide additional capability to ensure that the end-user loads at the end of distribution feeders receive acceptable voltage. 
With more penetration of DER, the voltage of a distribution substation may be regulated with DE embedded in the demand side rather than the centralized capacitor banks at the distribution substation. In fact, the cost of maintenance and operation of capacitor banks is a significant burden to utilities. In addition, capacitors are least effective when needed the most-at low voltages - since their reactive power capability drops off by voltage squared.

Figure 7-1 shows an example of a typical distribution system with DERs. A transmission substation is connected to a distribution substation which feeds a main feeder and a few secondary feeders. Loads are connected to the feeders at various locations.

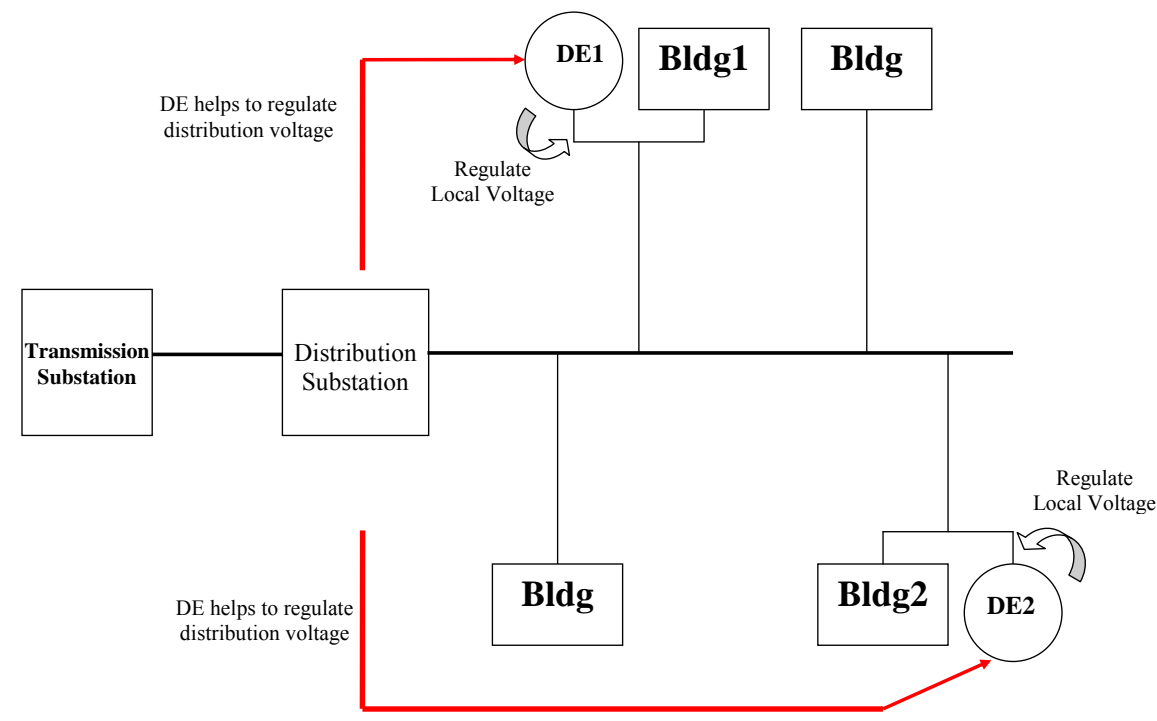

Figure 7-1. An illustrative diagram of a sample distribution system.

However, challenges arise when DE is placed in a distribution network. In particular, the control parameters, namely $K_{P}$ (proportional gain) and $K_{I}$, (integral gain) for the proportional integral $(\mathrm{PI})^{\mathrm{g}}$ controllers in Figure 7-1, remain an unsolved issue. (This controller is discussed at length in Section 8.2) In previous research, $K_{P}$ and $K_{I}$ are obtained by a trial-and-error approach for a specific system. When DE and the associated PI controllers are eventually deployed in large numbers and amount in a distribution network, it is not possible to set the parameters by trial and error because of the large combination of variables. However, if the parameters are not well chosen, problems of sluggish response or overshoot or instability may occur.

This can be verified with the simulation results. In the simulation, the impact of $K_{P}$ and $K_{I}$ on the dynamic response of the voltage regulation was tested in a distribution system with one and two DERs, respectively.

The system diagram is shown in Figure 7-2.

\footnotetext{
${ }^{\mathrm{g}}$ We assume PI feedback controllers in our discussion, since this has been the focus of our control for local voltage regulation with DE.
} 


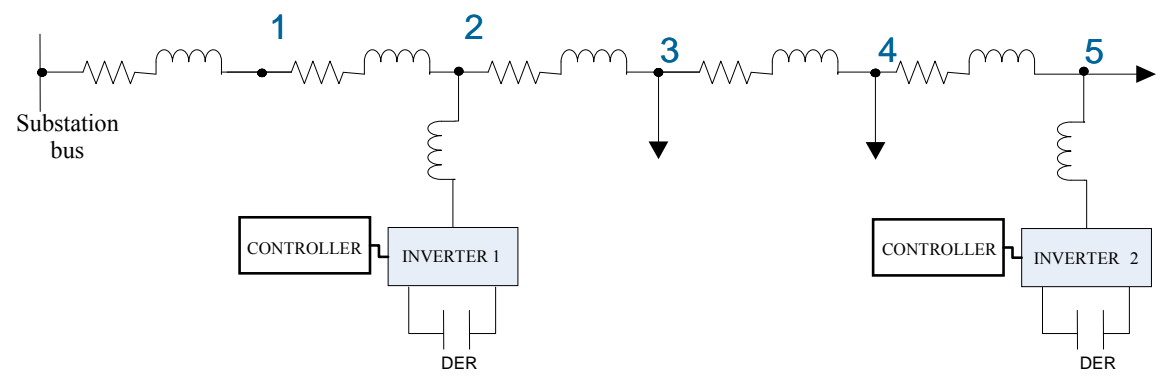

Figure 7-2. Single line diagram of the distribution system with DE.

It is a typical radial distribution network $(12 \mathrm{kV}$ at the system level and $480 \mathrm{~V}$ at end-user level) with two DERs with a PE interface connected at bus 2 and bus 5, respectively. The loads connected at buses 3, 4, and 5 are rated at $10.41 \mathrm{kVA}, 170.77 \mathrm{kVAand} 128 \mathrm{kVA}$, respectively. The circuit is a close representation of one of the ORNL circuits connected at the DECC Lab (see Section 10). It has been extended to include the third load connected at bus 5 and the second DER. In the following two test cases, the first omitted the DER at bus 5 to have a single DER case, while the second case has both DERs in service.

\subsection{Case of a single DER}

The first case is the system shown in Figure 7-2 with only one DE at bus 2. The PE controller was tested with different combinations of the control parameters, $K_{p}$ and $K_{I}$. The different responses are shown in Figure 7-3. The straight green line is the reference voltage, and the blue curve is the voltage at the point of common coupling (PCC). The PCC voltage was 263V before regulation and the reference voltage is set at $268 \mathrm{~V}$ for regulation. From 0 to $0.3 \mathrm{~s}$, there is no regulation; from $0.3 \mathrm{~s}$ to $1.5 \mathrm{~s}$, compensation is performed by the $\mathrm{DE}$ to regulate the voltage.

As shown in Figure 7-3, there is a stable range of $K_{p}$ and $K_{i}$; Figure 7-3(a) shows a desirable dynamic response with well-designed $K_{P}, K_{i}$. When the control parameters are outside this range, the system becomes unstable, as is shown in Figure 7-3(b). Even in the stable range, inappropriate values for $K_{p}$ and $K_{i}$ may cause an undesired response; that is the compensation speed is too slow as a result of a value of $K_{I}$ value that is too small, as in Figure 7-3(d), or an overshoot and oscillation at the start as shown in Figure 7-3(c).

\subsection{Case with two DEs}

Next, the distribution system with two DER was tested with different combinations of $K_{p}$ and $K_{I}$. The test results are shown in Figure 7-4. The left side plots show the voltage response at bus 2 with respect to different $K_{p}$ and $K_{I}$; the right side plots show the voltage at bus 5 . Prior to $0.3 \mathrm{~s}$, there is no regulation; from $0.3 \mathrm{~s}$ to $1.5 \mathrm{~s}$, the compensation is performed by the DERs to regulate voltage. Figure 7-4(a1) and (a2) show the desired response; Figure 7-4(b1) and (b2) show an unstable response; and Figure 7-4(c1) and (c2) show a slow response. In a similar manner to the single DER case, the values of $K_{P}$ and $K_{I}$ determine the response of the voltage regulation. However, in this case, with multiple DER, the range of $K_{P}$ and $K_{I}$ are different, which is clearly demonstrated by comparing Figure 7-3(c) with Figure 7-4(b1) and Figure 7-4(b2). Even with the 
same value of $K_{P}$ and $K_{I}$, the two-DER case is unstable while the one-DER case is stable. It suggests that the parameter range suited for a single DE case may not be directly used for voltage regulation with multiple DER. In order for them to work correctly together requires a coordinated design of the controller parameters for the multiple DER.

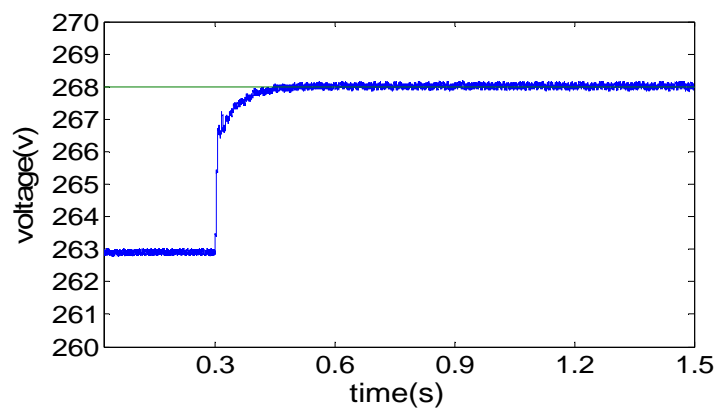

(a) $K_{p}=0.03 \& K_{i}=0.8$

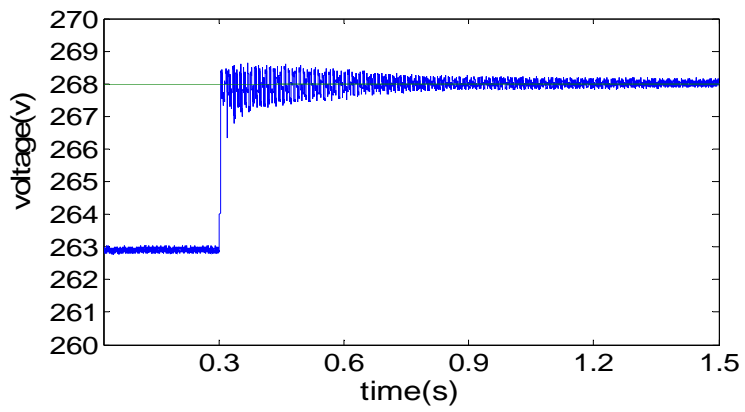

(c) $K_{p}=0.2 \& K_{i}=3.0$

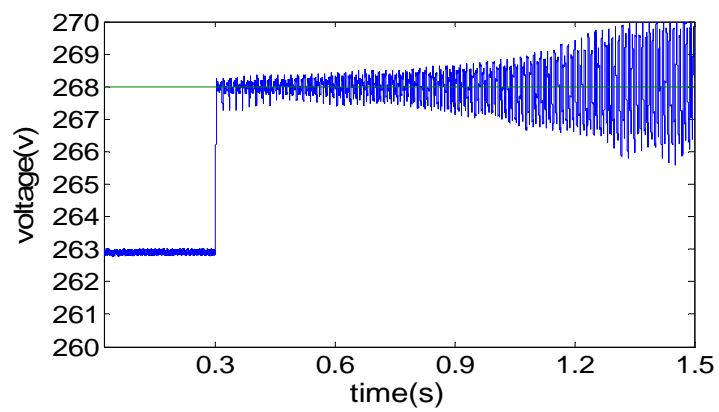

(b) $K_{p}=1.0 \& K_{i}=7.0$

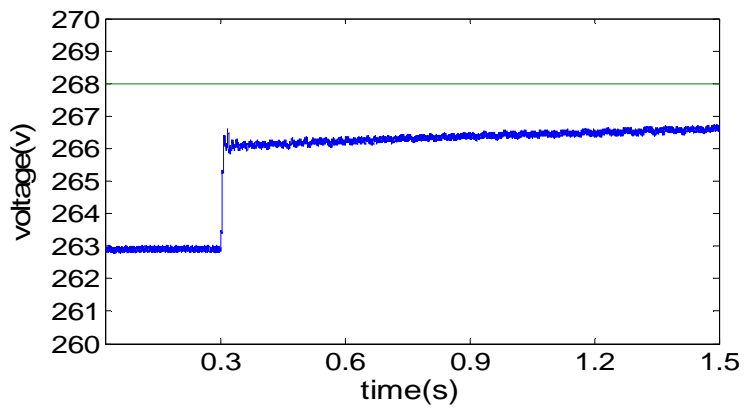

(d) $K_{p}=0.01 \& K_{i}=0.1$

Figure 7-3. Voltage regulation with different $K_{p}, K_{i}-$ one DE case.

More results about the impact of DER location and loading condition on the voltage regulation response can be found in reference 13 .

These simulation results in Figure 7-3 and Figure 7-4, as well as more studies in reference [13], clearly indicate the need to find a solution to identify the desired control parameters in real time in accordance with the system condition and the location. If the control paramerters are not appropriately chosen, the system response may be too slow to be efficient or too fast to be stable.

To address the parameter setting issue, a control scheme based on centralized communication may be possible such that the DER knows the need at the substation level and then adjusts its own settings. That is, data from the distribution substation must be forwarded to each DER. Because of the uncertain and dispersed location of customers' DE, this centralized communication may be costly. Therefore, it is desirable to identify an alternative, decentralized approach to regulate the distribution substation without a communication system. This research report presents an adaptive method to regulate local voltage by $\mathrm{DE}$ that is connected to regulate the voltage of the distribution substation by following a voltage schedule. The adaptive method 
is described in Section 8.

Bus 2

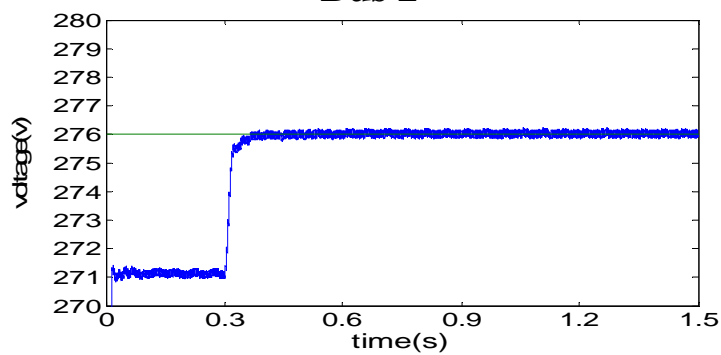

(a1) Voltage at bus 2 when $K p 1=K p 2=0.01$, $K i 1=K i 2=0.8$.

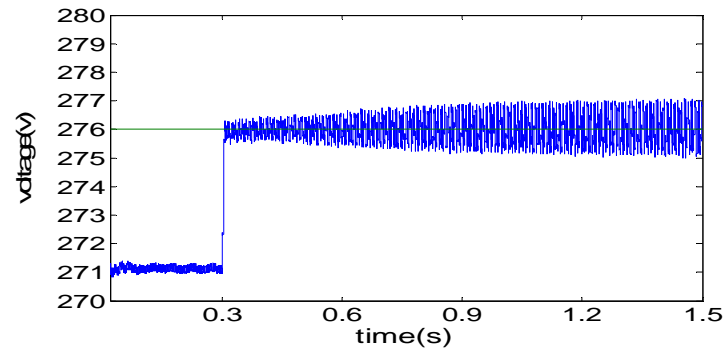

(b1) Voltage at bus 2 when $K p 1=K p 2=0.2$, $\mathrm{Ki} 1=\mathrm{Ki} 2=3$.

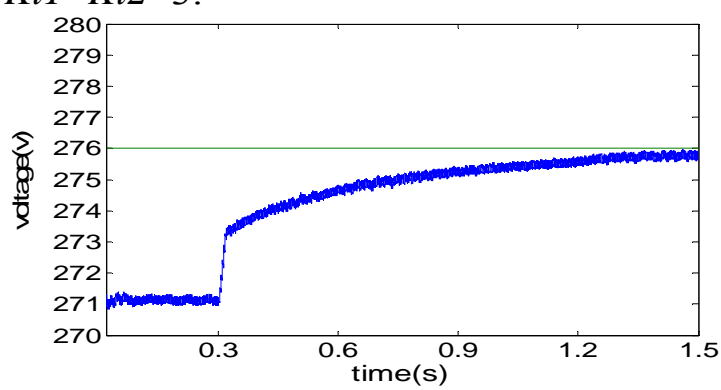

(c1) Voltage at bus 2 when $K p 1=K p 2=0.01$, $K i 1=K i 2=0.05$.

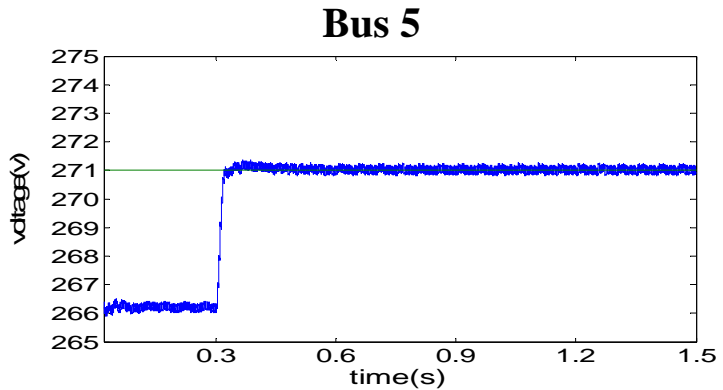

(a2) Voltage at bus 5 when $K p 1=K p 2=0.01$, Ki1 $=$ Ki2 $=0.8$.

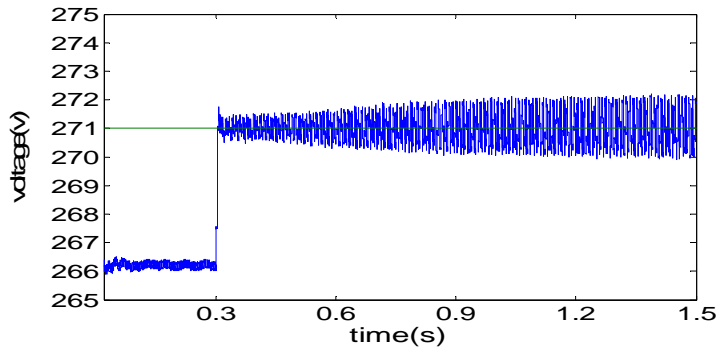

(b2) Voltage at bus 5 when $K p 1=K p 2=0.2$, $K i 1=K i 2=3$.

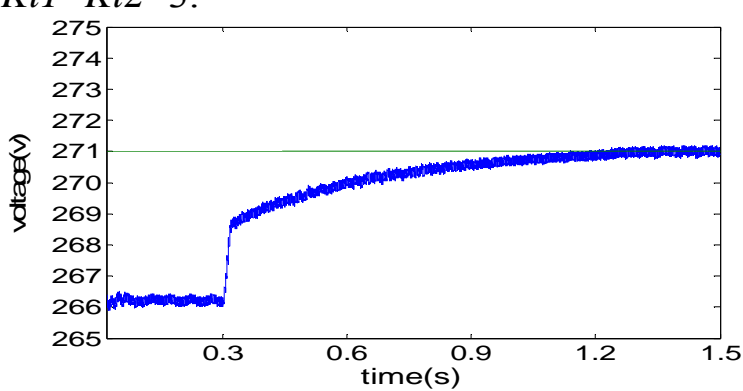

(c2) Voltage at bus 5 when $K p 1=K p 2=0.01, K i 1=K i 2=0.05$.

Figure 7-4. Voltage regulation with different $K_{P}, K_{I}$-two DEs case.

\section{THE LOCAL DYNAMIC REACTIVE RESOURCE SOLUTION}

Here we present a solution using DE to dynamically regulate local voltage near or at the end-user load. 


\subsection{Local dynamic reactive resources}

Changing the transformer taps and switching capacitor banks on and off are the two traditional means of local voltage regulation. By adjusting the transformer taps, the transformer turns ratio is increased or decreased to regulate the secondary output voltage. The capability for voltage regulation by transformers is usually within $\pm 5 \%$ of the rated voltage. This is the most widely used voltage regulation method in power systems, and no additional equipment is required except transformers with tap-changing capability. The drawback of this method is that the tap changing is not continuous, and does not respond to dynamic voltage variation. If the voltage is regulated at a wider range, the installation of capacitor banks is the other traditional and widelyused method. The voltage regulation effect of the capacitor banks is not continuous because a certain number of the capacitor banks are switched on or off each time. The two traditional means of local voltage regulation have some common characteristics. The capital costs are relatively inexpensive, but the maintenance costs are substantial. Capacitor switching causes a transient in system voltage, which may have a negative impact on sensitive loads. They cannot control the voltage continuously and they do not have dynamic capability to respond to rapid voltage variations and transients.

Because of the demand for high-quality power, local voltage regulation methods with real-time voltage control capability and fast transient response are playing a more and more important role in the distribution level. The SVC, static synchronous compensator (STATCOM), SC, and DER are some of the devices in the distribution level that have proven capable of performing local dynamic voltage regulation. They either readily have, or have the potential to provide, dynamic reactive power.

A typical SVC comprises a thyristor-controlled reactor and a capacitor bank or banks in which each capacitor can be switched on or off individually. The thyristor can automatically and continuously control the current through the reactor. The combination of controlling the thyristor and switching the capacitor bank can provide dynamic reactive power. The output of the SVC is dependent on the system voltage; therefore, when the system voltage drops-i.e., when the reactive power is mostly needed - the SVC's maximum output reactive power decreases with the square of the voltage.

A STATCOM is a voltage source converter connected in parallel to the power system to control power flow and improve the transient stability of the power system. The STATCOM uses forced-commutated power electronics devices to generate an ac voltage from a dc voltage source. A capacitor is connected on the dc side of the STATCOM as the voltage source because only reactive power is generated or absorbed by the STATCOM and no energy source is needed. The voltage output of a STATCOM is independent of the system voltage, which is an advantage to reactive power sources as the maximum reactive capacity drops only linearly with voltage. It has fast transient control capability and can improve voltage stability. However, it is more expensive than other reactive power sources.

There are more and more DER in distribution systems working as active power sources. There are several types of DER: micro-turbines, industrial gas turbines, fuel cells, reciprocating engine 
generators, PVs, wind turbines ${ }^{\mathrm{h}}$, etc. Most of them are operated as active power sources, but they have great potential for local voltage regulation by generating or absorbing reactive power for two reasons. First, a power-electronics-based interface is required for most DE. By modifying the control scheme, the interface not only can transfer the active power from the DE to the utility but also can control the reactive power flow between the DE system and the utility. Second, the distributed location of DER is ideally suited for voltage regulation.

\subsection{The basic idea of adaptive voltage control}

Feedback control is used in most dynamic reactive resources, including SVC, STATCOM, and DE. Feedback control compares the differences (errors) between the actual values of the system variables (controlled variables) and the desired values (references) and uses the error to determine and send control signals to the controlled system. In a robust and stable feedback control system, the controlled variables track the references at steady state and reach the value of the references after a desired period of time during a transient. The time to respond to a transient is exponential, and normally the steady-state condition is reached after five time constants.

A proportional-integral-derivative (PID) controller is a widely used feedback controller. There are three parts of the controller: (1) the proportional part that determines the reaction to the present error between the reference and actual value, (2) the integral part that determines the reaction to the sum of the recent error, and (3) the derivative part that determines the reaction to the rate at which the error has been changing. A PI controller is the most commonly used feedback controller in which the derivative part is dropped because it is very sensitive to measurement noise. In the design of a PI controller, the proportional gain $\left(K_{p}\right)$ and the integral gain $\left(\underline{K}_{i}\right)$ are the two control constants determined by the system (to be controlled) characteristics and the control strategy.

In a PI controller, inappropriate choices of the control gain constants ( $K_{p}$ and $\left.K_{i}\right)$ can result in unsatisfactory performance of the controlled system (such as when $K_{p}$ and $K_{i}$ are too low), system oscillation (when one of the gains is too high), or even system instability $\left(K_{p}\right.$ and $K_{i}$ are too high). System oscillation or instability must be avoided by selecting appropriate control gain constants. If all the system parameters are known, $K_{p}$ and $K_{i}$ can be determined by setting up the mathematical model of the system and the controller.

However, in a complicated system like an electric power system, there is often a lack of complete information for the system parameters and the system configuration. The power system also is quite dynamic, with varying loads, generation, and even network configuration making it difficult to model dynamically. An adaptive control method can adjust the $K_{p}$ and $K_{i}$ in real-time so that the system response meets these requirements.

In an adaptive PI controller, the values of $K_{p}$ and $K_{i}$ are adjusted in real-time based on the system behavior. In a non-adaptive PI controller, the values of $K_{p}$ and $K_{i}$ are preset and are fixed so that they are not adjusted throughout a control process. However, when there is lack of system information, a calculation such as this cannot be fulfilled so "trial and error" adjustment

\footnotetext{
${ }^{\mathrm{h}}$ We are referring to wind turbines that have been placed near end-user loads although wind turbines are usually grouped together to create wind farms.
} 
of the control gains and watching the response is usually the solution to this situation. It is difficult to choose the appropriate values of $K_{p}$ and $K_{i}$ so that the controller's performance is optimized.

In an ideal PI control process, the response of the control system to a step change is an exponential decay curve with the largest error at the beginning of the step change and the actual variable approaching the reference. By adjusting the values of $K_{p}$ and $K_{i}$, the time constant of this exponential curve is changed; i.e., the speed of the response is changed. The voltage response time for the DE should be so quick that it will not interfere with conventional utility voltage control. A response time of $0.5 \mathrm{~s}$ (equivalent to 30 cycles at $60 \mathrm{~Hz}$ ) was selected because it should be "invisible" to utility voltage control. Because 30 cycles is considered by utilities as appropriate response time for devices interconnected in the utility grid, it is used in the adaptive control as the $5 \tau$ decay time of the ideal exponential curve. By adjusting the values of $K_{p}$ and $K_{i}$ so that the error of the controller tracks the ideal exponential curve, the time of response of the voltage control is regulated to $0.5 \mathrm{~s}$.

A typical configuration of a utility-connected DE system is shown in Figure 8-1. The control logic is shown in Figure 8-2.

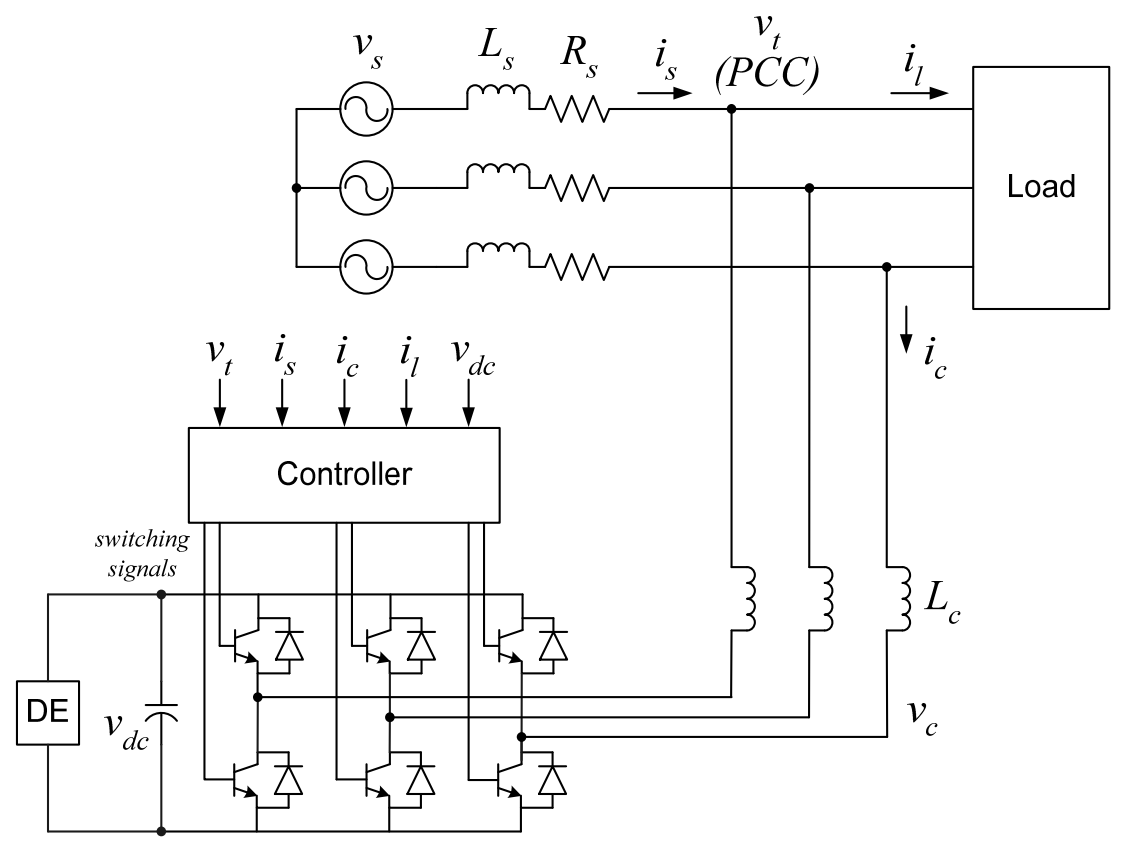

Figure 8-1. Utility-connected DE with controller. 


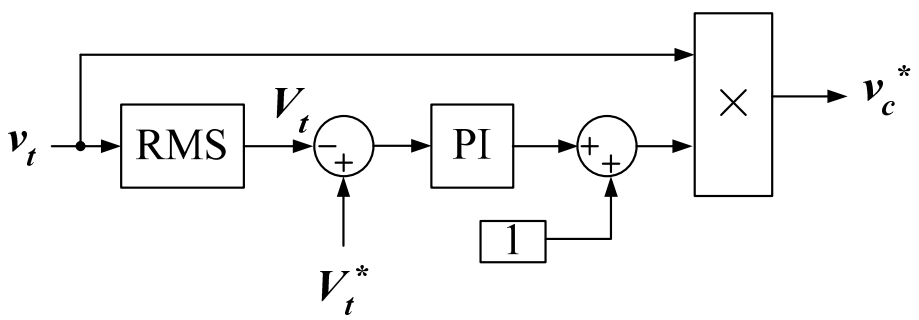

Figure 8-2. Controller diagram.

The basic idea of voltage regulation is to compare the controlled voltage and the reference voltage and then use the instantaneous difference and the accumulated difference as feedback signals to eventually change the controlled voltage to the reference voltage. The parameter to scale the instantaneous voltage difference is $K_{p}$, and the parameter to scale the accumulated voltage difference is $K_{i}$. This can be specifically expressed in Eq. (8-1):

$$
v_{c}^{*}=v_{t}(t)\left[1+K_{p}\left(V_{t}^{*}(t)-V_{t}(t)\right)+K_{I} \int_{0}^{t}\left(V_{t}^{*}(t)-V_{t}(t)\right) d t\right]
$$

As previously discussed, if $K_{p}$ and $K_{i}$ are not chosen well, the desired response may not be obtained. This is true for a common PI controller design in which $K_{p}$ and $K_{i}$ are fixed values. Without a communication system, the controller must include some self-learning capability to adjust the $K_{p}$ and $K_{i}$ parameters dynamically. Taking as an example a case in which local voltage needs to be raised, if the control logic shows voltage has been raised too rapidly, then $K_{p}$ and $K_{i}$ will be adjusted to lower values. If the voltage has been raised too slowly, then $K_{p}$ and $K_{i}$ will be adjusted to higher values. Certainly, this needs an additional logic to check the present voltage response with the desired response. These responses (actual, desired) are shown in Figure 8-3. The desired response of the dashed line is obtained with the difference between the present voltage and the reference voltage, and the desired time to correct the voltage to reference voltage. Here, the desired response curve is an exponential growth curve. Figure 8-4 shows the overall logic of the adaptive control method.

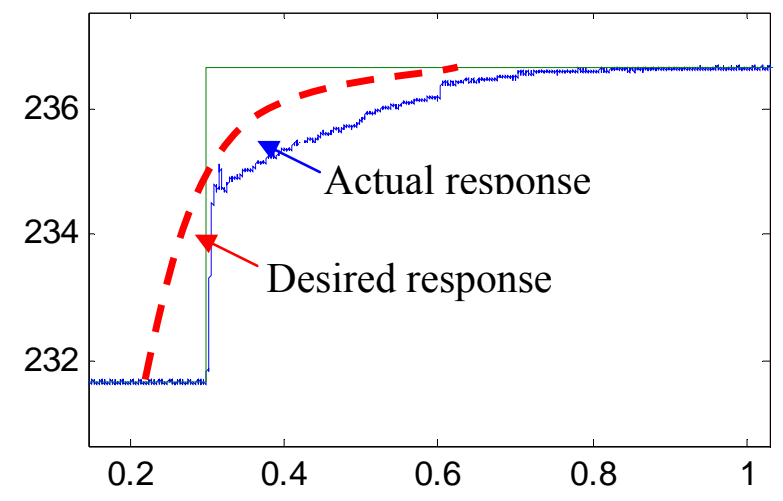

Figure 8-3 Desired response and actual response of the controller. 


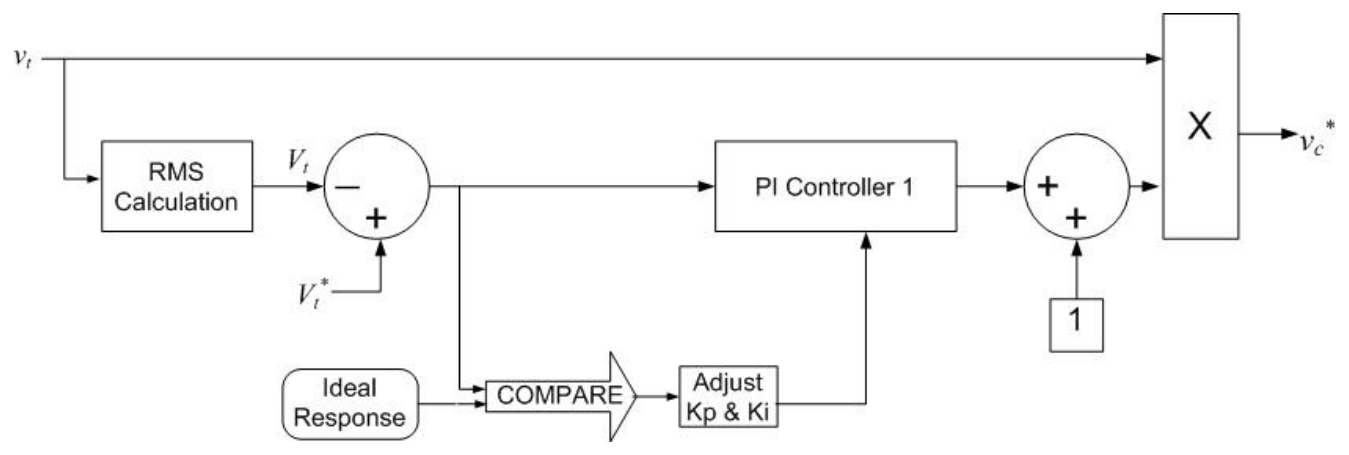

Figure 8-4. Adaptive controller diagram.

\subsection{Parameter selection approach}

This section presents guidelines for selecting the various parameters for the control approach.

\subsubsection{Determine $V_{\mathrm{dc}}$}

$V_{d c}$ is the dc supply voltage that determines the capability of the DER for the voltage regulation. It should be determined before the design of the control. To keep the pulse-width modulation (PWM) index less than or equal to 1 , the peak of $V_{c}$ should not exceed half of the dc voltage, i.e., $V_{c}^{\text {peak }}<\frac{1}{2} V_{d c} . V_{c}$ is the voltage that the DER should supply to keep $V_{t}$, the voltage at the PCC, at a desirable value in the post-disturbance state in the worst cases, which cause the largest voltage drop at the PCC. Since the probable load variation, voltage schedule, network parameters are known, calculation of the final state $V_{c}$ is a steady-state power flow problem.

\subsubsection{Determine the initial value of $K_{p}$}

Based on the previous simulation, if $K_{p}$ is too big, it will cause oscillation, instability, and a high percentage of harmonics, which deteriorate the regulation results. Therefore, the initial value of $K_{p}$ is chosen conservatively. At the time $0_{+}$moment, the integral $\left(K_{i}\right)$ part contributes nothing, so the PI controller output is $\left(K_{P} \times \Delta V_{t}+1\right) \times V_{c}^{\text {peak }}$ to keep the PWM index no bigger than 1 . This yields

$\frac{1}{2} V_{d c}=\left(K_{P} \times \Delta V_{t 0}+1\right) \times V_{t}^{\text {peak }}$ and hence $K_{P}=\frac{\frac{\frac{1}{2} V_{d c}}{V_{t}^{\text {peak }}}-1}{\Delta V_{t 0}}$

\subsubsection{Determine the initial value of $K_{i}$}

The desirable response time of the controller when a voltage change occurs is $0.5 \mathrm{~s}$ to provide sufficient time not to interfere with conventional voltage control implemented by the utility. As can be seen from the simulations, if $K_{p}$ and $K_{i}$ are chosen appropriately, the voltage response curve has the exponential decay characteristic. So it is reasonable to approximate the ideal 
response with the exponential decay function, i.e. $\Delta V(t)=\Delta V_{t 0} e^{-\frac{t}{\tau}}$. Here $\tau$ has a relationship with response time $5 \tau \approx 0.5 \mathrm{~s}$, five time constants since this is normally what is required to reach a new steady-state condition. When the steady-state is reached, the proportional $\left(K_{i}\right)$ part contributes almost nothing and the following relationship is obtained:

$K_{I} \times \int_{0}^{5 \tau} \Delta V_{t 0} \times e^{-\frac{t}{\tau}} d t+1=\left.\frac{V_{c}}{V_{t}}\right|_{\text {steady-state }}$ and hence $K_{I}=\frac{\left.\frac{V_{c}}{V_{t}}\right|_{\text {steady-state }}-1}{\int_{0}^{5 \tau} \Delta V_{t 0} \times e^{-\frac{t}{\tau}}}$

Here, $\left.\frac{V_{c}}{V_{t}}\right|_{\text {steady-state }}$ is a steady-state value and can be calculated for the worst case situation. $\Delta V_{t 0}$ is the acceptable maximum voltage variation.

\subsubsection{Adaptively adjust the value of $K_{p}$ and $K_{i}$}

The initial value of $K_{p}$ and $K_{i}$ is conservative and cannot reach the desirable $0.5 \mathrm{~s}$ response time. Adaptive adjustment of $K_{p}$ and $K_{i}$ method is used to improve the response speed. The ideal response $\Delta V(t)=\Delta V_{t 0} e^{-\frac{t}{\tau}}$ is used as the reference. Every $0.1 \mathrm{~s}$, the actual voltage error and the ideal voltage error are compared and the ratio $\frac{\text { actual voltage error }}{\text { ideal voltage error }}$ is calculated. If the ratio is greater than $1, K_{p}$ and $K_{i}$ will be multiplied by the ratio. If the ratio is less than $1 / 3$, which means the actual response is much faster than desired, $K_{p}$ and $K_{i}$ will be reduced by $20 \%$.

\subsection{An example of parameter selection}

The test system is shown below in Figure 8-5. (It is the same as the system shown in Figure 7-2. shown here again for easy reference.)

First, a single DER case is considered. It is placed at bus 5 . The line voltage at the bus station is $480 \mathrm{~V}$. Consider the heaviest load condition and calculate the initial phase voltage (without the support of the DER), which is $230.97 \mathrm{~V}$. 


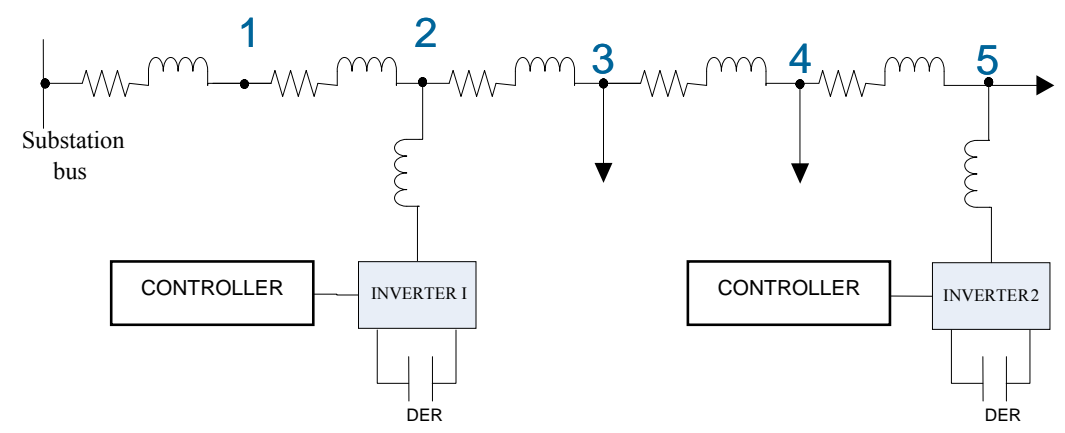

Figure 8-5. Studied radial distribution system.

1. Calculate $V_{d c}$

Assume that in the heaviest load condition, the desired voltage profile at bus 5 is $236 \mathrm{~V}$. Applying system reduction, gives

$$
\left[\begin{array}{c}
I_{G} \\
\underline{0}
\end{array}\right]=\left[\begin{array}{cc}
Y_{G G} & Y_{G L} \\
Y_{L G} & Y_{L L}
\end{array}\right]\left[\begin{array}{c}
V_{G} \\
V_{L}
\end{array}\right] \quad Y_{e q}=Y_{G G}-Y_{G L} Y_{L L}^{-1} Y_{L G}
$$

Assume in steady state $\dot{V}_{c}=V_{c} \angle \alpha$. From the following equation:

$$
\frac{V_{s}}{Z_{e q 12}+Z_{d g} / / Z_{e q 20}} * Z_{d g} / / Z_{e q 20}+\frac{V_{c} \angle \alpha}{Z_{d g}+Z_{e q 12} / / Z_{e q 20}} * Z_{e q 12} / / Z_{e q 20}=236 \angle \alpha
$$

$\mathrm{V}_{\mathrm{c}}$ can be calculated, which is $279.1 \mathrm{~V}$ in this case. $V_{d c}=2 \sqrt{2} V_{c} \approx 800 \mathrm{~V}$.

2. Determine initial $K_{p}$ by using the following equation:

$$
K_{P}=\frac{\frac{\frac{1}{2} V_{d c}}{V_{t}^{\text {peak }}}-1}{\Delta V_{t 0}}=\frac{400 /(230.97 * \sqrt{2})-1}{5}=0.045
$$

3. Determine initial $K_{i}$ by using the following equation:

$$
K_{I}=\frac{\left.\frac{V_{c}}{V_{t}}\right|_{\text {steady-state }}-1}{\int_{0}^{5 \tau} \Delta V_{t 0} \times e^{-\frac{t}{\tau}}}=\frac{\frac{279.1}{236}-1}{0.4966}=0.37
$$

Note that for the case with multiple DERs (such as $N$ DEs), the initial $K_{p}$ and $K_{i}$ for each individual DER shall be simply divided by $N$. As the adaptive control logic will adjust the parameter dynamically in real time, this simple estimation of the initial $K_{p}$ and $K_{i}$ provides a close solution. 


\section{ADAPTIVE VOLTAGE REGULATION METHOD AND SIMULATION RESULTS}

In this section, we describe the results of implementing the adaptive voltage regulation control of Section 8.

\subsection{Single DER case}

The simulation system is based on the system shown in Figure 8-5. In this case, only one DER is placed at bus 5 . The line voltage at bus station is $480 \mathrm{~V}$. Consider the heaviest load condition and calculate the initial phase voltage (without the support of the DER), which is $230.97 \mathrm{~V}$.

Figure 9-1 shows voltage regulation with adaptive adjustment of $K_{p}$ and $K_{i}$. The ideal response is shown in green and the actual in blue. The response satisfies the $0.5 \mathrm{~s}$ response time requirement.

Figure 9-2 shows a comparison of the ideal voltage error and the actual voltage error. After a big voltage variation, the difference of the two voltages will be checked every $0.1 \mathrm{~s}$. At $0.5 \mathrm{~s}, 0.6 \mathrm{~s}$, and $0.7 \mathrm{~s}, K_{p}$ and $K_{i}$ will be increased to track the ideal response. It can be observed that the actual voltage response attempts to follow the desired voltage response, as Figure 9-2 shows the voltage errors both decrease and converge with time.

Figure 9-3 shows voltage regulation with the initial $K_{p}$ and $K_{i}$ without any adaptive adjustment. The response time to reach the reference voltage is $1 \mathrm{~s}$, longer than the desired $0.5 \mathrm{~s}$. This also means that the initial values of $K_{p}$ and $K_{i}$ are conservative.

\subsection{Two DERs Case}

In this case, two DERs are placed at bus 2 and bus 5 , respectively. We can calculate the initial $K_{p}$ and $K_{i}$ for DER 1 at bus 2 , assuming it is a single-DER case, which are 0.06 and 0.5 , respectively. When both DER are online, the initial value of $K_{p}$ and $K_{i}$ can be simply set to be half of the value in the single-DER case.

Figure 9-4 and Figure 9-6 show the voltage regulation with adaptive adjustment of $K_{p}$ and $K_{i}$ at bus 2 and bus 5 , respectively.

Figure 9-5 and Figure 9-7 show a comparison of the ideal voltage error and the actual voltage error at bus 2 and bus 5 , respectively. As these diagrams show, $\mathrm{K}_{\mathrm{p}}$ and $\mathrm{K}_{\mathrm{i}}$ of DER1 are reduced at $0.3 \mathrm{~s}$; and $\mathrm{K}_{\mathrm{p}}$ and $\mathrm{K}_{\mathrm{i}}$ of DER2 are increased at $0.4 \mathrm{~s}$ and $0.5 \mathrm{~s}$. Also shown is that the actual response curve at each bus consistently attempts to follow the desired voltage response curve. 


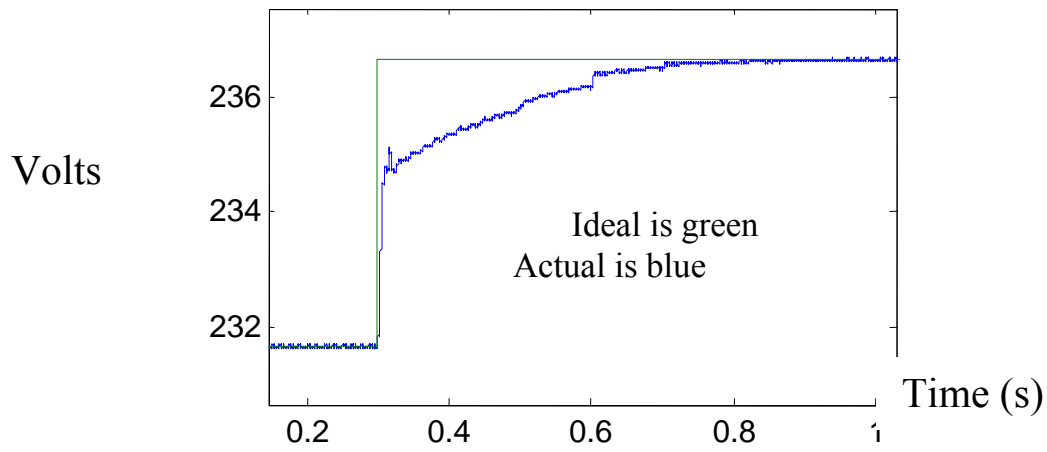

Figure 9-1. Voltage regulation with adaptive adjustment of $K_{p}$ and $K_{i}$.

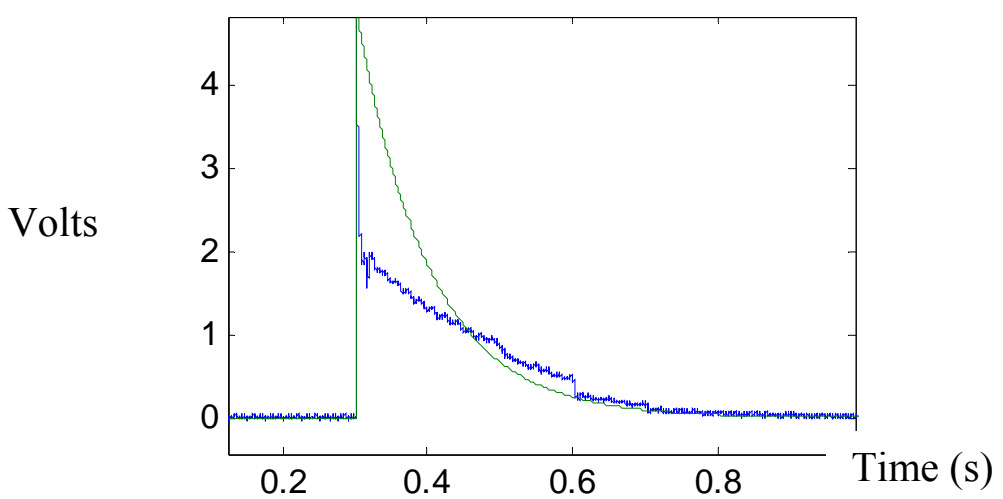

Figure 9-2. Comparing ideal voltage error and the actual voltage error.

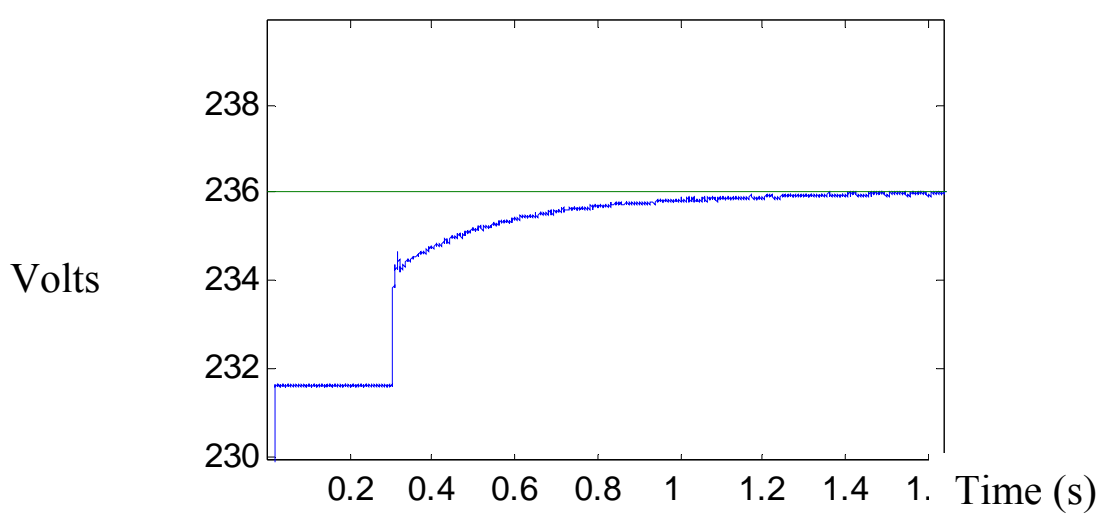

Figure 9-3. Voltage regulation with initial $K_{p}$ and $K_{i}$. 


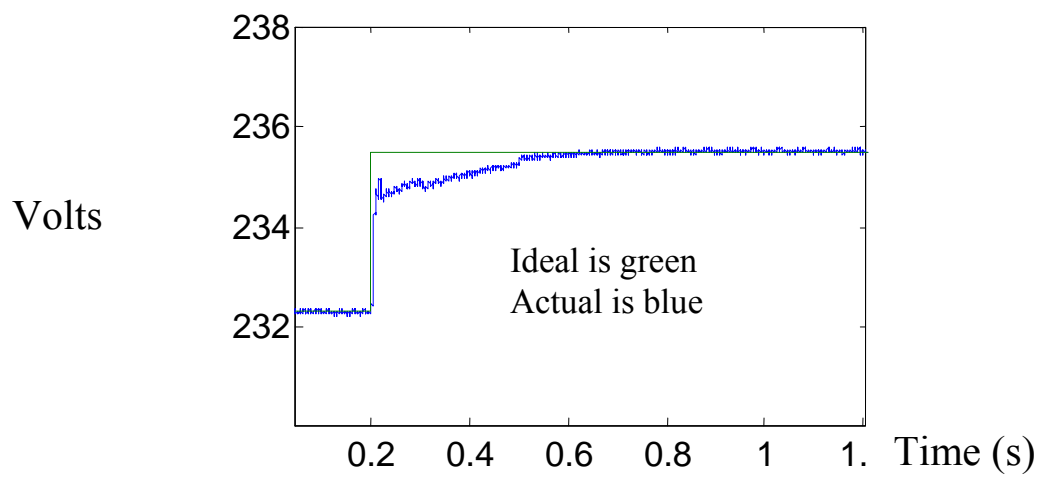

Figure 9-4. Voltage regulation with adaptive adjustment of $K_{p}$ and $K_{i}$ at bus 2

Volts

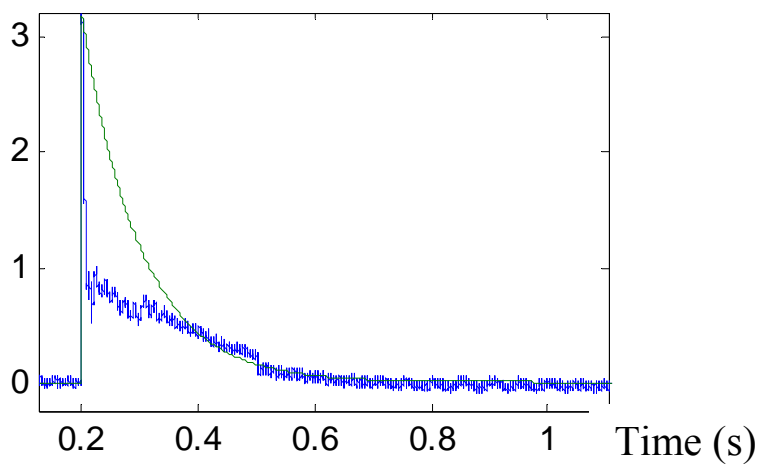

Figure 9-5. Comparing ideal voltage error and the actual voltage error at bus 2.

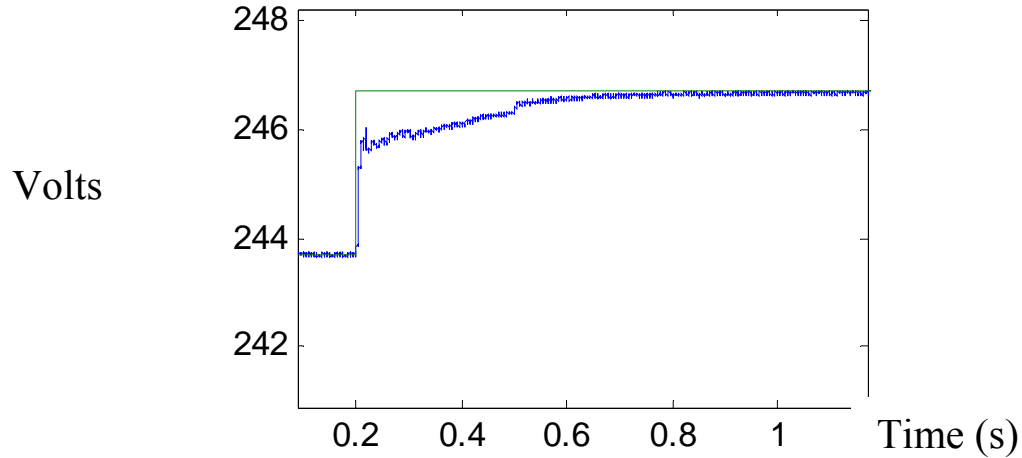

Figure 9-6. Voltage regulation with adaptive adjustment of $K_{p}$ and $K_{i}$ at bus 5 .

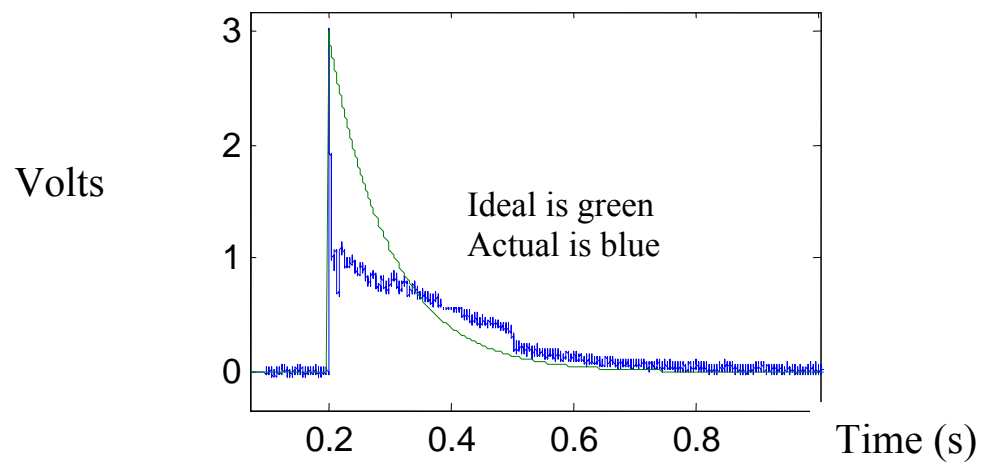

Figure 9-7. Comparing ideal voltage error and the actual voltage error at bus 5. 


\section{TESTING AT DECC AND RESULTS}

The DECC Laboratory, its capabilities, and the results of our testing of dynamic voltage regulation with $\mathrm{DE}$ is described in this section. We completed development of control methods for both our DE mockup systems (an SC using an overexcited synchronous motor with 6.6kW dc power supply and a programmable inverter with a $800 \mathrm{Vdc}$ power supply). The controls that use PI -integral feedback control were developed using the non-active instantaneous power theory developed at the University of Tennessee by Dr. Yan Xu, et. al. [14]. A test matrix describing the overall category of tests conducted with DE at the DECC Lab is provided in Table 10-1. The test matrix considers a number of operational test scenarios for evaluating dynamic DE control algorithms. These scenarios involve (1) balanced/unbalanced voltage conditions (i.e., sags), (2) various dynamic load conditions (i.e., motor starts), (3) changing load conditions (i.e., step load changes), (4) severe abnormal conditions (i.e., fault conditions), and (5) changing voltage schedules for the DE. Based on the results of these tests, general engineering guidelines or rules of thumb will be developed along with a control methodology framework that will provide a streamlined engineering approach for utilities to implement various ancillary services using DER.

Table 10-1. DECC Test Matrix*

\begin{tabular}{|l|c|c|c|c|c|c|}
\hline & $\mathrm{SC}$ & $\mathrm{Inv}$ & $\mathrm{SC}+\mathbf{i n v}$ & $\mathrm{Inv}+\mathbf{M T G}$ & SC+MTG & SC+inv+MTG \\
\hline $\begin{array}{l}\text { Temperature/current } \\
\text { rating }\end{array}$ & & $\mathrm{x}$ & & & & \\
\hline Voltage regulation & $\mathrm{X}$ & $\mathrm{x}$ & $\mathrm{X}$ & $\mathrm{X}$ & $\mathrm{X}$ & $\mathrm{X}$ \\
\hline Unbalanced voltage & & $\mathrm{x}$ & $\mathrm{X}$ & $\mathrm{X}$ & & $\mathrm{X}$ \\
\hline Fault clearing & & $\mathrm{x}$ & & $\mathrm{X}$ & & $\mathrm{X}$ \\
\hline Circuit reconfiguration & $\mathrm{X}$ & $\mathrm{x}$ & $\mathrm{X}$ & $\mathrm{X}$ & $\mathrm{X}$ & $\mathrm{X}$ \\
\hline
\end{tabular}

*SC - synchronous condenser, inv - inverter and MTG - micro-turbine. Testing that has been conducted is indicated by $\mathrm{x}$.

Temperature/current rating of inverter. The inverters had to be characterized with regard to maximum current output based on cooling capability. The inverters operate at high power $(800 \mathrm{Vdc} / 480 \mathrm{Vac})$ as well as high switching frequency, which drives up the inverter operating temperature. We have found that our $150 \mathrm{~A}$ inverter can operate at a continuous level of 54.4 Arms $\left(77 \mathrm{~A}_{\text {peak }}\right)$ or lower without exceeding the temperature region of $77^{\circ} \mathrm{C}$ at the heat sink, which equates to $100^{\circ} \mathrm{C}$ or less ${ }^{i}$ at the inverter's IGBT junctions. However, the inverter is capable of operating at its maximum current output of $150 \mathrm{~A}$ for several cycles to minutes. We have placed temperature measuring instrumentation on the inverter's heat sink near the IGBT junctions to monitor the temperature as we operate the inverter during our testing. We initially characterized the maximum continuous current output by loading up the inverter with our local load banks until the maximum temperature of $77^{\circ} \mathrm{C}$ was reached and stabilized.

Voltage regulation._Our primary focus has been on evaluating methods for local voltage regulation with the modulation of reactive power output from DE. We have been using a PIcontroller based on instantaneous non-active power theory. We are implementing the control with our SC and inverter that are connected to the ORNL distribution system. The goal is to

\footnotetext{
${ }^{\mathrm{i}}$ The danger zone for IGBT junction operating temperature is the range of 100 to $120^{\circ} \mathrm{C}$. At $120^{\circ} \mathrm{C}$, it can fail; above $100^{\circ} \mathrm{C}$, it can start to degrade. The IGBT junction will operate at 20 to $30^{\circ} \mathrm{C}$ higher than the heat sink surface. Thus setting the upper temperature criterion at $77^{\circ} \mathrm{C}$ for the heat sink ensures a comfortable margin of $20^{\circ} \mathrm{C}$.
} 
maintain voltage regulation for balanced as well as slightly unbalanced phase voltages and for both steady state and transients. We want to achieve fast response without creating local voltage instability in the form of oscillations or overshoot. We have the flexibility to test the SC and inverter connected on separate circuits or reconfigured to have the same substation feed. Also, we have a conventional $30 \mathrm{~kW}$ micro-turbine, without power factor control, that can be operated with the SC and inverter. Finally, we have the ability to relax the taps at our local distribution transformers feeding the power panels and the reactive power compensation at the local substation (900 kVar with $150 \mathrm{kVar}$ increments) to worsen the voltage profile for testing. In regard to transients, we will evaluate the response of the control to voltage shifts due to the PI control reference reset, motor start, load bank setting changes, and/or to disconnection of capacitors at the local substation. The specific tests include (1) testing of the SC and inverter in parallel and (2) testing of the SC, inverter and microturbine together.

Unbalanced voltage. Voltage imbalance is very bad for three-phase motor operation. Motors must be de-rated when operated with voltage unbalance per NEMA MG-1. The maximum allowed continuous voltage unbalance according to NEMA MG1 is 5\%. Initially, we have slightly unbalanced phase voltages feeding the inverter panel, so we use our controls to correct this imbalance. Later, we use the starting of a single-phased (one phase lead open) three-phase motor to evaluate our controls for balancing the voltage using the inverter. The initial motor that we use for the testing is $7.5 \mathrm{hp}$ and it can draw $\sim 80 \mathrm{~A}$ on two phases for over $2 \mathrm{~s}$. We control the inverter to correct the unbalance up to the inverter's current limit and the SC to restore the average voltage to match the control reference voltage.

Fault clearing. Our focus for fault clearing has been to evaluate (1) how quickly the inverter with our controls can trip with nearby fault-like condition and (2) how well our controls can limit the inverter and SC current when there is a nearby fault condition. In the former case, we want the inverter to protect itself and thus trip when the fault is extremely close to prevent any damage to the inverter and prevent it from feeding the fault. However, in the latter case, we want the inverter and SC to continue to support the sagged voltage due to the fault but without exceeding its rated current output. We use several sizes of three-phase motors to produce severe/unbalanced voltage sags for several cycles similar to that due to a fault. We were able to test the nearby fault for the inverter with the startup of a $250 \mathrm{hp}$ synchronous motor and with induction motors, single-phased, so that they can not start. The purpose of these tests has been to evaluate how the inverter and SC can support system-wide voltage sags associated with subtransmission faults or faults on neighboring distribution circuits without the DE providing current beyond its capability. The specific tests include (1) see how the slower response of the SC works with a transient event such as a fault, (2) see how the inverter responds to a mild transient (i.e., startup of a small motor) and to an extreme transient (i.e., startup of a large motor), and (3) verify that the conventional microturbine does not respond to voltage.

Circuit reconfiguration. Our focus here is to evaluate the impact of varying the electrical distance among the DER or between the DER and the substation. We are interested in the impact of varying the electrical distance on the performance of the PI controls that we are using for the dynamic voltage regulation. We are testing this by reconfiguring the two circuits to which the $\mathrm{SC}$ and inverter are connected so that they are in series (having the same single-source feed from the substation) rather than in parallel (having separate source feeds from the substation). By using a 
normally open tie switch that connects the two circuits, we can reconfigure the circuits so that both the SC and inverter are electrically closer together than in the normal circuit configuration. Two different reconfigurations can be used for the testing, depending on which of the two circuits provides the single feed (one circuit switch at the substation is open while the other circuit switch is closed). The voltage regulation control methods were tested with the SC and inverter in series.

\subsection{DECC Laboratory}

ORNL developed the DECC Lab (Figure 10-1) for studying dynamic voltage and power factor control supplied from DER. This unique laboratory currently has installed both rotating and inverter-based technologies.
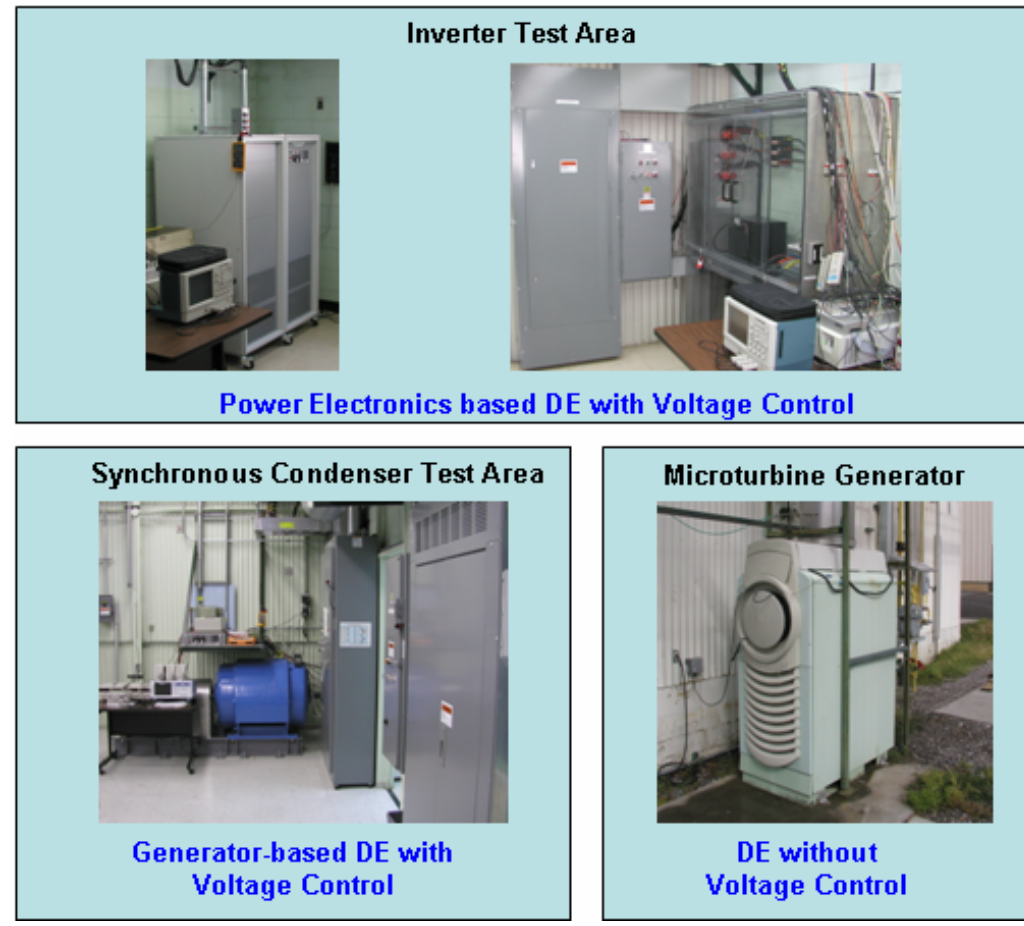

Figure 10-1. Inverter, synchronous condenser, and microturbine generator tested simultaneously.

At present, equipment at DECC consists of three DE devices: a 300-kVar SC, a 150 A (or 125 $\mathrm{kVA}$ ) inverter, and a $30 \mathrm{~kW}$ microturbine generator. There is also a $100 \mathrm{~kW}$ microturbine with heat recovery at the DECC Lab that is connected to the distribution network; it is hoped it will be operational early in FY 2009. Figure 10-2 shows the one-line electrical diagram of the DECC $\mathrm{Lab}$ and its connection to the ORNL distribution system. ORNL owns and operates its own electric distribution utility for the Laboratory campus and can configure the distribution system to provide optimum opportunities for testing of non-active power (including reactive power) injection benefits and impacts from rotating and inverter-based DE. Real-time monitoring and programmable controls are available at the end-user laboratory level for testing and developing local controls for DE. There is also a real-time monitoring system for the overall distribution system via the PowerNet ${ }^{\circledR}$ System, and power meters are located at all of the ORNL substations. 
A complete hierarchy of power distribution system testing, such as load changes, startup of dynamic loads, and feeder reconfiguration, is offered by the DECC Lab via its equipment and linkage with the ORNL distribution system, which ties in with the Tennessee Valley Authority (TVA) bulk system.

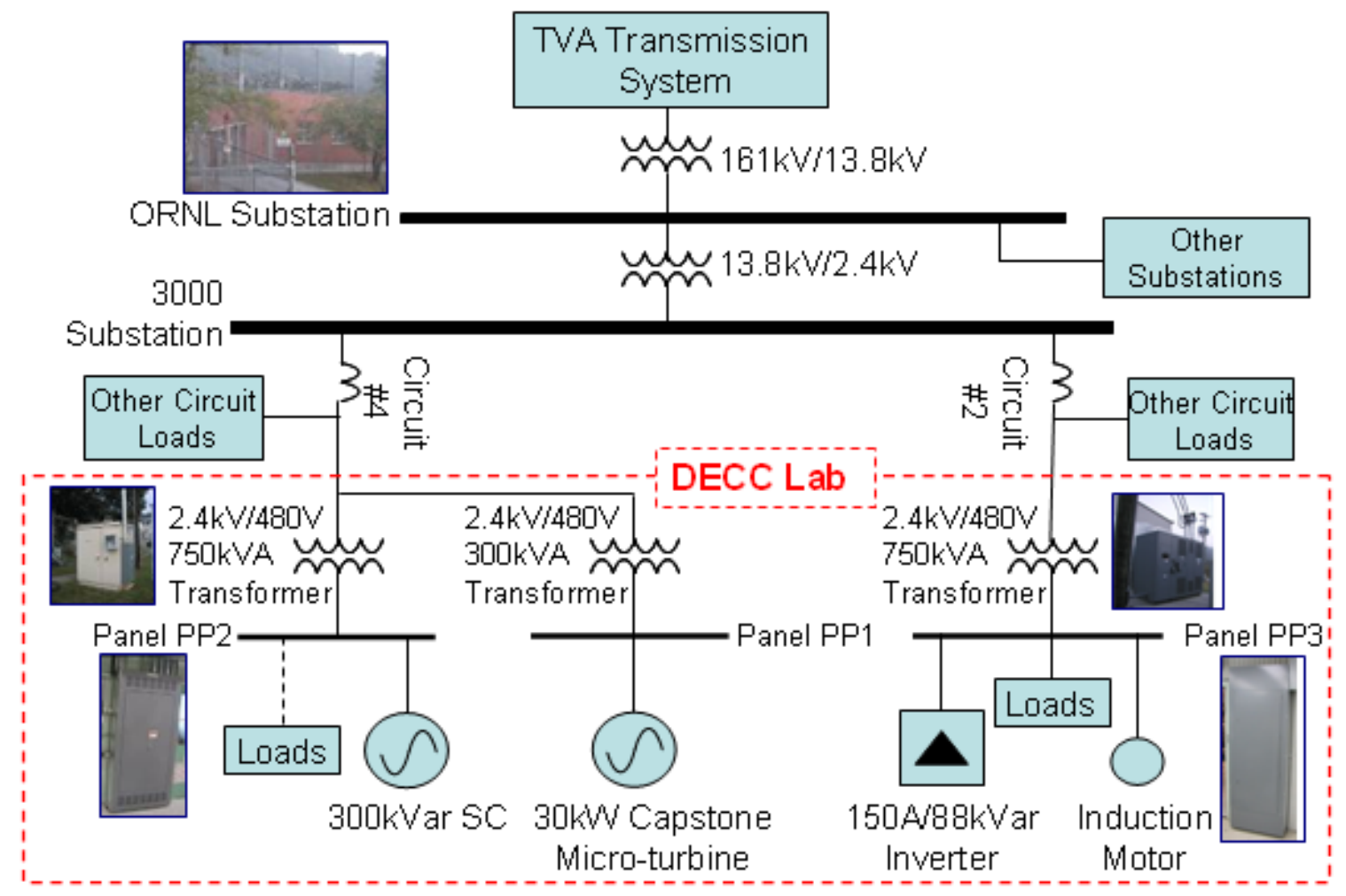

Figure 10-2. Electrical configuration (diagram) of the DECC laboratory and equipment.

The SC, which is an overexcited synchronous motor, is capable of providing up to $300 \mathrm{kVar}$ of reactive power injection. It is on its own $480 \mathrm{~V}$ panel connected to circuit \#4 of the ORNL distribution system. The $30 \mathrm{~kW}$ microturbine generator is on another panel but on the same circuit. We are currently working with a $150 \mathrm{~A}(125 \mathrm{kVar})$ inverter which is on its own $480 \mathrm{~V}$ panel connected to circuit 2 of the ORNL distribution system. We also have two other inverter sizes available for testing, $75 \mathrm{~A}$ and $300 \mathrm{~A}$. All three DE devices are connected to the same substation, ORNL's 3000 substation. ORNL is a direct distributor from the TVA $161 \mathrm{kV}$ backbone transmission system.

In addition to the DE systems at DECC, ORNL has two load banks for varying the local load. There is a $500 \mathrm{~kW}$ resistive load bank with $1 \mathrm{~kW}$ step change capability and a $375 \mathrm{kVar}$ reactive load bank with $3.75 \mathrm{kVar}$ step change capability. The load banks are connected to the same power panel as the inverter. Currently, there are no load banks connected to the SC power panel, as shown in Figure 10-2; plans are to add one in FY 2009. In addition to the load banks for varying local load, we have an induction motor (a range of motors from 7.5 to $75 \mathrm{hp}$ are available) connected to the inverter panel and a $250 \mathrm{hp}$ synchronous motor connected to the SC panel to provide dynamic loads. 
A feedback control system is used to adjust the reactive power output from the SC and inverter based on the measured end-user voltage at their power panels. The control algorithm compares the measured values against a desired reference or target and adjusts the output of the DE device based on the error between them. The dynamic control of local voltage is important for improving power quality to local and nearby loads and improving line losses because the injection of reactive power offsets the demand by local loads, reducing the delivery current from the utility. Conventionally, shunt feeder capacitors and line regulators are used to control distribution voltages, but they are slow and are not continuous (fixed step sizes). Also, reactive power from capacitor banks drops off with the square of the voltage, so they provide diminishing value at low voltage when they are most needed. Further, capacitor switching can cause transients on the distribution network; in the worst cases, they can cause magnified voltages when the capacitance and inductance of the network are matched. DE with the ability to absorb or inject reactive power can also improve the voltage stability of the power grid by providing reactive power during system stress, i.e., when there is a shortfall or transport limitations on reactive power delivery from central generators and on major transmission lines.

Local controls have been designed using Matlab/Simulink and dSpace software and hardware to operate both the $\mathrm{SC}$ and the inverter to provide voltage regulation locally and dynamically. The $\mathrm{SC}$ and inverter operate as reactive power generators or sinks depending upon the voltage needed: they generate reactive power to boost voltage when voltage is low and absorb reactive power to lower voltage when it is too high. The current $30 \mathrm{~kW}$ micro-turbine connected at the DECC Lab uses conventional controls and is designed to operate only when grid voltage is present and within specified limits and to provide active power locally or to the grid. It is operated at unity power factor and does not perform any voltage regulation or power factor correction support of any kind. A second micro-turbine, a $100 \mathrm{~kW}$ Elliott unit, has also been installed and it is expected to be operational by early FY 2009. This second microturbine will provide a DER that has some limited capability to produce leading or lagging reactive power (Vars).

The two DE devices, SC and inverter, can be controlled autonomously, a unique arrangement that involves no central communication and control or need for the two devices to talk to each other. The DECC is comparing how "smart" DE that can dynamically control its local voltage compares with conventional DE. The controls are based on the worst case of no communication but greater functionality could be added if communication were available.

The SC system has a response time in the millisecond range whereas the inverter system has a response time in the microsecond range. With small voltage changes, such as $0.1 \mathrm{~V}$, the two devices can respond quickly; with larger voltage changes, such as 0.5 to $4 \mathrm{~V}$, it takes them around 0.5 to $1 \mathrm{~s}$ to settle to a new steady-state voltage condition if the control gains are kept constant. The response can be made more rapid (i.e., $0.5 \mathrm{~s}$ ) by increasing the gains during a transient voltage change up to a limit to prevent overshoot or undershoot of voltage and to prevent local voltage instability (voltage oscillation during the transient).

By incorporating larger generators in rotating $\mathrm{DE}$ (such as reciprocating generator sets) and larger inverters in microturbine or fuel cell DE), end users can meet both their active power and 
nonactive or reactive power needs to support end-user and system voltages. The active power performs actual work, and reactive power is what inductive loads need to store energy, for example, for the operation of motors. Even idle synchronous motors, such as those used in industry, could be modified like our $250 \mathrm{hp}$ synchronous motor to provide reactive power at the customer site. Incentives for end users to provide reactive power support are growing, and perhaps in a few years they will match the incentives for providing active power.

Our industry partners of the DECC Laboratory view DE providing local voltage regulation as the wave of the future. The use of DE is growing, and local voltage regulation is a necessary ancillary service for ensuring power quality for more demanding loads, such as computers and electronics-based loads. Loads like these are increasingly showing up on the power system. One of our utility partners, SCE, is looking toward implementation of this technology on its "Distribution System of the Future." SCE envisions providing for more than $30 \%$ of the reactive power needs of the distribution circuit using local DE.

The DECC Lab offers the capability to test DE technologies in a real-world distribution system environment. It provides the link between testing and simulation needed to ensure accuracy of experimental results. Additionally, renewable energy technologies, many of them inverter-based technologies such as PV, can be accommodated in the DECC facility. A 50-kW PV array placed on the north end of the ORNL campus will provide a $600 \mathrm{~V} / 134$ Adc supply for testing our controls with PV inverters.

\subsection{Testing Approach}

To date, local dynamic voltage regulation at our DECC Laboratory has been tested at the DECC Lab. The approach was to dynamically change the reactive power output of the DE to either produce or absorb reactive power to raise or lower the voltage in order to regulate it to some voltage reference. The voltage reference may be based on a voltage schedule provided by the local utility. Obviously, end users would need a price incentive to produce VARs dynamically to regulate the local voltage, which would also support the overall distribution system.

The DECC Lab currently has two DE mock-up systems. The SC provides a rotating-based DE consisting of a synchronous motor that is excited by a $6.6 \mathrm{~kW}$ dc power supply. The other system is power-electronics based with a programmable inverter fed by a $144 \mathrm{~kW}$ dc power supply. Both systems are connected to an actual distribution system; the ORNL distribution system. For transient testing, we have a range of induction motors (this project used a 7.5hp motor) and two large load banks (500 kW with $1 \mathrm{~kW}$ steps and $375 \mathrm{kVar}$ with $3.75 \mathrm{kVar}$ steps). The focus of the testing was on the controls needed to perform dynamic voltage regulation. Development has centered on a PI controller for both the SC and the inverter.

The various functional capabilities tested include (1) balanced voltage regulation, (2) unbalanced voltage regulation, (3) voltage regulation with current control, and (4) adaptive control gain.

Balanced voltage regulation. This approach used PI control to dynamically regulate the average voltage of the three-phase voltages to maintain a reference voltage. PI control calculates the error between the average and the reference rms voltage to determine how to change the PWM of the inverter. The average rms voltage, updated at every sample, is the average of the three line-to- 
line or line-to-neutral voltages. Initially, line-to-line voltages were used to calculate the line-toneutral voltages based on the assumption that the three phases are balanced. However, instrumentation was later modified to measure line-to-neutral voltages directly so that the measures could be used both for balanced or unbalanced conditions. For balanced voltage regulation, the inverter's PWM for each of the three phases is the same. When the voltage produced by the inverter is higher than the system voltage and lagging the current, the inverter is injecting reactive power.

Unbalanced voltage regulation. This approach used the rms voltage calculation for each of the three phase-to-neutral voltages and compared each to the reference to determine the voltage errors for each phase. Each phase of the inverter was controlled independently to correct the voltage error.

Voltage regulation with current control or regulation. The previous two approaches did not include the ability to limit the current output of the inverter. Limiting the current output is important in case of a large transient, such as a large change in voltage. If the current output were not limited, the inverter would trip out on overcurrent protection when the voltage change was severe. This is desirable only in case of a fault; otherwise, we prefer that the inverter produce up to its capability to continue supporting local voltage to the best of its ability. Otherwise, the inverter would trip out and any support that it could provide would be lost. For current control, the inverter switches from voltage regulation to current regulation when the inverter current starts to exceed its rated or preset limit. Thus current control prevents the inverter from tripping out when a large transient occurs unless the transient is a fault. Some logic would be needed to distinguish between a severe voltage sag and a fault. For example, a voltage sag that requires $150 \%$ of the inverter's rated current output (although the inverter would be limited to its full 100\% output) could be classed as a severe transient, whereas a sag that requires higher output could be classed as a fault. Current regulation works much like voltage regulation: the average rms current for all three phases is calculated and compared with a current limit. If the current is below the limit, the inverter switches back to voltage regulation mode. However, if the current nears or reaches the limit, it is regulated to the reference current, which is slightly less than the limit. The control switches back to voltage regulation mode only when the current drops below the limit again.

Adaptive gain control. Normally the gains of the PI controller, in this case the proportional gain or $K p$ and the integral gain or $K i$, stay constant for voltage regulation regardless of whether the system is in steady state (very little change in voltage) or transient (a large voltage change occurs as the result, for example, a motor start or load step change). Normally, the best gain values are determined (e.g., for $K p$ and $K i$, and they are left fixed for the control. However, it is helpful for the gain to change dynamically during a transient, depending upon the severity of the voltage error (difference between actual and reference voltage). Adaptive gain control employs a step response for a voltage change that closely fits the exponential ideal response and reduces the voltage error to zero in five time constants. The time constant depends on the response capability of the DE; in this study, the time constant is about $0.06 \mathrm{~s}$ for the SC and much smaller for the inverter. The PI gains change only during the transient; they are thus unchanged before and after the transient event. Limits are set on the gain to prevent overshoot or undershoot of voltage during the transition and to avoid voltage instability (voltage oscillations) during the transition. 


\subsection{Testing Configurations}

As shown in Figure 10-3, the two DE mockup systems at the DECC Lab are normally connected to two different distribution circuits of the ORNL 3000 substation. The SC, a synchronous motor that is under-excited to absorb Vars or overexcited to supply Vars, is connected to a 480 V/1000 A power panel fed from circuit 4 . The inverter is connected to a $480 \mathrm{~V} / 600$ A power panel fed from circuit 2. There is a tie load break switch (4-2-S) connecting circuit 4 and 2 that is normally open. Load break switches $4-\mathrm{S}$ and 2-S, which connect circuits 4 and 2, respectively to the substation and energize the circuit are normally closed.

Testing was conducted with two different circuit configuration schemes: one is the normal, parallel configuration, with the two DER connected with separate circuit feeds, and reconfigured circuits in a series configuration, with only one feed to the two circuits with the tie switch between them closed. Connecting the two DER in parallel to the distribution system gives the greatest electrical distant between them. For this configuration, the $\mathrm{SC}$ was fed from circuit 4 of the substation and the inverter was connected to circuit 2 . The load break switches connecting the circuits to the substation were closed and the tie switch was open. There are two possible series configurations as indicated in Table 10-2 below. For series configuration 1, only the circuit 4 and tie load break switches are closed, and circuit 4 feeds the two DER and loads of both circuits 4 and 2. For series configuration 2, only circuit 2 and the tie load break switches are closed, and circuit \#2 feeds the DER and loads of both circuits.

Table 10-2. Switching for the Three Different Circuit Configurations.

\begin{tabular}{|c|c|c|c|}
\hline Switches & $\begin{array}{c}\text { Normal or parallel } \\
\text { configuration }\end{array}$ & $\begin{array}{l}\text { Reconfigured to series } \\
\text { configuration } 1 \text { - Single } \\
\text { feed via circuit } 4\end{array}$ & $\begin{array}{c}\text { Reconfigured to series } \\
\text { configuration } 2-\text { Single } \\
\text { feed via circuit } 2\end{array}$ \\
\hline $4-\mathrm{S}$ & Closed & Closed & Open \\
\hline 2-S & Closed & Open & Closed \\
\hline $4-2-S$ & Open & Closed & Closed \\
\hline
\end{tabular}

The difference between the two series configurations is which DE is closer electrically to the substation. In configuration 1, the SC or rotating-based DER is closer to the substation; in configuration 2 the inverter-based DER is closer. Either series configuration puts the two DER much closer together electrically than the parallel configuration. It is important to test multiple DER both when they are electrically close and when they are electrically further away from each other to predict what will occur in actual utility installations of multiple DER. 


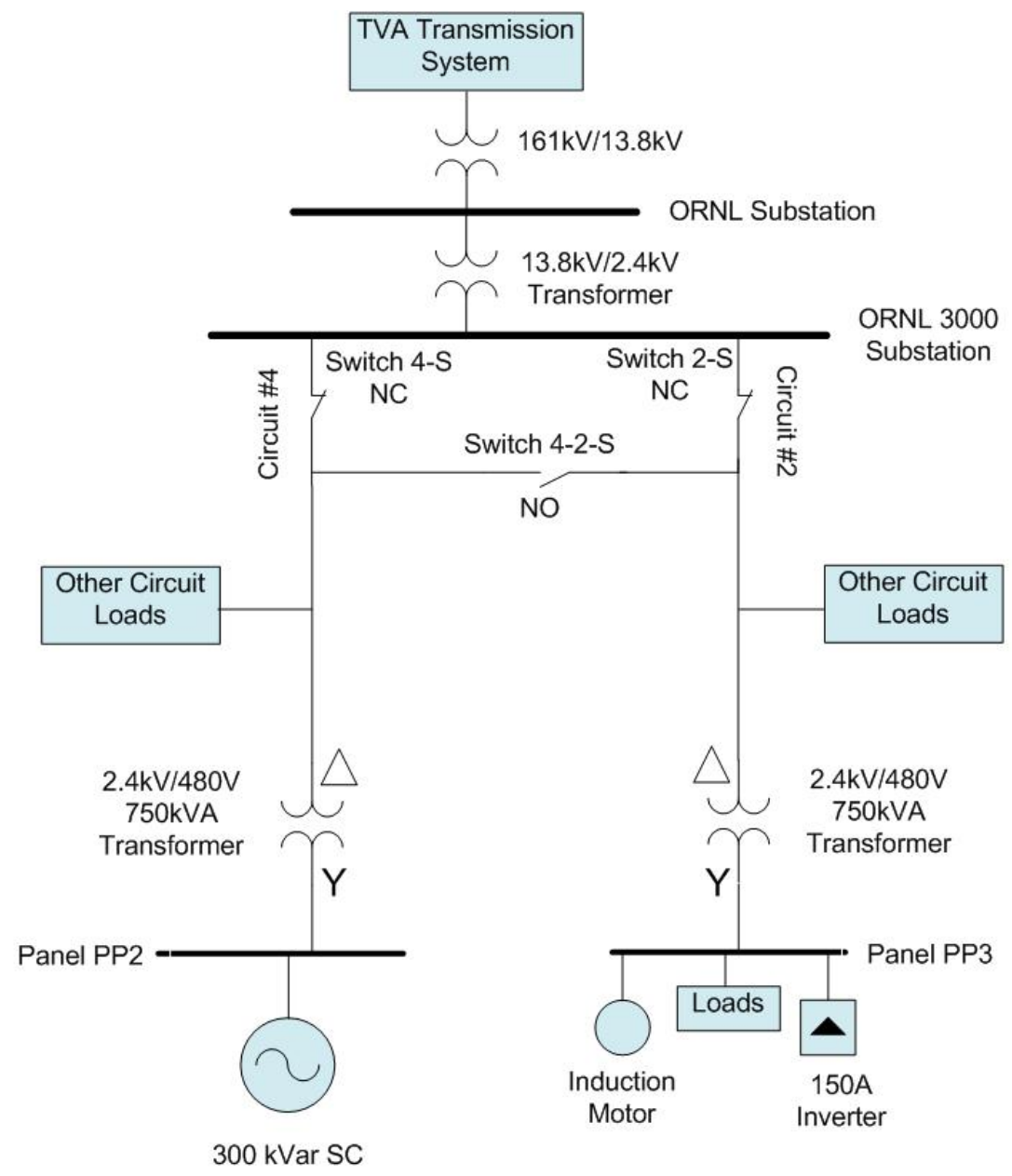

Figure 10-3. Parallel (normal) configuration of circuits 2 and 4 forDECC testing.

\subsection{Testing Transients}

There are several means of producing transients to test dynamic voltage regulation methods. The voltage reference for the PI controls can be changed to force the controls to respond to a voltage change. The inverter, which has a range of 0 to $\sim 62 \mathrm{kVar}$ output, can respond to a $0-3 \mathrm{~V}$ change. The SC, which has a range of 0 to $300 \mathrm{kVar}$ output, can respond to a change of $0-5 \mathrm{~V}$ or more. Ideally the response is a step function; but in reality, the response is more exponential, with the PI control reaching steady state at the new reference at around 5 time constants. The DECC Lab equipment for testing voltage transients includes an induction motor and load banks. The $7.5 \mathrm{hp}$ motor used in this study was connected to the same power panel as the inverter. The motor produces a voltage sag of $\sim 2.2 \mathrm{~V}$ for $0.13 \mathrm{~s}$ when started balanced (Figure 10-4) and $\sim 1 \mathrm{~V}$ for $2 \mathrm{~s}$ when started single-phased ${ }^{\mathrm{j}}$ as shown in Figure 10-5.

\footnotetext{
${ }^{\mathrm{j}}$ Single-phased refers to one phase of the motor being opened. In this study, the fuse was removed from one phase to achieve single-phasing. In the single-phased configuration, the motor cannot start and draws locked-rotor current, which can be 5-6 times rated. The motor logic protection trips the motor after $3 \mathrm{~s}$ to prevent motor damage.
} 


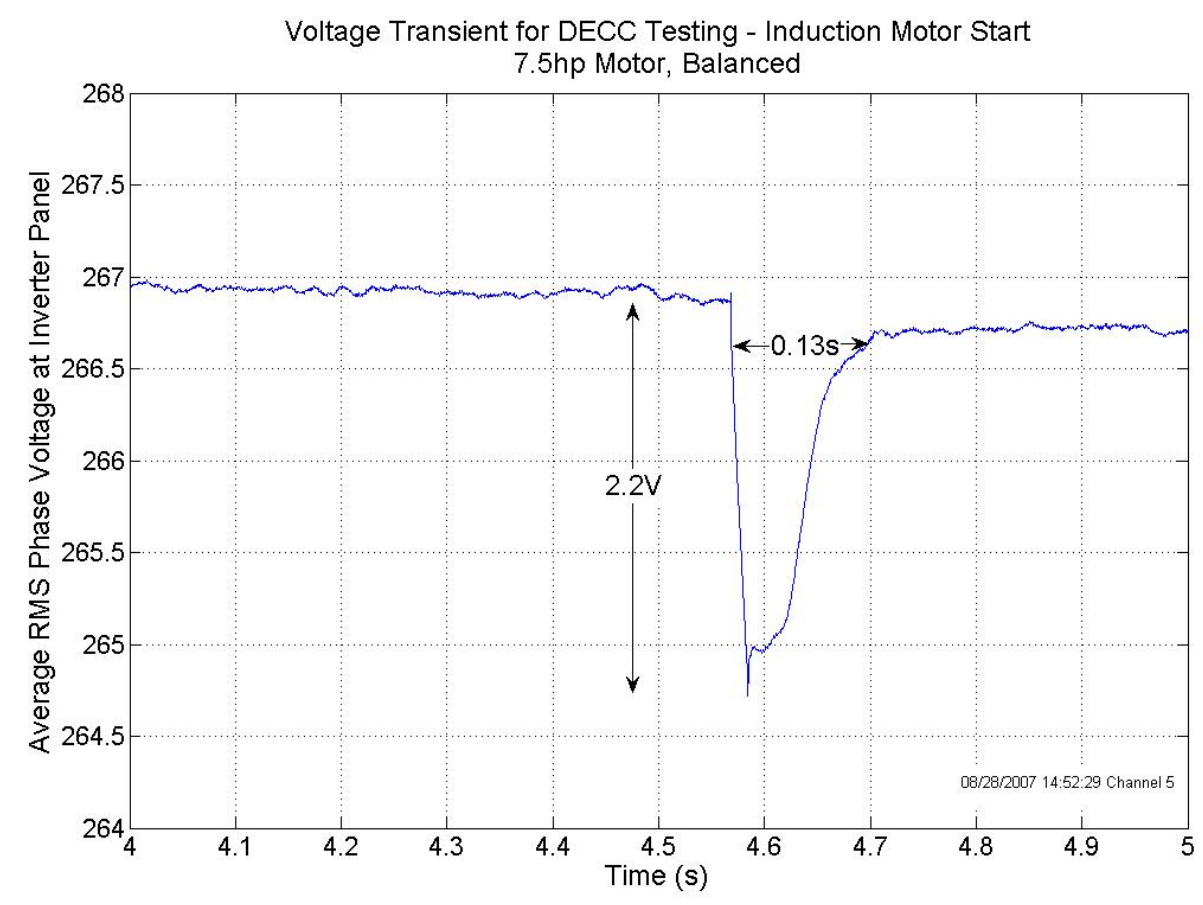

Figure 10-4. Voltage transient due to balanced motor start.

For the single-phased motor start, the voltages are unbalanced so that two of the phase-to-neutral voltages (in this case $a$ and $c$ ) are sagged while the third phase (b) is open and thus causes no impact on that phase voltage. The motor is unloaded, so the transient is caused by the startup current of the motor. The current is sustained for a longer time because the motor is unable to start and only trips out after the motor protection logic trips the motor. In the balanced motor case, the startup transient is short due because of the low horsepower of the motor.

The load banks also provide the ability to produce sustained voltage changes. The resistive bank has a range of 1 to $500 \mathrm{~kW}$ and the reactive bank has a range of 3.75 to $375 \mathrm{kVar}$. Since the resistive and reactive banks have step increments of $1 \mathrm{~kW}$ and $3.75 \mathrm{kVar}$, respectively, the degree of voltage change can be significantly varied for a test. Figure 10-6 and Figure 10-7 are examples of load bank step changes.

A quite severe voltage transient can be produced when the $250 \mathrm{hp}$ synchronous motor used for the SC is started. As shown in Figure 10-8, it creates a $\sim 60 \mathrm{~V}$ sag on the SC panel. When the SC and Inverter are connected in normal parallel configuration of Figure 10-3, the synchronous motor creates a 2.5 to $3 \mathrm{~V}$ sag on the inverter panel. However, when they are connected in series configuration represented in Table 10-2, the synchronous motor startup on the SC panel produces $\sim 7 \mathrm{~V} \mathrm{sag}^{\mathrm{k}}$ on the inverter panel (Figure 10-9).

\footnotetext{
${ }^{\mathrm{k}}$ The voltages on the SC power panel are measured line-to-line, whereas the voltages on the inverter panel are measured line-to-neutral. The voltage sag shown for the inverter panel as due to the synchronous motor start has been converted to the $480 \mathrm{~V}$ line-to-line base.
} 


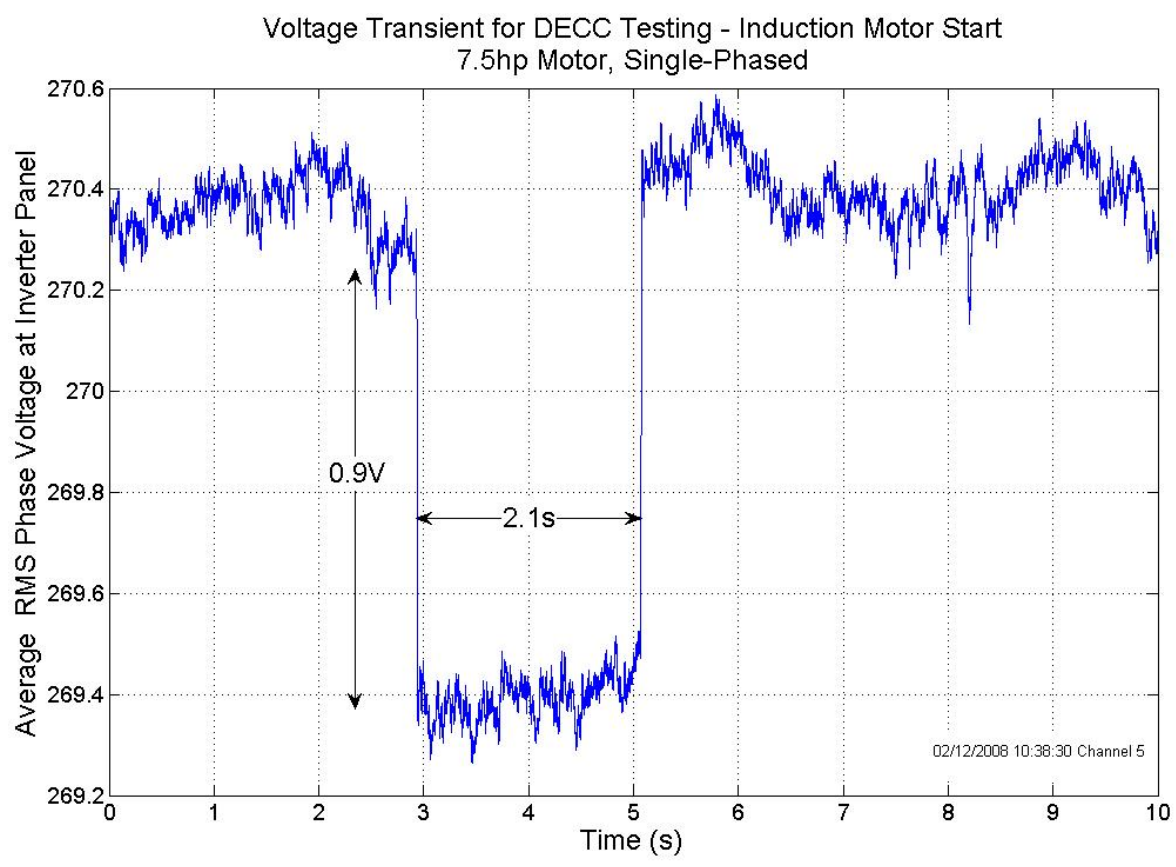

Figure 10-5. Voltage transient due to single-phase motor start.

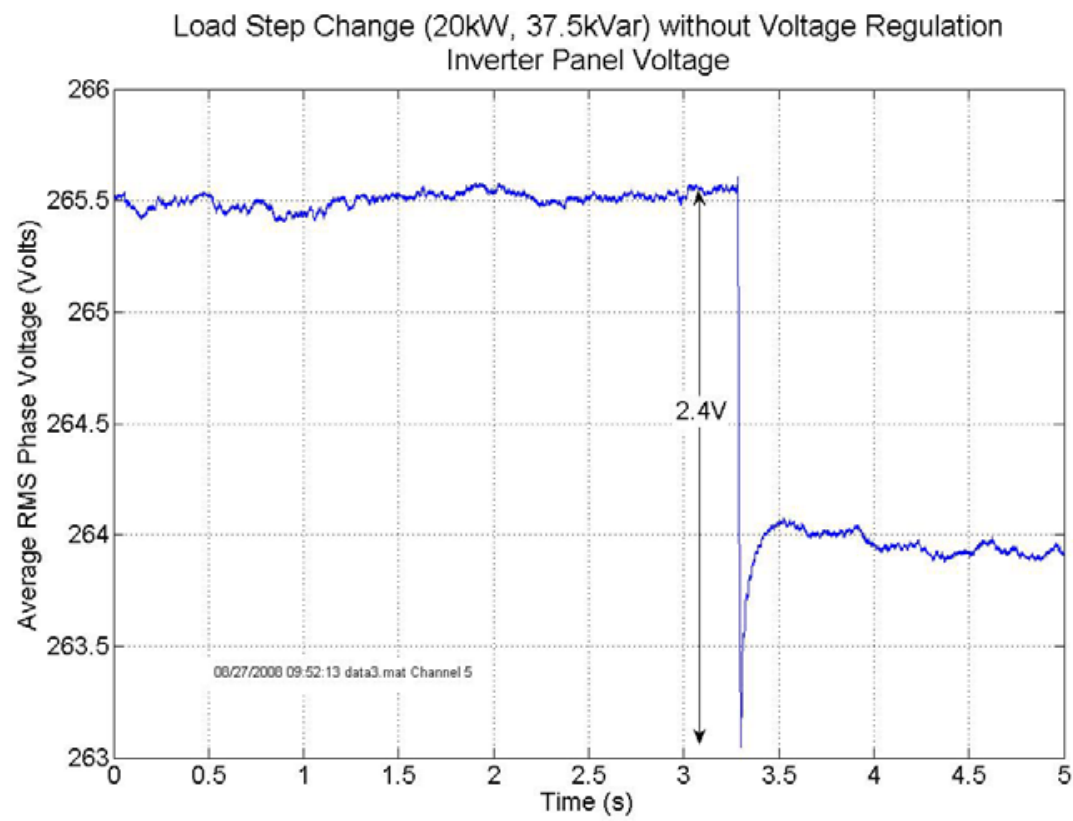

Figure 10-6. Load step transient with the addition of $20 \mathrm{~kW}, 37.5 \mathrm{kVar}$ load. 


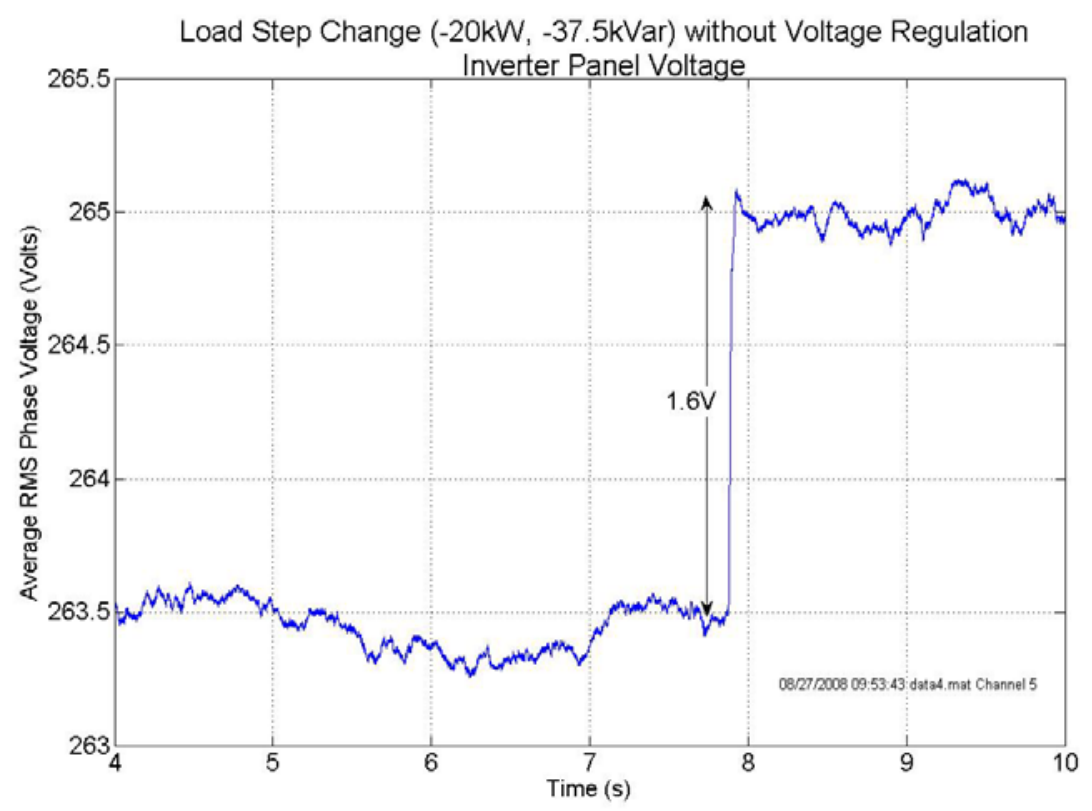

Figure 10-7. Load step transient with the removal of $20 \mathrm{~kW}, 37.5 \mathrm{kVar}$ load.

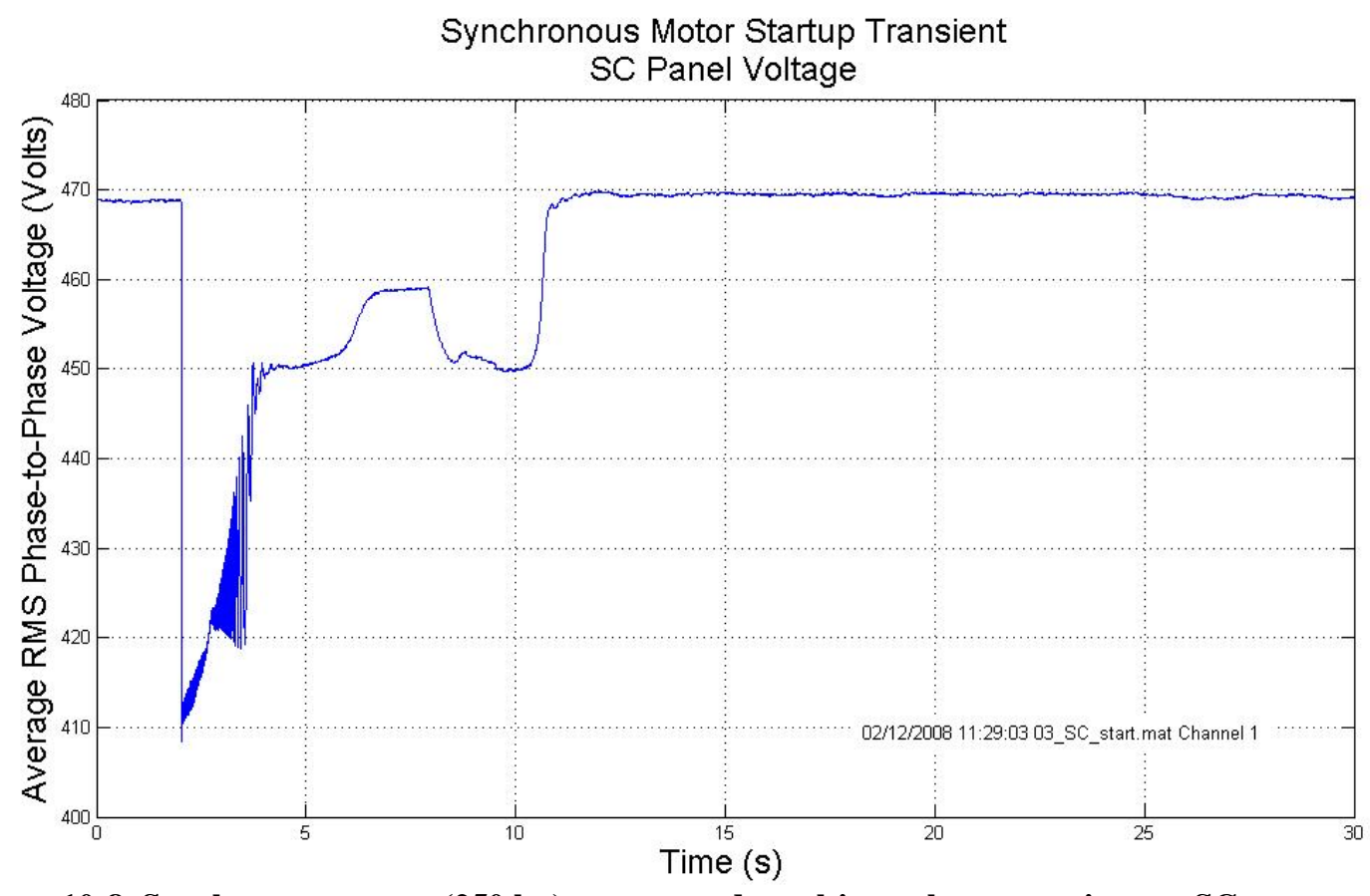

Figure 10-8. Synchronous motor (250 hp) startup and resulting voltage transient on SC power panel. 


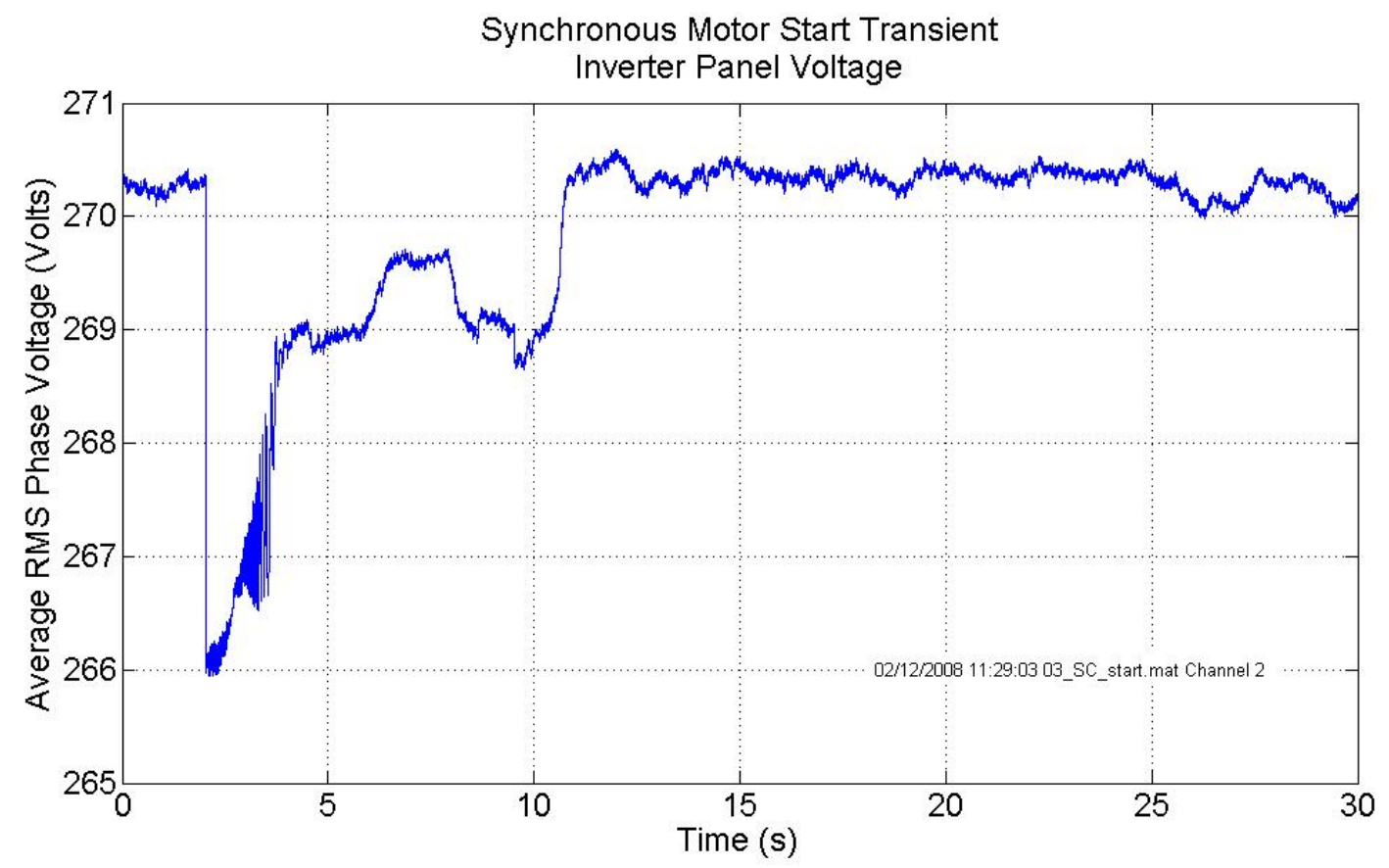

Figure 10-9. Synchronous motor (250 hp) startup transient and resulting voltage sag on inverter power panel when the SC and inverter are connected in series.

The characteristics of the three different motor startup transients, balanced, unbalanced, and motor are shown in Table 10-3.

Table 10-3. Degree of Voltage Sag and Unbalance and Duration of the Different Motor Start Transients.

\begin{tabular}{|l|c|c|c|}
\hline \multicolumn{1}{|c|}{ Voltage Sag Test Event } & Sag & Duration & \% Unbalance \\
\hline $\begin{array}{l}\text { Startup of 7.5hp Induction Motor on the Inverter } \\
\text { Panel }\end{array}$ & $\sim 2 \mathrm{~V}$ & $\sim 0.1 \mathrm{~s}$ & 5 to $10 \%$ \\
\hline $\begin{array}{l}\text { Attempted Start of 7.5hp Single-Phased Induction } \\
\text { Motor on Inverter Panel }\end{array}$ & $\sim 1 \mathrm{~V}$ & $\sim 2 \mathrm{~s}$ & $50 \%$ \\
\hline $\begin{array}{l}\text { Startup of 250hp synchronous motor on SC panel } \\
\text { when circuits connected in parallel }\end{array}$ & $\sim 3 \mathrm{~V}$ & $\sim 9 \mathrm{~s}$ & $15 \%$ \\
\hline $\begin{array}{l}\text { Startup of 250hp synchronous motor on SC panel } \\
\text { when circuits connected in series }\end{array}$ & $\sim 7 \mathrm{~V}$ & $\sim 9 \mathrm{~s}$ & $15 \%$ \\
\hline
\end{tabular}

Voltage sag due to the startup of an induction motor on the inverter panel. A $7.5 \mathrm{hp}$ induction motor was installed on the inverter's panel (PP2) to test the response of the voltage regulation control (of the inverter and SC) to voltage sags caused by the motor start. All three phases of the motor were connected so that the motor starting would produce essentially a balanced (roughly equal) voltage sags on all three phases $a, b$, and $c$. The sag reading in Table 10-3 refers to the greatest change in voltage during the motor start. A small motor was chosen for the initial test since it was uncertain how large of a motor the $150 \mathrm{~A}$ rms rated inverter could handle. The $7.5 \mathrm{hp}$ motor start produced a very short (several cycles) voltage sag of $\sim 2 \mathrm{~V}$ on the inverter panel without any regulation. (Besides this motor, the DECC Lab has 15, 25, 40, 50, 60 and $75 \mathrm{hp}$ induction motors available that will provide a range of voltage sags against which the inverter can be tested in the future. These larger motors will provide more severe balanced and unbalanced voltage sags.) 
Voltage sag due to a single-phased motor start on the inverter panel. One of the three fuses (phase b) was removed from the fuse block protecting the induction motor. Removing the fuse prevented the induction motor from starting when the motor starter was activated, resulting in longer voltage sag and in unbalanced voltage sag. The motor starter's logic tripped out the motor allowing a more sustained voltage sag event of 0.7 to $1 \mathrm{~V}$ for $\sim 2 \mathrm{~s}$.

Voltage sag due to the synchronous motor start on an adjoining panel/circuit. The $250 \mathrm{hp}$ synchronous motor on the SC panel (circuit 4) was started to create a 57-59 V sag on the panel. This translated to a $3 \mathrm{~V}$ sag on the inverter panel when the circuits were normally configured (DER in parallel) and $7 \mathrm{~V}$ when the circuits were reconfigured (DER in series). This voltage transient event was the most severe of the three events on the voltage of the inverter panel (PP3).

\subsection{Test Schedule and Data Collected}

The schedule for testing the various control capabilities at the DECC Lab during FY 2008 is given in Table 10-4. The testing started with balanced-voltage regulation control developed in FY 2007 and further refined. To apply unbalanced voltage regulation control to the inverter, lineto-line voltages and calculations of the line-to-neutral voltages from them could no longer be used. Instead, we had to convert our instrumentation to measure line-to-neutral voltages. In May, we started testing balanced, unbalanced, and current control voltage regulation with various transients starting with reference and then load changes. (See Section 10.2 for a discussion of voltage regulation with current control). In August, we started testing adaptive PI gain control, which was developed and initially checked with simulations. First, the SC was tested separately, and then the inverter separately, and the SC and inverter 'together connected in parallel and then in series. Adaptive PI gain control was tested with various transients, including reference changes, load step changes, and motor starts.

\subsection{Control Algorithms and Testing Results}

The PI control algorithms used in the testing, along with results from the testing at the DECC Lab, are described in this section.

\subsubsection{Voltage Regulation}

As shown in Figure 10-10, DER connected in parallel can inject or consume reactive power to regulate the system voltage $v_{t}$ at the point of common coupling (PCC). The DE current $i_{c}$ is only reactive current if the DER output voltage $v_{c}$ is in phase with the PCC voltage $v_{t}$. When the amplitude of $v_{c}$ is larger than the amplitude of $v_{t}$, the DER injects reactive power to the system and therefore boosts the PCC voltage; on the other hand, when the amplitude of $v_{c}$ is smaller than the amplitude of $v_{t}$, the DER consumes reactive power, causing PCC voltage to decrease. 
Table 10-4. Schedule for testing of DE control at the DECC Lab.

\begin{tabular}{|c|c|c|c|c|}
\hline Date & DE equipment & Test & Transients & \begin{tabular}{|c|} 
Note \\
\end{tabular} \\
\hline $02 / 12 / 2008$ & $\mathrm{SC}$ and inverter & $\begin{array}{l}\text { Balanced } \\
\text { voltage } \\
\text { control }\end{array}$ & Load changes & $\begin{array}{l}\text { Using line-to-line } \\
\text { voltages for rms } \\
\text { calculation }\end{array}$ \\
\hline $03 / 03 / 2008$ & Inverter & $\begin{array}{l}\text { Unbalanced \& } \\
\text { balanced } \\
\text { voltage } \\
\text { control }\end{array}$ & None & $\begin{array}{l}\text { Changed to line-to- } \\
\text { neutral voltages for } \\
\text { rms calculation }\end{array}$ \\
\hline $04 / 23 / 2008$ & Inverter & $\begin{array}{l}\text { Voltage } \\
\text { regulation } \\
\text { with current } \\
\text { control }\end{array}$ & & $\begin{array}{l}\text { Controller modified } \\
\text { to provide both } \\
\text { voltage and current } \\
\text { limits and regulation }\end{array}$ \\
\hline $05 / 01 / 2008$ & Inverter & $\begin{array}{l}\text { Voltage } \\
\text { regulation } \\
\text { with current } \\
\text { control }\end{array}$ & Load changes & \\
\hline $05 / 08 / 2008$ & $\begin{array}{l}\text { SC and inverter series } \\
\text { configuration } 1\end{array}$ & $\begin{array}{l}\text { Unbalanced \& } \\
\text { balanced } \\
\text { voltage } \\
\text { control }\end{array}$ & $\begin{array}{l}\text { Load changes } \\
\text { unbalanced motor } \\
\text { starts }\end{array}$ & \\
\hline $8 / 20 / 2008$ & $\mathrm{SC}$ & $\begin{array}{l}\text { Adaptive PI } \\
\text { gains }\end{array}$ & $\begin{array}{l}\text { Change in voltage } \\
\text { reference }\end{array}$ & \\
\hline $8 / 25 / 2008$ & $\mathrm{SC}$ and inverter & $\begin{array}{l}\text { Adaptive PI } \\
\text { gains }\end{array}$ & Load changes & \\
\hline $08 / 27 / 2008$ & $\begin{array}{l}\text { SC separately, SC and } \\
\text { inverter together }\end{array}$ & $\begin{array}{l}\text { Adaptive PI } \\
\text { gains }\end{array}$ & $\begin{array}{l}\text { Reference and load } \\
\text { changes } \\
\text { Balanced motor } \\
\text { starts }\end{array}$ & \\
\hline 09/03/2008 & $\begin{array}{l}\text { SC and inverter } \\
\text { separately }\end{array}$ & $\begin{array}{l}\text { Adaptive PI } \\
\text { gains }\end{array}$ & Reference changes & $\begin{array}{l}\text { Response } \\
\text { characteristics with } \\
\text { variation in initial } \\
\text { gains }\end{array}$ \\
\hline $09 / 08 / 2008$ & $\mathrm{SC}$ & $\begin{array}{l}\text { Adaptive PI } \\
\text { gains }\end{array}$ & Reference changes & Same as above \\
\hline
\end{tabular}

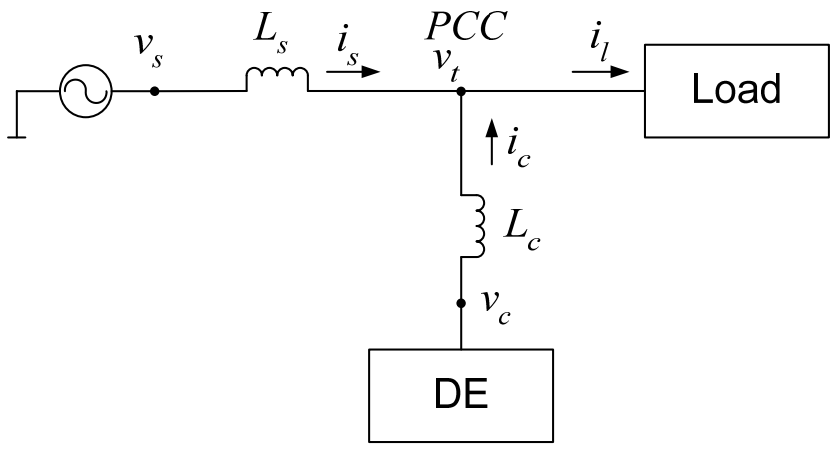

Figure 10-10. Simplified system diagram.

A closed-loop feedback controller is adopted in voltage regulation; the control diagram is shown in 
Figure 10-11. The power system (simplified as a voltage source with impedance and a load as shown in Figure 10-10) is the controlled system. The PCC voltage is the control objective, i.e., the controlled variable. In feedback control, the rms value of the PCC voltage is controlled at a certain level, specified as the voltage reference in

Figure 10-11. In each control step, the voltage reference and the actual PCC rms voltage are compared, and the difference (error) is input to the controller. A PI control algorithm is used in the controller and the demanded DE output voltage $v_{c}$ is given, which results in a new PCC voltage. This control loop repeats every stepsize $(90 \mu \mathrm{s})$, and the PCC voltage is precisely regulated.

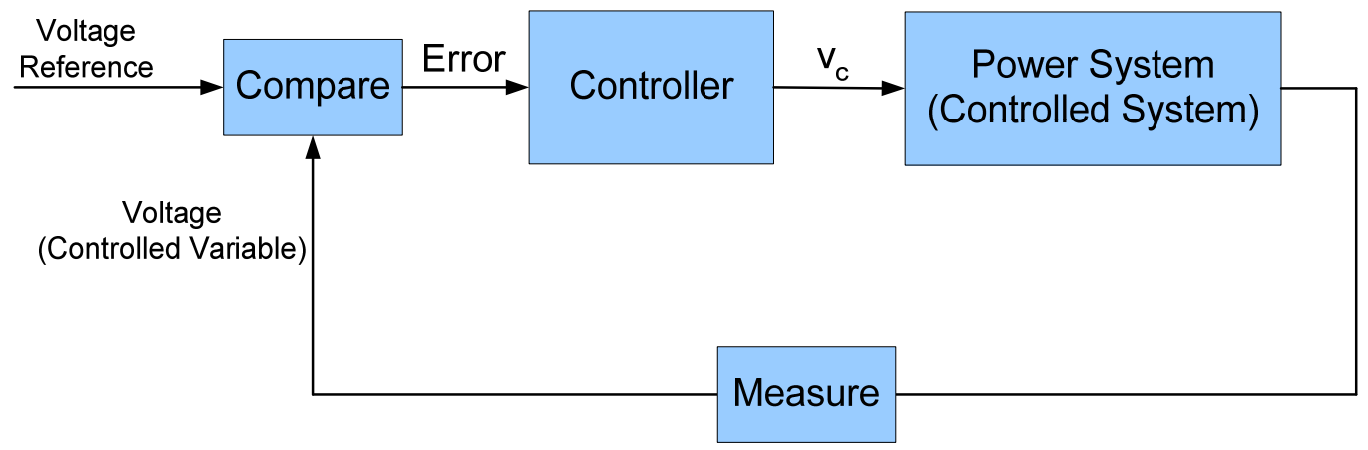

Figure 10-11. Feedback controller.

To verify the control method, a sudden load change, caused by switching the active power and reactive power of the resistive and reactive load banks on or off, was applied in the DECC Lab. Testing results are shown in Figure 10-12. The PCC rms voltage, shown in Figure 10-12a, is the voltage when there is a sudden load change in the system but no voltage regulation. Because of the load change, the PCC voltage drops $1.3 \mathrm{~V}$ (from 266.7 to $265.4 \mathrm{~V}$ ). Figure 10-12b shows the load current (in rms), which shows the sudden load increase from the load bank setting change. With voltage regulation from DE, the PCC voltage is shown in Figure 10-12c, which is maintained at the reference voltage level despite the load increase. The transient time of the voltage is around $10 \mathrm{~s}$. The reactive current injected by the DE to the system (see Figure 10-12d) was increased from 40 to $95 \mathrm{~A}$. The performance of the controller was improved, as will discussed in the following sections, by modifying the control method.

\subsubsection{Current Limit}

The inverter in the DE system is vulnerable to overcurrent, but in the voltage regulation schemes in the previous section, the DE current was not monitored or controlled. If a large amount of reactive power is required to regulate the voltage, the current flowing through the inverter may exceed its rating and fail. To solve this problem, a current limit control loop is added to the voltage regulation controller. There are two control loops - a voltage control loop, as discussed in the previous section, and a current limit loop. The control diagram is shown in Figure 10-13. The current control loop is triggered when the current is detected at a level beyond the preset current limit and the voltage still has not reached the reference level. The entire control method ensures that voltage regulation is performed to the current capacity of inverter or limit setting of the control. 


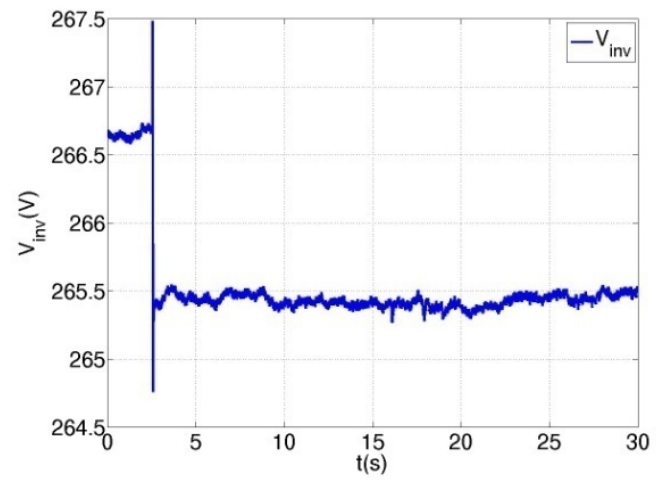

(a) PCC line-to-neutral rms voltage (V).

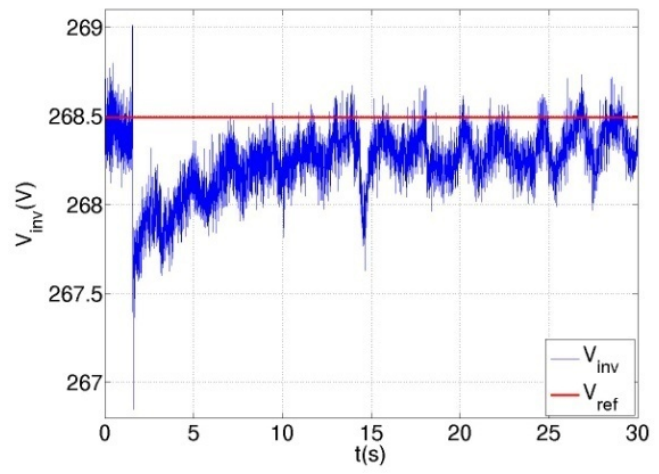

(c) PCC rms voltage with voltage regulation (V).

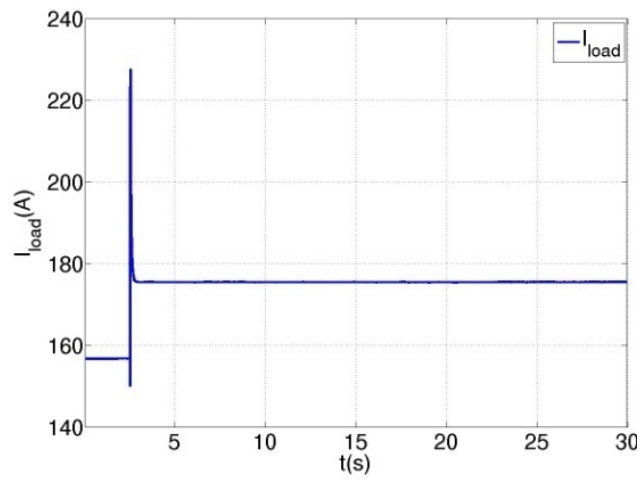

(b) Load current rms value with a sudden load change applied (A).

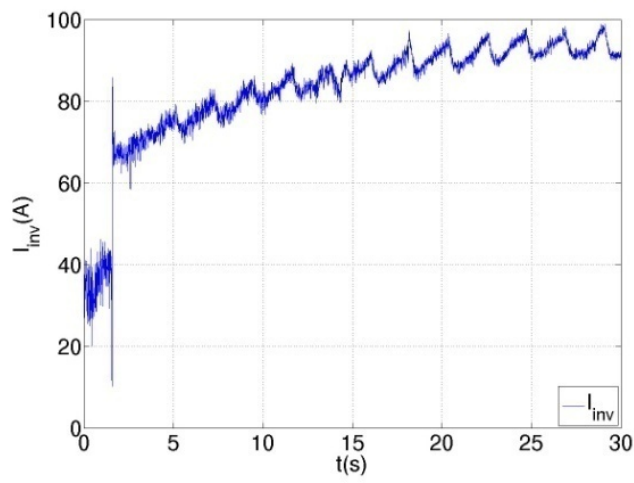

(a) The reactive current injected to the system rms value (A).

Figure 10-12. Voltage regulation with a sudden load change.

In the other case, the load bank was off at the beginning, and then turned on (at $t=2.9 \mathrm{~s}$ into the data capture). The inverter current and the PCC voltage are shown in Figure 10-14c and Figure 10-14d respectively. The current limit was set at $70 \mathrm{~A}$, the red waveform in Figure 10-14c. The voltage reference was $269.5 \mathrm{~V}$, the red waveform in Figure 10-14d. When the load was off, less reactive power was required to keep the voltage at the reference level. The inverter was operated at voltage regulation control mode, the current was below the current limit, and the voltage was controlled at the reference level. After the load bank was turned on at $t=2.9 \mathrm{~s}$, the voltage dropped and more reactive power was required to maintain the voltage at the same level. However, because of the current limit, the inverter could not provide reactive current of more than $70 \mathrm{~A}$. The current limit was triggered, the current was controlled at $70 \mathrm{~A}$, and the voltage was lower than the reference level. 


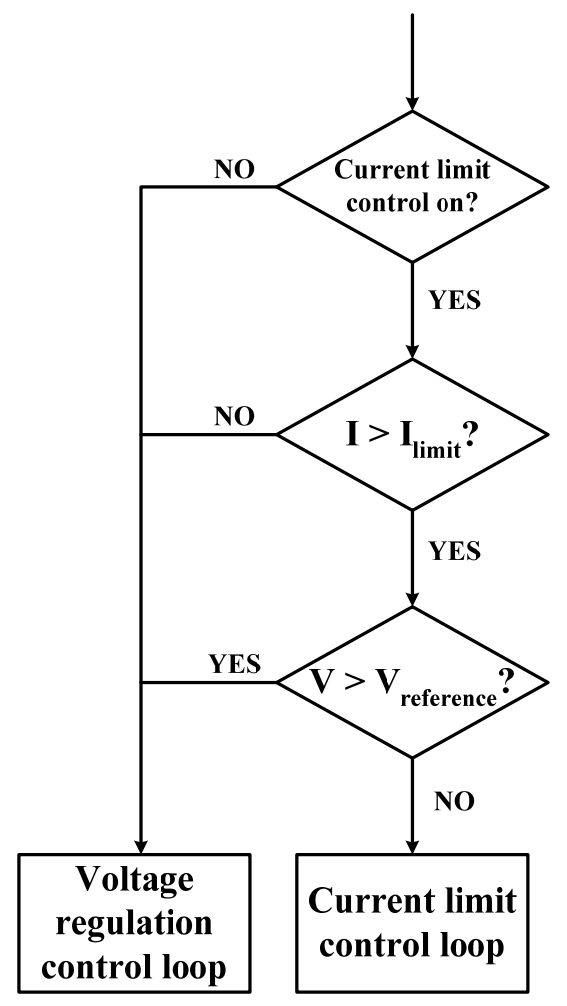

Figure 10-13. Control diagram of current limit for voltage regulation controller. ${ }^{1}$

Voltage regulation control with current limit capability allowed the inverter to provide voltage support at its maximum level, and ensured that the inverter would not be operated beyond its ratings.

\subsubsection{Voltage unbalance Compensation}

In power systems, most voltage unbalance conditions are due to magnitude inequalities while the phase-angles are equal $\left(120^{\circ}\right.$ or $\left.2 \pi / 3\right)$ or nearly equal. If the voltage unbalance is in this category and the inequalities in the magnitudes are not very large (less than $1 \%$ ), the DE with an inverter interface can compensate for the voltage unbalance by providing reactive power. By controlling the three phase magnitudes of the inverter voltage $v_{c}$ individually, the rms values of the three phase voltages of $v_{t}$ are controlled at a given reference level.

To compensate for the unbalance in each phase, the three-phase voltages are controlled separately, instead of the average value of the three-phase voltages, which is the control scheme in the previous sections. The requirements of the inverter current ratings, the inverter dc side voltage rating, and the inverter dc side capacitor rating are higher then the balanced voltage regulation case.

\footnotetext{
${ }^{1}$ The controller performs voltage regulation only to the extent that current is kept equal to or below the current limit.
} 


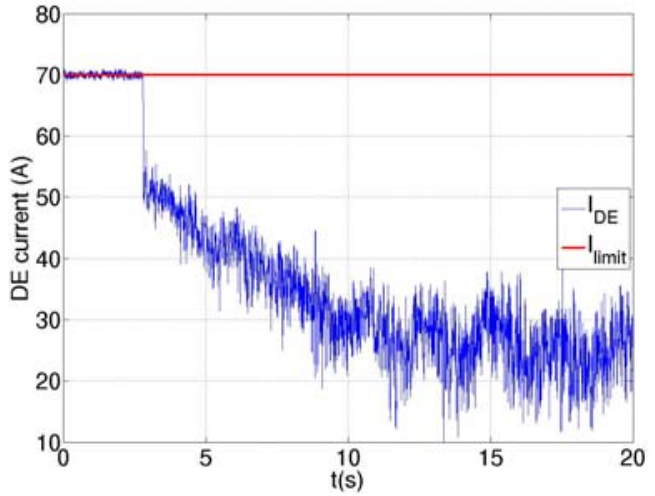

(a) Inverter current $\left(\mathrm{A}_{\mathrm{rms}}\right)$ when the load bank is switched on.

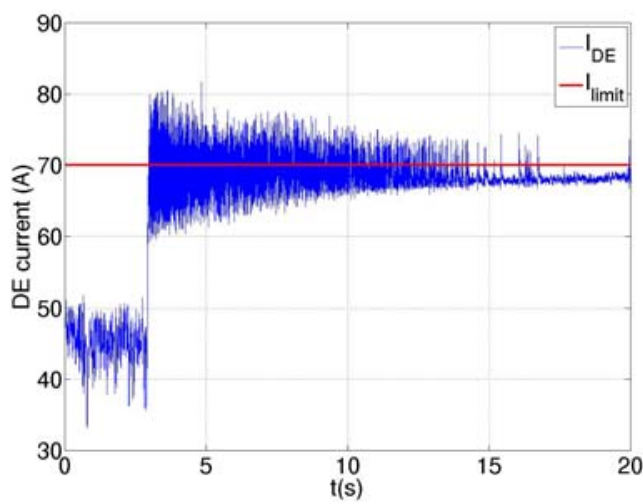

(c) ) Inverter current $\left(\mathrm{A}_{\mathrm{rms}}\right)$ when the load bank

is switched off.

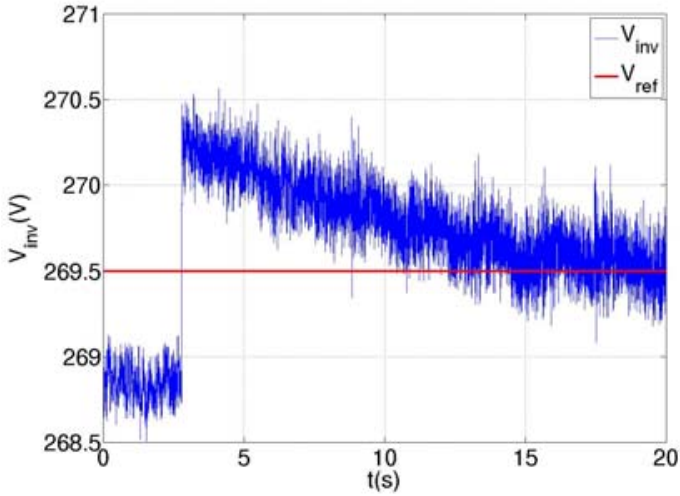

(b) PCC voltage $\left(\mathrm{V}_{\mathrm{rms}}\right)$ when the load bank is switched on.

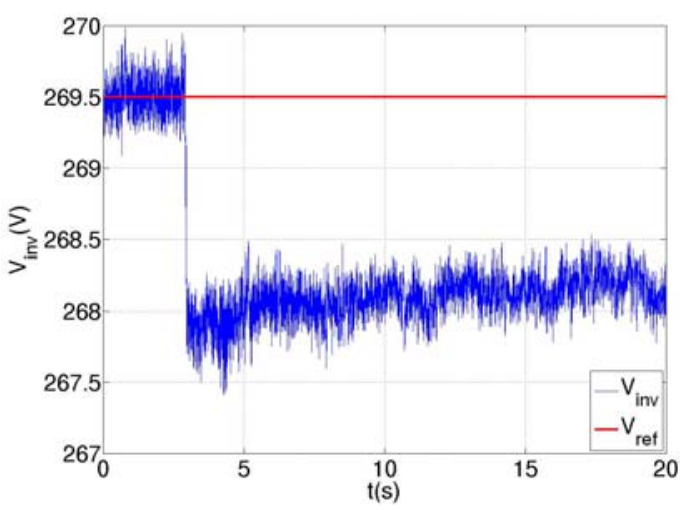

(d) PCC voltage $\left(\mathrm{V}_{\text {rms }}\right)$ when a load bank is switched off.

Figure 10-14. Testing results of current limit for voltage regulation controller.

Figure 10-15 shows the testing results for the unbalanced voltage compensation. Figure 10-15a shows the waveforms of the three-phase voltages $\left(\mathrm{V}_{\mathrm{rms}}\right)$ and the reference voltage, 267.7 V. The high-frequency switching at $12.5 \mathrm{kHz}$ does create noise on the signal to some degree; better shielding of instrumentation may eliminate this in the future. As shown in the Figure 10-15, from $\mathrm{t}=0$ to $\mathrm{t}=7.1 \mathrm{~s}$, the inverter is operated in the unbalanced voltage compensation mode and after $\mathrm{t}=7.1 \mathrm{~s}$, it is turned off. While the inverter is operating, the three-phase voltages are regulated at the reference level and nearly balanced, and while the inverter is off, the voltages are unbalanced and lower than the reference. Figure $10-15 \mathrm{~b}$ shows the three-phase inverter currents $\left(\mathrm{A}_{\mathrm{rms}}\right)$ produced by the inverter to balance and regulate the voltages. The maximum current is phase $\mathrm{c}$ current, which is $70 \mathrm{~A}$ at its maximum, and the minimum current is only $20 \mathrm{~A}$ (phase b). 


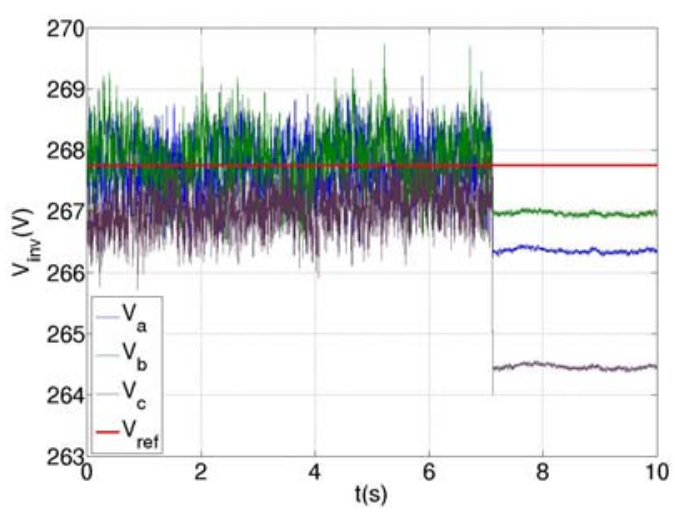

(a) PCC line-to-neutral voltages (Vrms).

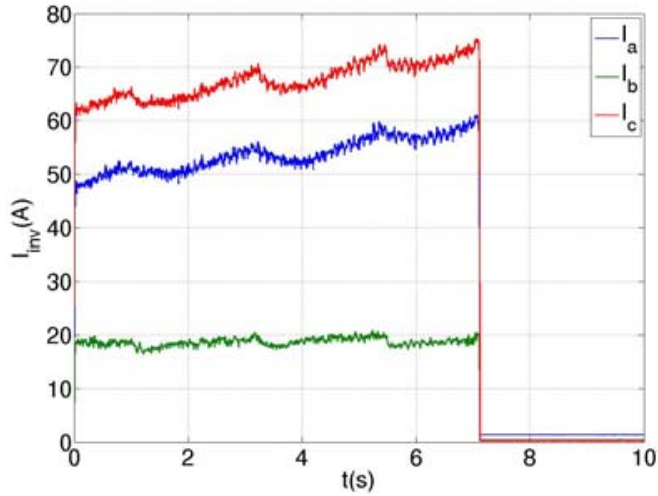

(b) Inverter phase currents (Arms).

Figure 10-15. Testing results of unbalanced voltage compensation controller.

\subsubsection{Adaptive voltage control}

In the previous sections, the two gains, the proportional gain $\left(K_{p}\right)$, and the integral gain $\left(K_{i}\right)$ of the PI controller are preset. Based on the system characteristics and the control algorithm, The $K_{p}$ and $K_{i}$ ranges can be calculated. The controller's performance is usually stable and satisfactory if the $K_{p}$ and $K_{i}$ values are within their ranges. Their values are preset and not adjusted throughout one testing sequence. However, sometimes there is lack of system information and such calculation cannot be fulfilled. "Trial and error" is usually the solution in such a situation. It is difficult to choose the appropriate values of $K_{p}$ and $K_{i}$ and the controller's performance is not optimized. To improve the controller, an adaptive voltage control method was developed based on the control method used in the previous sections. In the adaptive control method, instead of the values for $K_{p}$ and $K_{i}$ being kept constant during the testing, their values are adjusted in real-time throughout the testing.

In an ideal PI control response to a step change, the difference between the reference and the actual controlled variable is an exponential curve; by adjusting the values of $K_{p}$ and $K_{i}$, the time constant of this exponential curve is changed, i.e., the speed of the response is changed. Because $0.5 \mathrm{~s}$ (30 cycles) is considered by utility companies as an appropriate response time for the devices connected in the utilities, it is used in the adaptive control as the $5 \tau$ decay time of the ideal exponential curve. By adjusting the values of $K_{p}$ and $K_{i}$, the controller makes the error track the ideal exponential curve; therefore, the time of response of the voltage control is regulated at $0.5 \mathrm{~s}$.

A sudden load change of $20 \mathrm{~kW}$ (80 to $100 \mathrm{~kW}$ ) and $37.5 \mathrm{kVar}$ (37.5 to $75 \mathrm{kVar}$ ) was applied to the DE inverter system at its power panel. The load change resulted in a voltage drop if there was no voltage regulation. The inverter voltage (average rms of all three phases) waveform is shown in Figure 10-16a without voltage regulation. The voltage dropped $1.5 \mathrm{~V}$ because of the load increase. Figure 10-16b is the load current (average rms), which increased from 108 to 153.5 Figure 10-16c shows the inverter voltage using the voltage regulation method (nonadaptive) presented in Section 10.6.1. The same load change was applied during the voltage regulation test and the response time was $2.42 \mathrm{~s}$. Figure 10-16d shows the inverter current (rms), which increased from $\sim 40$ to 90 A to maintain the voltage at the reference level despite the load change. 


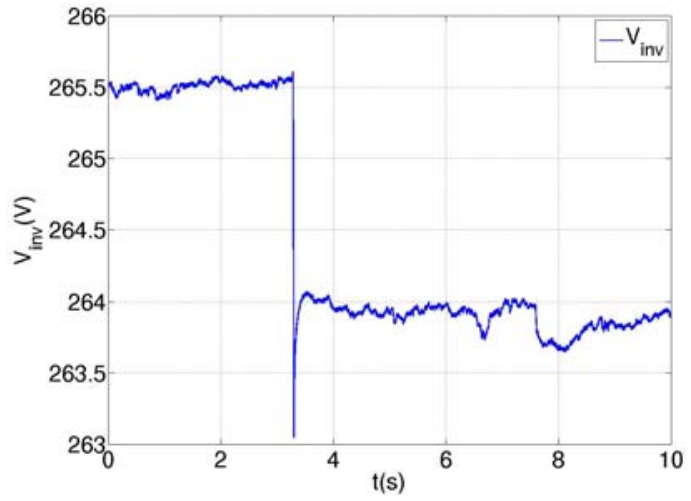

(a) PCC voltage $\left(\mathrm{V}_{\mathrm{rms}}\right)$ without regulation.

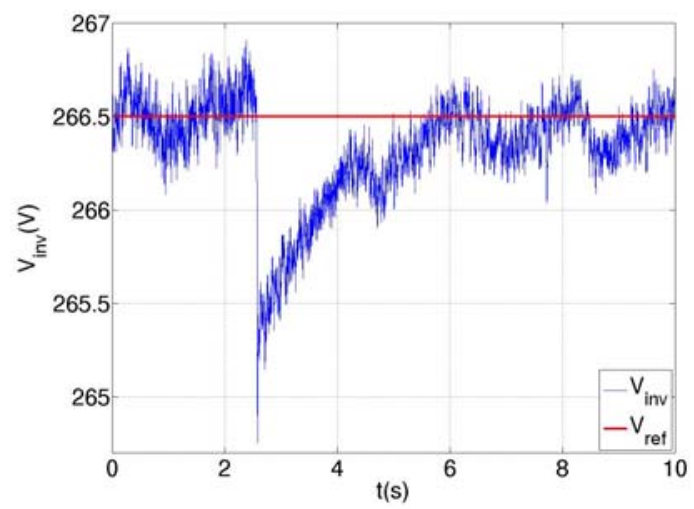

(c) ) PCC voltage $\left(\mathrm{V}_{\mathrm{rms}}\right)$ with non-adaptive voltage regulation.

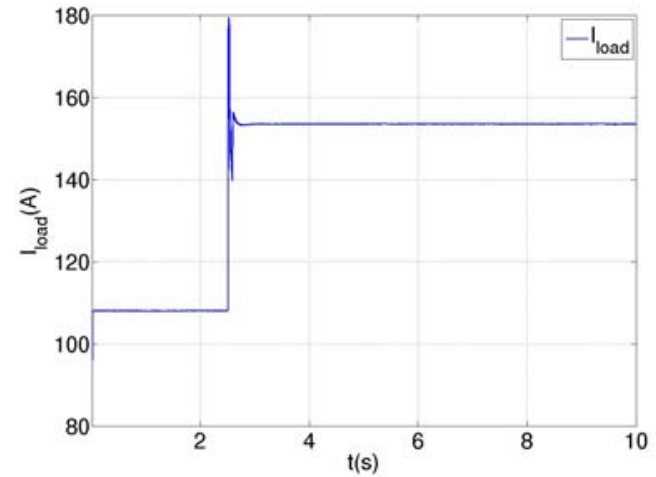

(b) Load current $\left(\mathrm{A}_{\mathrm{rms}}\right)$ during load change.

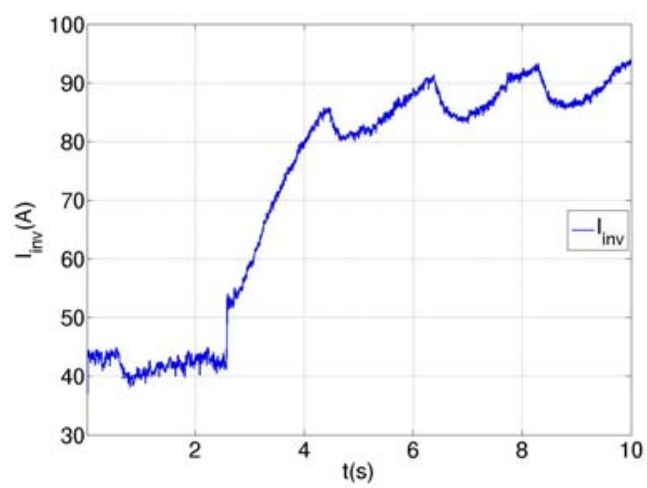

(e) Inverter current output $\left(\mathrm{A}_{\mathrm{rms}}\right)$ during load change.

Figure 10-16. Testing results of voltage regulation for load change.

By applying the same sudden load change as shown in Figure 10-16, the adaptive voltage regulation control was implemented. The test results are shown in Figure 10-17. Figure 10-17a shows the inverter voltage waveform with adaptive control. The same load was applied as above and the response time is $0.44 \mathrm{~s}$. Figure $10-17 \mathrm{~b}$ shows the ideal exponential curve (red waveform) and the actual voltage error (blue waveform). The actual error decay time was $0.44 \mathrm{~s}$, which matches the $5 \tau$ decay time of the ideal curve $(0.5 \mathrm{~s})$. Figure $10-17 \mathrm{c}$ and Figure $10-17 \mathrm{~d}$ show the increase in the inverter current and the inverter reactive power output for the load change.

The adaptive voltage control method was also applied to the SC. The results are given in the Table 10-5.To verify the validation of the control method, both the inverter and the SC were tested with different response times; results of that testing are listed in Table 10-5. The first two columns show the setting and actual response times for the inverter, respectively. The third and fourth columns show the settings and actual response times for the SC, respectively. The testing results verify that compared to the voltage control method described in Section 10.6.1, the adaptive voltage control method has a faster transient response time. As a result, the response time was controllable and the local voltage stability was ensured because the system was operated at the selected response speed. 


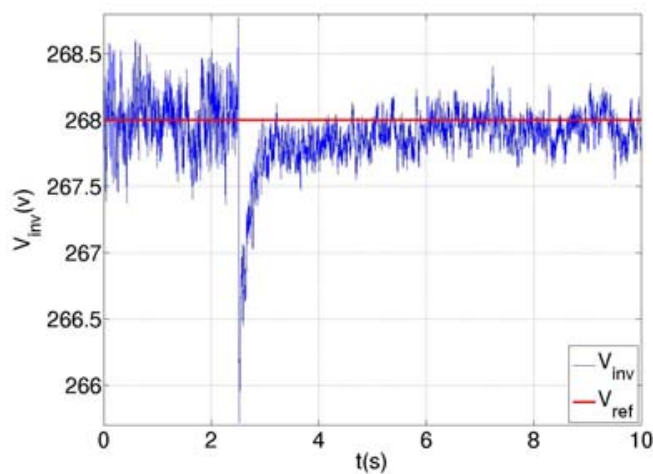

(a) PCC voltage $\left(\mathrm{V}_{\text {rms }}\right)$ with adaptive voltage regulation.

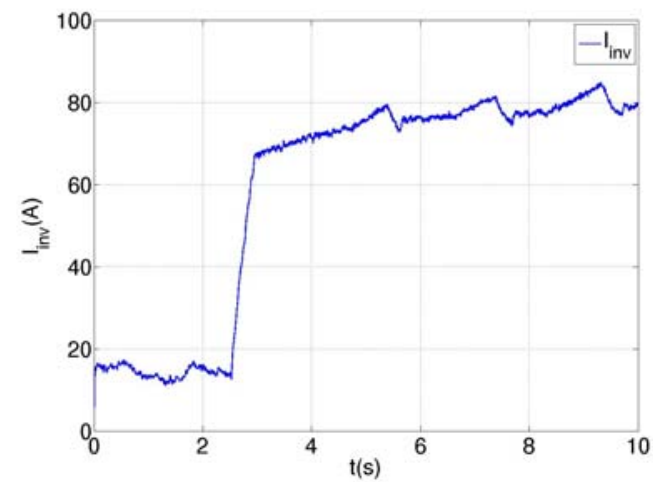

(b) Inverter current $\left(\mathrm{A}_{\mathrm{rms}}\right)$ before and after load change.

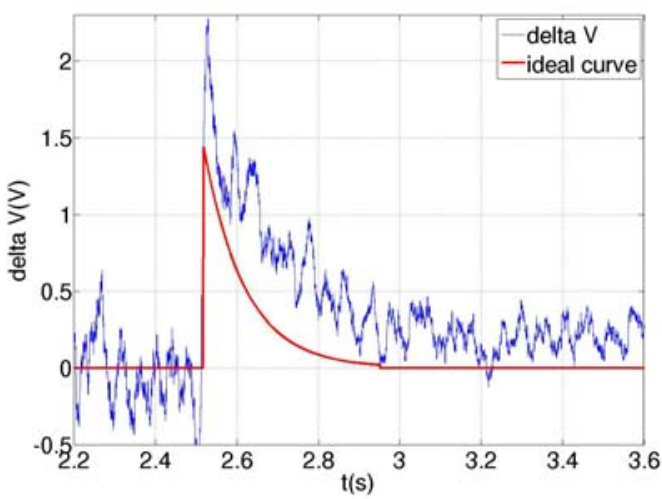

(b) Inverter delta voltage $(\Delta \mathrm{V})$ and ideal exponential response curve.

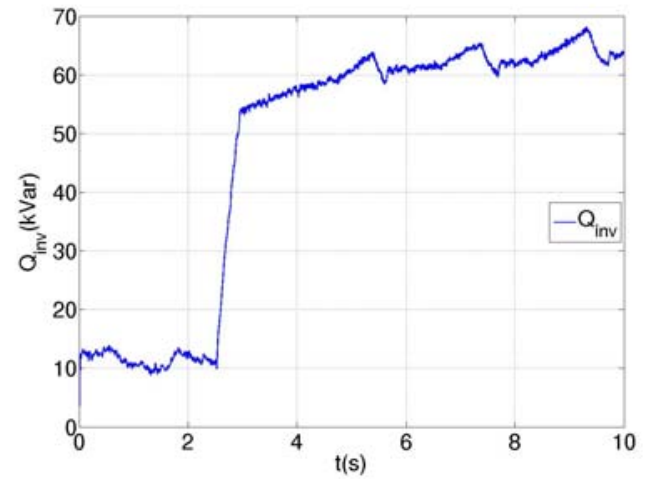

(d) Inverter reactive power (kVAR) before and after load change.

Figure 10-17 Testing results of adaptive voltage regulation for load change.

Table 10-5. Response times for adaptive voltage regulation.

\begin{tabular}{|c|c|c|c|}
\hline \multicolumn{2}{|c|}{ Inverter } & \multicolumn{2}{c|}{ Synchronous condenser } \\
\hline Setting (s) & Actual (s) & Setting (s) & Actual (s) \\
\hline 0.1 & 0.176 & 0.5 & 0.663 \\
\hline 0.2 & 0.332 & 1.0 & 1.006 \\
\hline 0.5 & 0.64 & 2.0 & 2.417 \\
\hline 1.0 & 0.927 & 5.0 & 5.214 \\
\hline 2.0 & 2.408 & 10.0 & 7.151 \\
\hline 5.0 & 2.82 & 15.0 & 9.158 \\
\hline 10.0 & 4.212 & 25.0 & 12.007 \\
\hline
\end{tabular}

\subsection{Overall Findings}

ORNL has developed an autonomous local control scheme for inverter-based DE that dynamically regulates local voltage. The scheme is near-real time in that it calculates the rms value of the local voltage in every sample and uses it as input to aPI controller for the inverter 
PWM. The inverter operates at $12.5 \mathrm{kHz}$ switching frequency while the control sampling rate is every $90 \mu \mathrm{s}$. Thus the PI controller is updated every $90 \mu \mathrm{s}$. The feedback controller compares the actual voltage based on the calculated rms with a reference, which can be based on a utilityspecified voltage schedule, to determine the voltage error. The error, along with the PI gains of the controller, determines the new output for PWM values and thus the new ac voltage waveform generated by the controller.

The controller which was previously only for voltage control, now also provides current control. While the inverter is in voltage control mode, the current control mode activates when voltage control calls for the inverter to provide more current than it is limited to or capable of providing to meet the voltage reference. If the controller is in current control mode and the current control calls for the inverter to provide a higher voltage than the inverter is limited to or capable of providing, then the controller reverts to voltage control mode. The current control mode ensures that the inverter does not operate beyond its rated (thermal or electric limitation) capability and thus ensures continuous support of system voltage for various transient conditions unless a nearby fault necessitates that the inverter trip out.

The advantage of the rotating-based DE or SC in the DECC-specific testing situation is its robustness, although it is slower than and not as versatile as power electronics-based or inverterbased DE. Another short-coming of the SC is its inability to independently regulate each phase voltage separately as can be done with the inverter.

The programmable PWM inverter tested can operate at up to $20 \mathrm{kHz}$ switching frequency, although the controls have been tested with it operating in the 10 to $12.5 \mathrm{kHz}$ range. The sampling rate of the control systems is on the order of $90 \mu \mathrm{s}$, and the rms calculation used for the voltage control is updated at every sample.

This project successfully implemented balanced voltage regulation control, which maintains the voltage within $\pm 0.1 \mathrm{~V}$ of the reference voltage. Unbalanced voltage regulation was also successfully implemented, but this control scheme requires much more current output capability from the small research inverter in the DECC Lab for voltage unbalance than is normally on the ORNL distribution circuits 2 and 4. The extra calculations (instead of one rms calculation we now have three) did not impact the unbalanced control implementation.

With regard to testing of adaptive gain control, we were able to implement the controller with adaptive gain on both the SC and inverter. The SC was tested with both an increase and a decrease in the voltage references to check dynamic response of the control. Adaptive gain continuously calculates what new gain is needed to follow the exponential time response curve of the unit based on voltage error and time, but it changes the gain only when a significant difference between the actual and reference voltage values exists, e.g., $\geq \pm 1 \mathrm{~V}$. Otherwise, the gain is kept fixed since, the transient is perceived to be mild enough to be handled by the existing PI gain settings. An area of future research, is analyzing the sensitivity of adaptive gain control to changes in the voltage detection sensitivity, i.e., instead of a $\pm 1 \mathrm{~V}$, use a $\pm 0.5 \mathrm{~V}$. Different time constants were tried to determine which ones gave the best fit. If too low a time constant was used, it pushed the gain too high and saturated at the limits set to prevent overshoot. If too high a time constant was used, the gain stayed very low with a slow response to the voltage 
change. Adaptive gain control adapted the gains for whatever voltage change occurred to ensure a response to a fixed time such as $0.5 \mathrm{~s}$. This rapid response time was selected as it will prevent $\mathrm{DE}$ interaction with conventional utility system equipment for regulating voltage. The DE will have responded to the voltage change and reset its reactive power (VAR) output well before the conventional utility equipment begins any level of control. In other words, fast rapid control is transparent to the utility system control. The inverter could be operated with gains, especially Ki, much higher than those seen in our earlier testing.

Current control was successfully implemented with balanced voltage control. The logic that controls the switchover from voltage to current was fast enough for most events.

Adaptive gain control accelerated the response of the SC and inverter for the various voltage transients. The input variables for adaptive gain control included the initial gains, minimum voltage error before it is engaged, and the time constant. Neither the SC nor the inverter wass fast enough to respond to the balanced motor start, which only lasts $0.1 \mathrm{~s}$. However, both can be fast enough to respond (reach a new operating point) within $0.5 \mathrm{~s}$.

\subsection{Next steps}

We will continue to adjust the voltage regulation controls to achieve better response. We will test a greater variety of load changes to characterize the capability of the adaptive controls to respond to voltage change, and to evaluate the accuracy of our simulation results. The variables involved in the controls include setting the desired time window of response (e.g., 0.5s) and setting the initial and maximum gains for the PI controls. In addition, the desired trigger points (voltage deviation from the reference) for engaging and disengaging adaptive gain should be further evaluated.

Another area of study involves setting the optimal initial gains for the feedback controller. This research has developed a method for the controller gains to be adaptive during a transient, but it may be useful to add a self-learning function so that the controller adjusts its initial gains (which stay fixed for steady-state regulation) to optimize its response for continual regulation during circuit reconfiguration or major circuit load changes. The initial gains, once optimized, may not need to be changed again unless the circuit is reconfigured or there are circuit or load changes that move the controller from its optimal performance. It may be that the fixed gains will need to be checked on a periodic basis by having the inverter tweak its reference setting (to force a change) to determine whether the response is still optimized and make adjustments as necessary.

\section{SIMULATIONS OF SYSTEM DYNAMIC LOCAL VOLTAGE REGULATION USING SYSTEM LOAD MODEL}

This section describes a simulation of system dynamic local voltage regulation on the distribution system using a composite load model. Among the different loads present in the practical distribution systems, A/C loads are of major interest as they have the greatest impact on the system voltage recovery after fault. The reason behind stalling of motors and the behavior of stalled A/C motor loads was described in Section 4. 
This section encompasses simulation results from modeling normal and stalled $\mathrm{A} / \mathrm{C}$ loads along with other percentages of constant impedance and constant power loads. Several cases were considered for the study. Case A and B were considered to present the simulation results for the behavior of $\mathrm{A} / \mathrm{C}$ motors before and after a fault. These two cases did not consider the installation of DER into the system. The modeling methodology adopted in Case A and B was again used to model the loads in Case C, where DE was simulated to help the system with voltage recovery.

The modeling of residential loads was done based on different load compositions: e.g., A/C compressor motors, constant impedance loads, constant power loads, and normal three-phase motor loads. The distribution of load among different components was simulated to mimic the practical distribution and makeup of loads. For the Case A simulation, the load composition was based on reference [15] and considering certain assumptions that are mentioned later. Case A considered the aggregate model of a larger subtransmission system so that all the generation and loads were represented by a single substation and loads respectively.

Once the results were obtained from Case A using the Matlab SimPowerSystem platform, another small model was developed with the distribution feeder made up of a total motor load of $50 \mathrm{kVA}$ and constant impedance loads with different power factors. The simulation results for this case are presented in Case B. Finally, a model was developed with a system similar to the one used in the adaptive voltage regulation method. The results for this case are presented in Case C. This model also considered the introduction of DE into the system and showed the effect of $\mathrm{DE}$ in preventing the stalling of motors.

The basic underlying assumptions and the methodology for developing of induction motor models to reveal the actions of motor stalling during the system disturbance, such as a threephase to ground fault, are described in Section 11.2.1. The assumptions are mainly based on the behavior of induction motors in the case of faults found from the testing of $\mathrm{A} / \mathrm{C}$ units.

\subsection{Assumptions and Methodology}

The assumptions and methodology of the cases are described in this section. The methodology involved the use of Matlab and SimPowerSystem library along with the development of logic to simulate an $\mathrm{A} / \mathrm{C}$ stall event.

\subsubsection{Assumptions:}

1. According to the test results on $\mathrm{A} / \mathrm{C}$ motors, these compressor motors can stall in as little time as 3 cycles. This time is considered as a benchmark for the transition of induction motors to stalled mode.

2. The voltage magnitude criterion for induction motors to enter a stalled condition is $0.6 \mathrm{pu}$. If the voltage at the induction motor terminal is below $0.6 \mathrm{pu}$ for 3 cycles or more, the motors stall. 
3. Once the $\mathrm{A} / \mathrm{C}$ units are stalled, they remain stalled until they are eventually taken out of the system provided that there is no additional reactive power (VAR) support in the system.

\subsubsection{Methodology:}

While the loads were modeled in the MATLAB platform, the Asynchronous Motor model of the SimPowerSystem library was considered to model the A/C units. In normal mode, the actual induction motor model is used. Following the fault, if the voltage at the motor terminal falls below 0.6 pu for 3 cycles or more, the induction motor model switches to the constant impedance load model and stalled complex power is increased by 6 times that in the normal mode of operation. The power factor considered for the normal mode of operation is 0.88 and the stalled mode is 0.58 .

The flowchart of overall methodology of the induction motor loads modeling is presented in Figure 11-1.

$\begin{aligned} & \text { Induction motor } \\ & \text { (Normal Mode) }\end{aligned}$
Asynchronous motor
model of
Simpowersystems with
pf 0.88

Induction motor

Asynchronous motor model of pf 0.88
Fault occurs and if $\mathrm{V}<0.6 \mathrm{pu}$ for 3 cycles or more

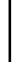

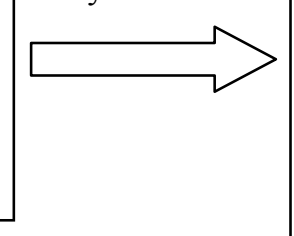

Induction motor (stalled mode)

1. Constant Impedance load model

2. Compute Sstall $=$ 6xSnormal 3. Computer Pstall and Qstall with pf of 0.58

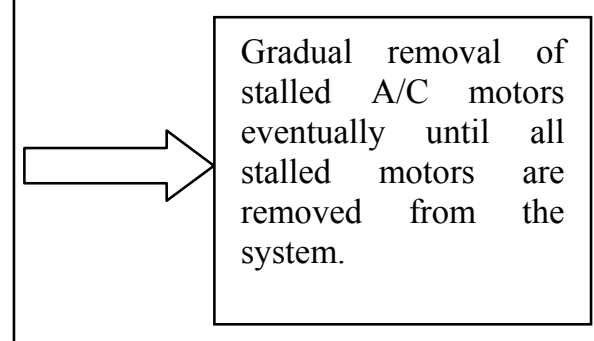

Figure 11-1. Overall methodology of load modeling.

\subsection{Simulation Results}

\subsubsection{Case A: Verification of motor load characteristic during a subtransmission fault using the aggregate load model}

The system configuration of a transmission and sub-transmission model is shown in Figure 11-2. This is a hypothetical utility system based on reasonable assumptions. The complete load composition for this case is shown in Table 11-1. The test data were extracted from reference [15]. 


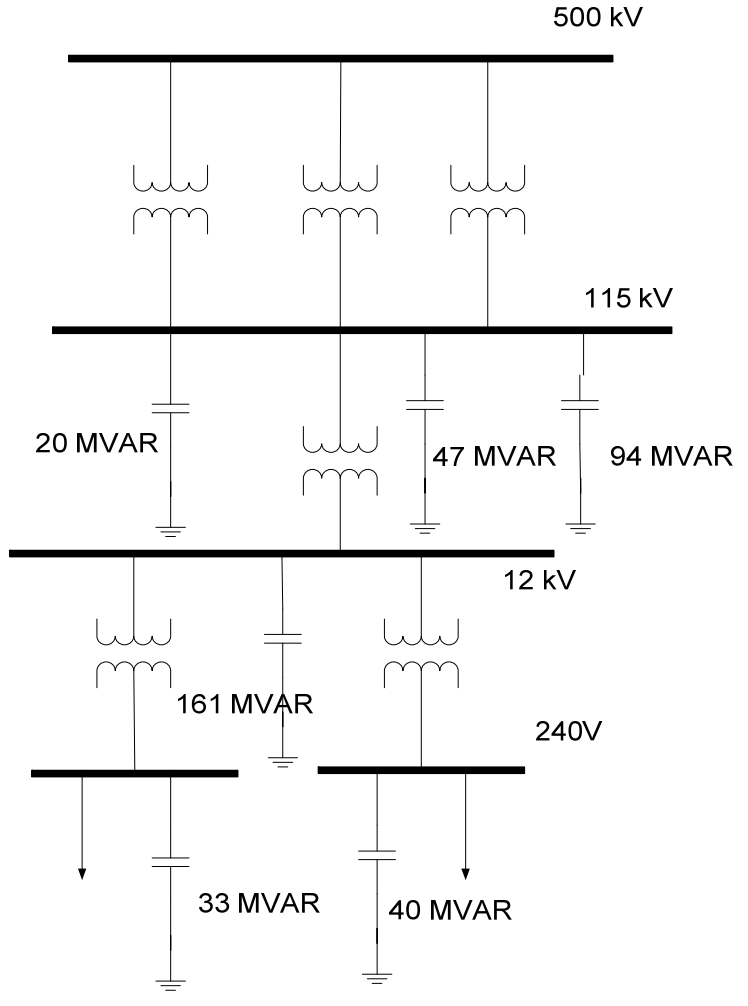

Figure 11-2. System configuration for Case A.

Table 11-1. Load composition for Case A.

\begin{tabular}{|l|c|c|c|c|}
\hline $\begin{array}{c}\text { Load } \\
\text { Parameters }\end{array}$ & $\begin{array}{c}\text { Constant power } \\
\mathbf{( 3 3 . 6 \% )}\end{array}$ & $\begin{array}{c}\text { Constant impedance } \\
\mathbf{( 2 1 . 9 \% )}\end{array}$ & $\begin{array}{c}\text { 3-ph motor } \\
\mathbf{( 1 5 . 6 \% )}\end{array}$ & $\begin{array}{c}\text { Residential A/C } \\
\mathbf{( 2 8 . 8 \% )}\end{array}$ \\
\hline MW & 320 & 209 & 133 & 246 \\
\hline MVAR & 0 & 0 & 66 & 121 \\
\hline PF & 1.0 & 1.0 & 0.9 & 0.9 \\
\hline
\end{tabular}

During the simulation, the following assumptions were made based on Reference [15]:

1. Three-phase-to-ground fault is applied at $0.5 \mathrm{~s}$ on the $500 \mathrm{kV}$ bus.

2. Fault is cleared in 4 cycles.

3. One of the $500 \mathrm{kV} / 115 \mathrm{kV}$ transformer is isolated once the fault is cleared.

4. The load models considered are the aggregate load model for all kinds of loads, e.g., A/C loads, three-phase motor loads, and constant impedance loads.

5. All induction motors stall if the voltage is below $0.6 \mathrm{pu}$ for 3 cycles or more.

6. Stalled three phase motors are taken out of the system gradually over $30 \mathrm{~s}$ after the fault.

Figure 11-3 shows the voltage profile at the $115 \mathrm{kV}$ bus for the load composition of Figure 11-2 without modeling of the stalled motor loads. It clear shows that the voltage recovers quite quickly after the fault is cleared, and the effect of stalling of $\mathrm{A} / \mathrm{C}$ motors does not appear in the response. 


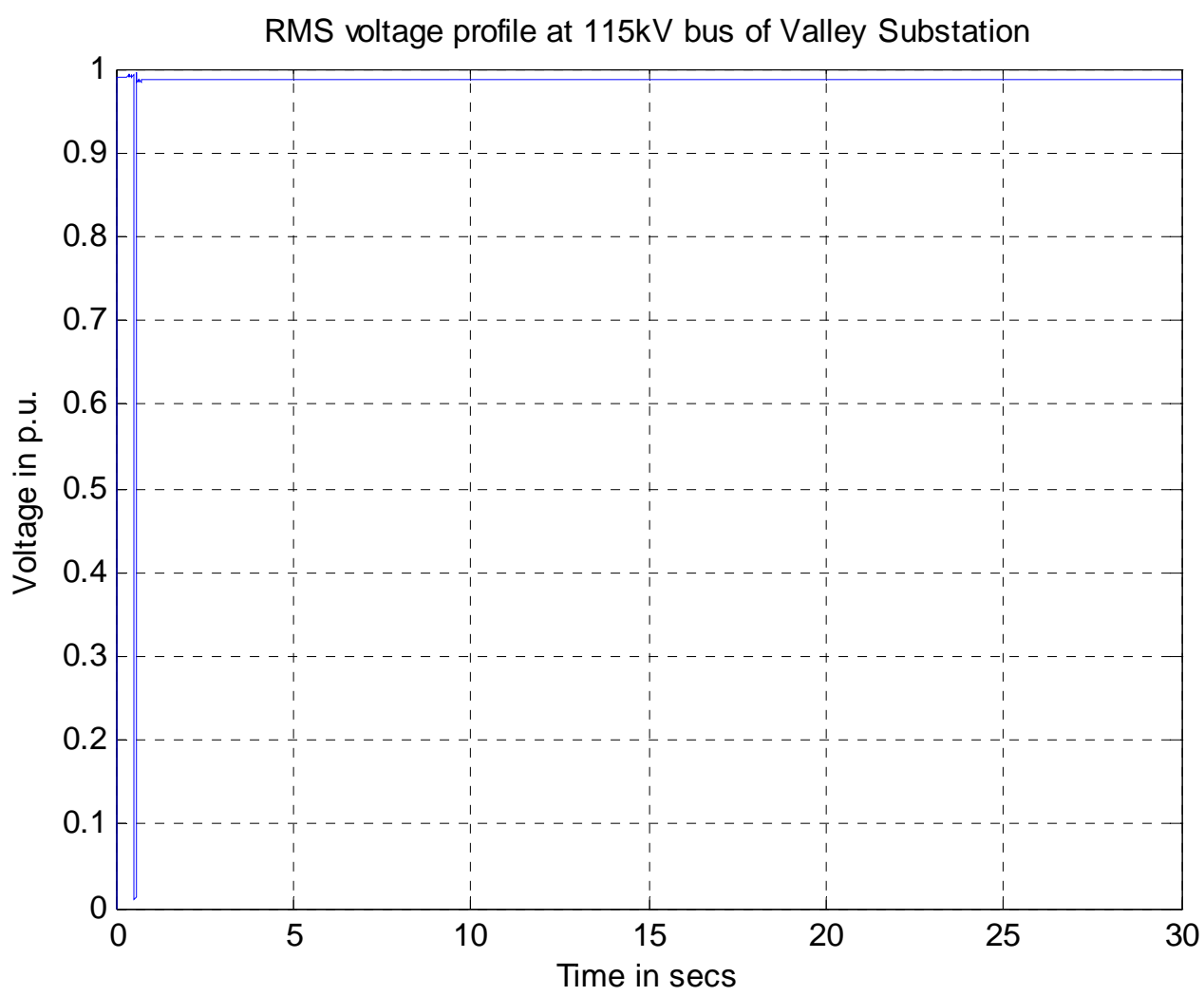

Figure 11-3. Voltage profile of bus $115 \mathrm{kV}$ without modeling of stalled case.

Figure 11-4 shows the voltage profile at the $115 \mathrm{kV}$ bus with the load model of Figure 11-2 modeling the stalled induction motors based on the methodology described in section 11.1.2. The voltage profile clearly shows the effect of induction motor stalling. Once the fault is cleared, the voltage recovers to $0.6 \mathrm{pu}$, but is not able to recover to the original value as quickly as in the first case. All the motors stall 3 cycles after the fault and remain stalled because voltage cannot recover quickly to its pre-fault level. The tripping of the residential A/C motors starts after $2.5 \mathrm{~s}$ and continues until all motors are tripped in $30 \mathrm{~s}$. As the stalled motor loads are taken out of the system, the voltage profile of the $115 \mathrm{kV}$ bus gradually restores to its original value. The plot of Figure 11-4 is very close to the operational data given in reference [15].

\subsubsection{Case B: System with 240 V distribution feeder}

This is a hypothetical test system with ten motors connected at $240 \mathrm{~V}$ along a distribution circuit to represent a worst-case commercial system. The buses, motor starters, etc. are not shown in the system diagram. The system has ten induction motors with a capacity of $5 \mathrm{kVA}$ each. The system also includes constant impedance loads of power factor of 0.5 and 0.9 in a feeder at single-phase $240 \mathrm{~V}$ level is considered for this case. Constant impedance loads with power factor of 0.5 are included to represent compact (standard) fluorescent lamp loads. The system configuration used for this case is shown in Figure 11-5. A methodology similar to the one described in Section 11.1.2 is adopted to model the stalled motors. The motor inertia is set to a value of $0.02 \mathrm{~s}$ to represent high-efficiency motors. In this case, the fault is applied the $12 \mathrm{kV}$ 
level in $0.5 \mathrm{~s}$ and cleared after 4 cycles. The load composition for this case is presented in Table $11-2$.

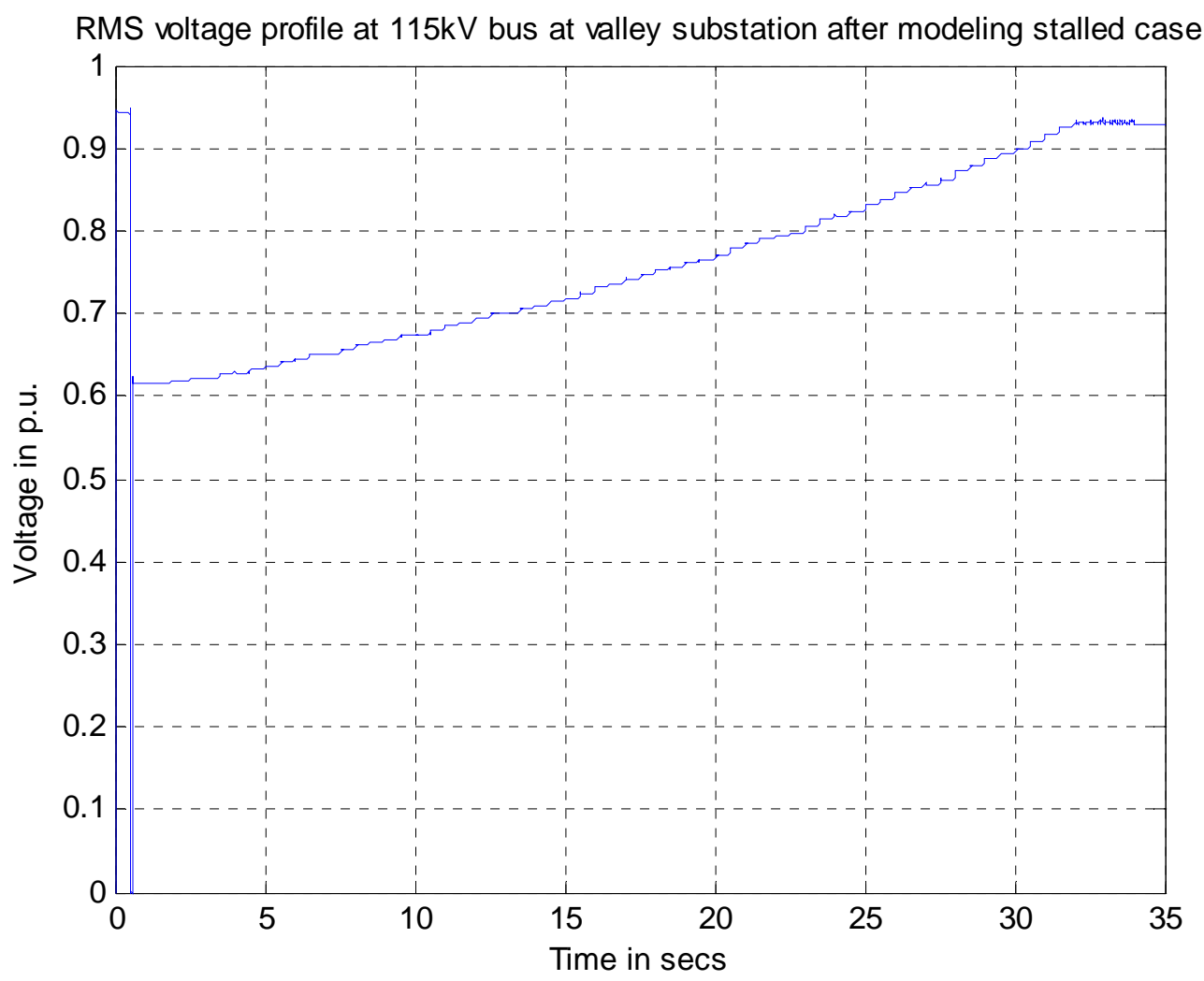

Figure 11-4. Voltage profile at the $115 \mathrm{kV}$ bus after using composite load model and modeling of stalled case.

The voltage profile of the substation at the $12 \mathrm{kV}$ level is shown in Figure 11-6. The capacitors in the system are adjusted so as to maintain the substation voltage at exactly $1.0 \mathrm{pu}$. The voltage profile for load bus 1, which is the nearest bus of the feeder, and the voltage profile of load bus 10, which is the farthest bus of the feeder, are shown in Figure 11-7 and Figure 11-8, respectively. The simulation is carried out for $12 \mathrm{~s}$. It can be observed from Figure 11-7 that once the fault is cleared, the voltage at load bus 1 recovers only to around $0.45 \mathrm{pu}$ and takes $10 \mathrm{~s}$ to recover to the value before fault. The effect is due to the stalling of $\mathrm{A} / \mathrm{C}$ compressor motors when the fault occurs. Once the fault is cleared, the voltage gradually starts to recover following the subsequent tripping out of the stalled motor loads by their thermal relays. The original value of voltage is reached only after all the $\mathrm{A} / \mathrm{C}$ motor loads are taken out of the system. Figure 11-8 presents a similar delayed voltage recovery following a fault at bus 10 , but since this bus is the farthest one in the radial feeder, the voltage after the fault is only around $0.1 \mathrm{pu}$. 


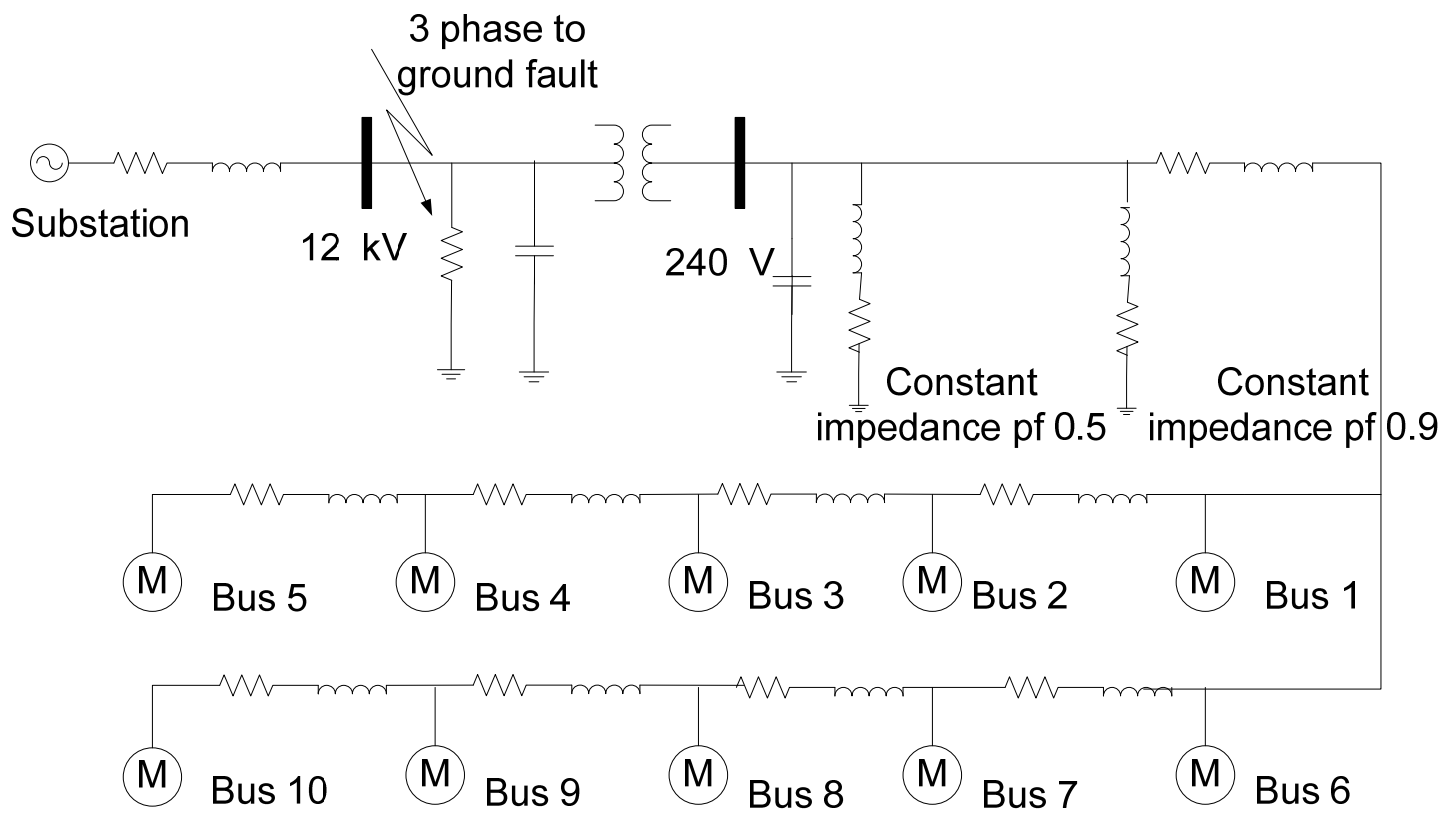

Figure 11-5. System configuration with 50kVA motor loads.

Table 11-2. Load composition for Case B.

\begin{tabular}{|l|c|c|c|}
\hline $\begin{array}{c}\text { Load } \\
\text { parameters }\end{array}$ & $\begin{array}{c}\text { Constant } \\
\text { Impedance } \\
(\mathbf{3 0 \% )}\end{array}$ & $\begin{array}{c}\text { Constant } \\
\text { Impedance } \\
\mathbf{( 2 0 \% )}\end{array}$ & $\begin{array}{c}\text { Residential } \\
\mathbf{A} / \mathbf{C} \\
\mathbf{( 5 0 \% )}\end{array}$ \\
\hline $\mathrm{kW}$ & 15 & 18 & 44 \\
\hline $\mathrm{kVAR}$ & 25.98 & 8.717 & 23.748 \\
\hline $\mathrm{PF}$ & 0.5 & 0.9 & 0.88 \\
\hline
\end{tabular}




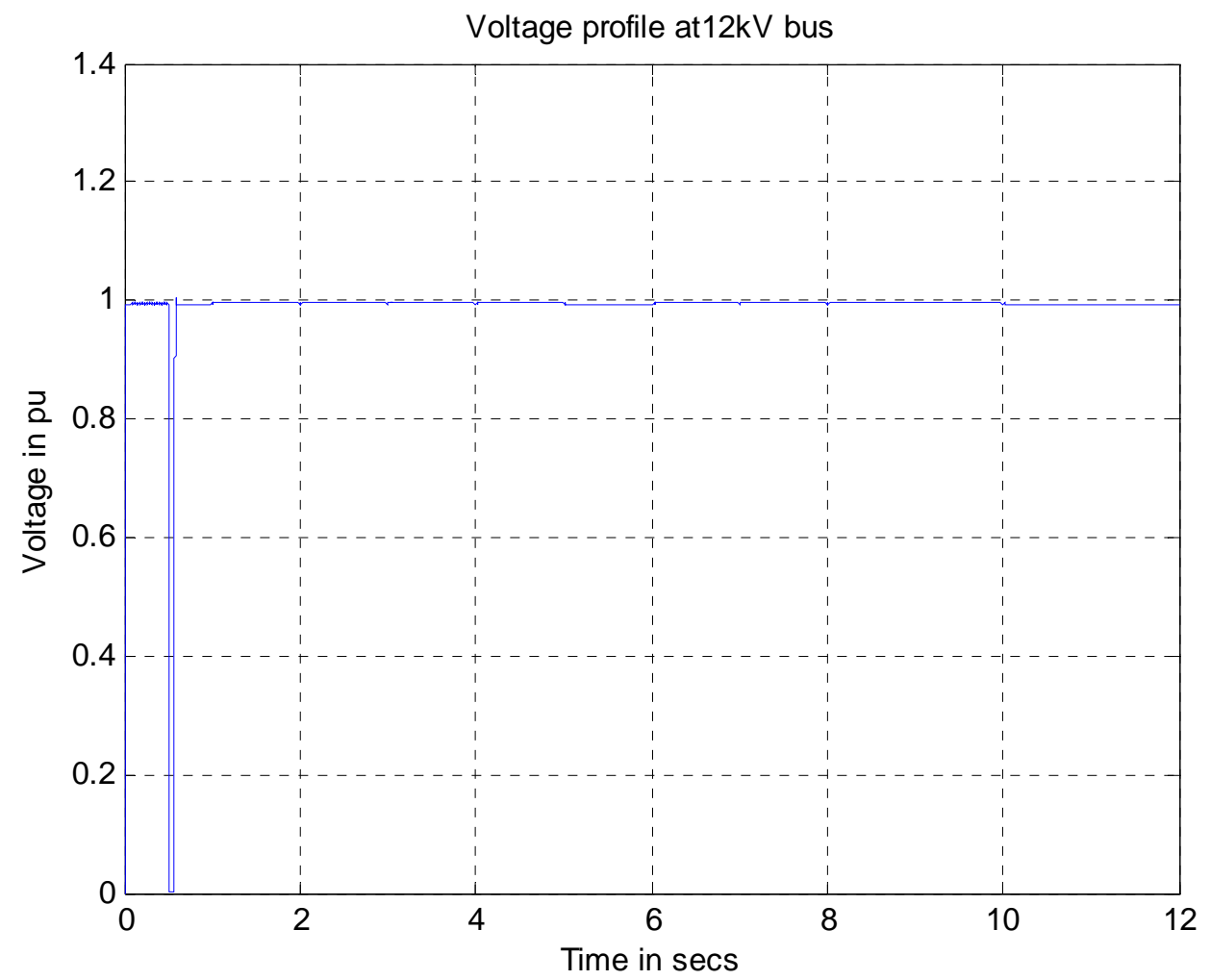

Figure 11-6. Voltage profile of substation at $12 \mathrm{kV}$ level.

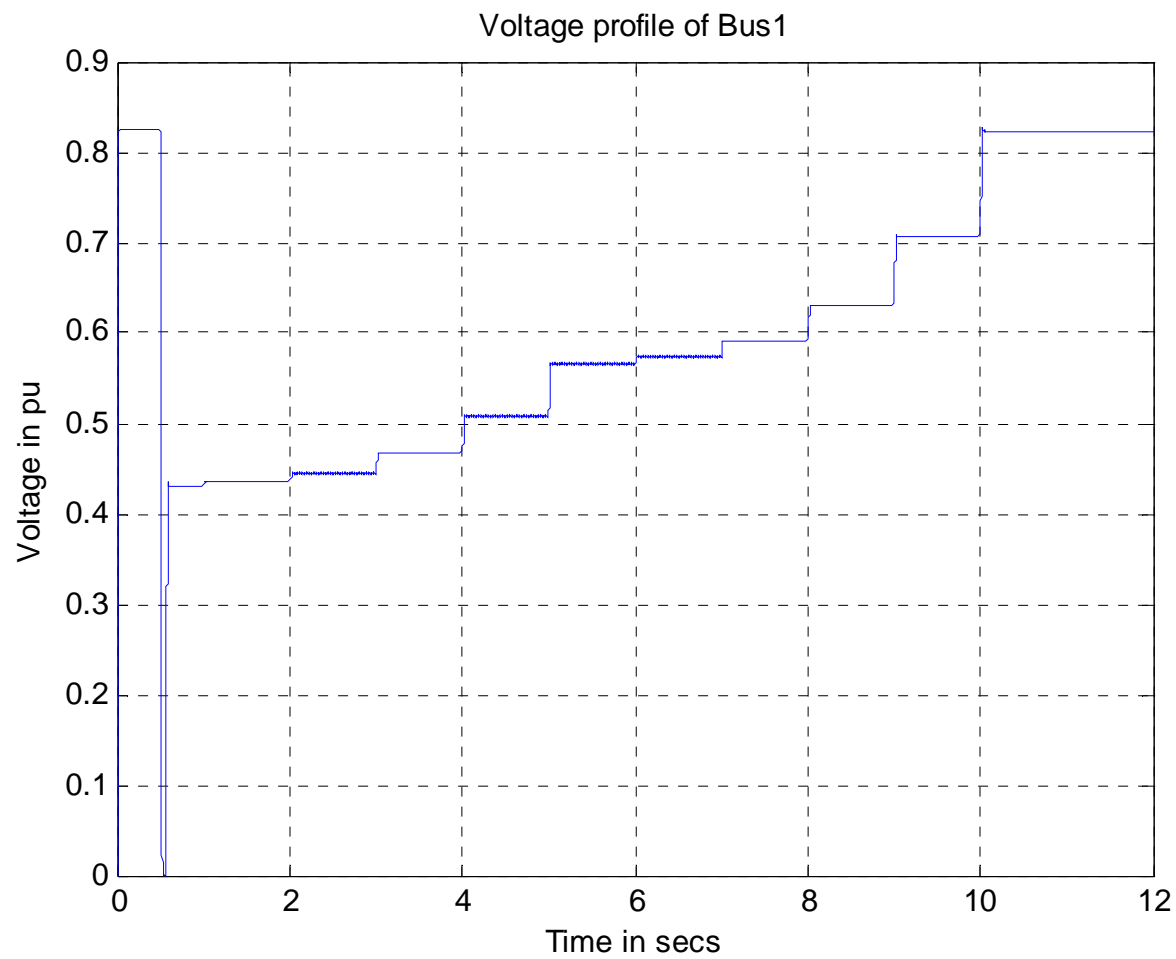

Figure 11-7. Voltage profile of load bus 1. 


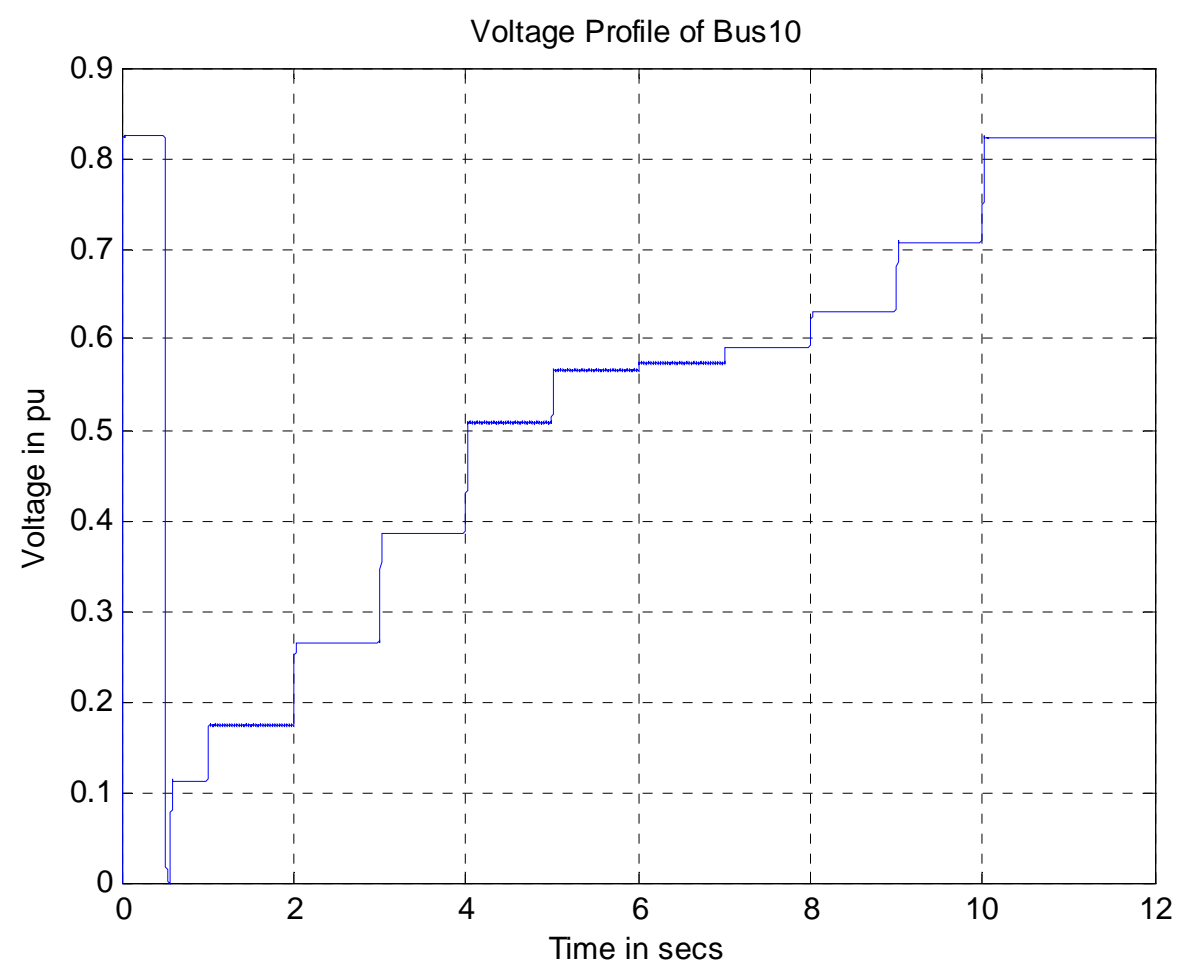

Figure 11-8. Voltage profile of load bus 10.

\subsubsection{Case C: System with 10 MVA loads in a 13.8kV feeder}

The next case considered is one with 10 MVA loads in a $13.8 \mathrm{kV}$ feeder with the fault at the 115 $\mathrm{kV}$ bus. This represents a typical distribution primary feeder. The system configuration is as shown in

Figure 11-9.

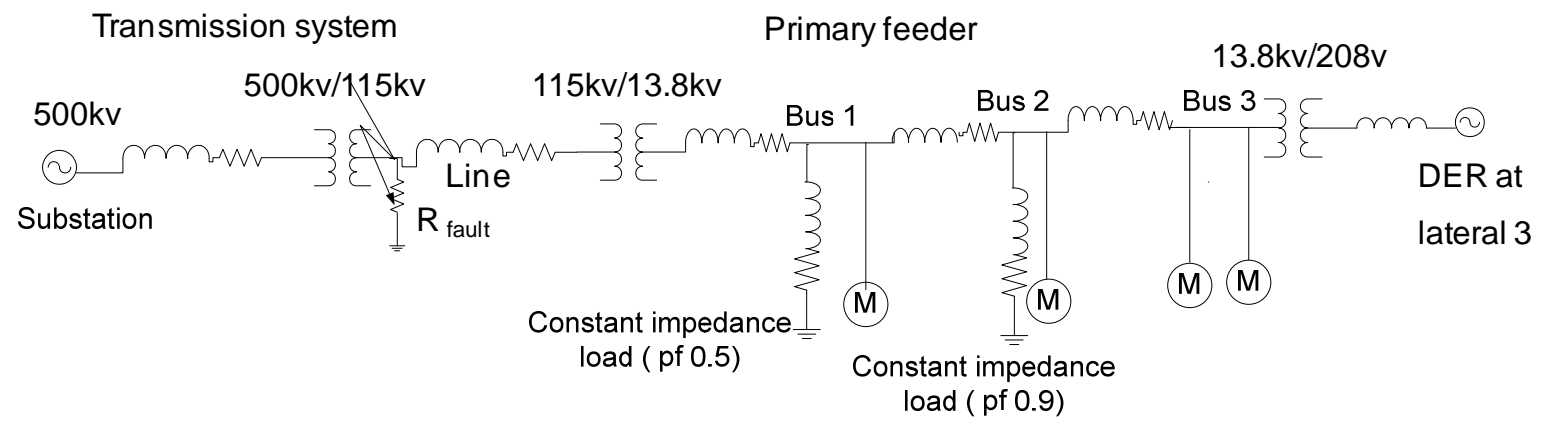

Figure 11-9. System configuration with 10 MVA loads.

The DER is connected to the $13.8 \mathrm{kV}$ feeder via a $208 \mathrm{~V} / 13.8 \mathrm{kV}$ distribution transformer. Control of the DER is carried out with the adaptive voltage control method described in Section 10.6.4. The size of the DER is considered to be unlimited, which injects the reactive power required to improve the fault voltage to above $0.6 \mathrm{pu}$ in 3 cycles so that none of the $\mathrm{A} / \mathrm{C}$ motors 
will enter stalled mode. The controller gain $K_{P}$ and $K_{I}$ values chosen for the adaptive control of the DER during the simulation are shown in Table 11-3.

Table 11-3. Controller gain values for adaptive control of DER for Case C.

\begin{tabular}{|l|l|l|}
\hline Event & $\underline{\boldsymbol{K}_{\boldsymbol{P}}}$ & $\boldsymbol{K}_{\boldsymbol{I}}$ \\
\hline Before fault & 0.05 & 1 \\
\hline During fault & 0.4 & 3.5 \\
\hline After fault & 0.6 & 6 \\
\hline
\end{tabular}

The load composition for this system is given in Table 11-4.

Table 11-4. Load composition for Case C.

\begin{tabular}{|l|c|c|c|}
\hline $\begin{array}{c}\text { Load } \\
\text { Parameters }\end{array}$ & $\begin{array}{c}\text { Constant } \\
\text { impedance } \\
\mathbf{( 3 0 \% )}\end{array}$ & $\begin{array}{c}\text { Constant } \\
\text { impedance } \\
\mathbf{( 2 0 \% )}\end{array}$ & $\begin{array}{c}\text { Residential } \\
\text { A/C (50\%) }\end{array}$ \\
\hline MW & 1.5 & 1.8 & 4.4 \\
\hline MVAR & 2.59 & 0.871 & 2.37 \\
\hline PF & 0.5 & 0.9 & 0.88 \\
\hline
\end{tabular}

For this case, the simulation was carried out for the case with and without DER at bus 3 . For the system shown in

Figure 11-9, the fault was applied at the $115 \mathrm{kV}$ bus at $0.1 \mathrm{~s}$ and cleared at $0.2 \mathrm{~s}$.

Figure 11-10 shows the voltage profile at bus 1 without DER. Without the reactive power support from DER, the A/C motor loads entered the stalled mode so that the voltage could not recover quickly to the value before the fault. The delayed voltage recovery to a value slightly above the original one can be clearly seen in Figure 11-10.

Similarly, Figure 11-11 and Figure 11-12 show the voltage profile at bus 2 and 3, respectively. The voltage of bus 3 can recover to a slightly higher value after the fault than bus 2 and bus 3 , which is visible in Figure 11-12. Note that in these figures, the voltages from $0 \mathrm{~s}$ to $0.02 \mathrm{~s}$ are due to the starting process of the simulation and thus do not correspond to any actual activity.

Figure 11-13 shows the active and reactive power of the stalled motor terminal located at bus 3 . It can be observed that the motor drew a huge amount of reactive power in the stalled case. Before the fault occurred, the motor was in normal running state, so the active and reactive power of the stalled motor terminal was simply zero. The motor unit is taken out of the system at $0.3 \mathrm{~s}$ so the real and reactive power are zero after $0.3 \mathrm{~s}$. 


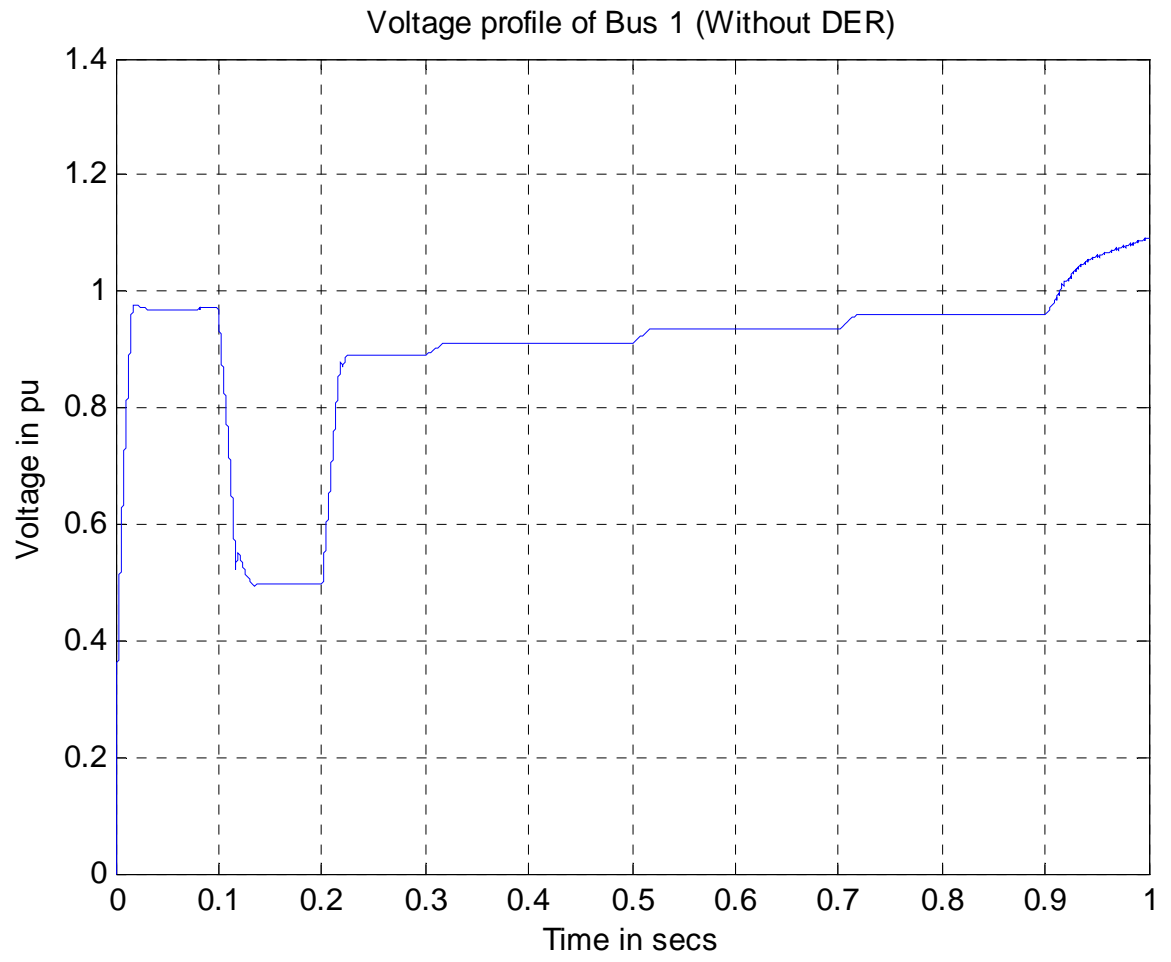

Figure 11-10. Voltage profile at bus1 without DER. 


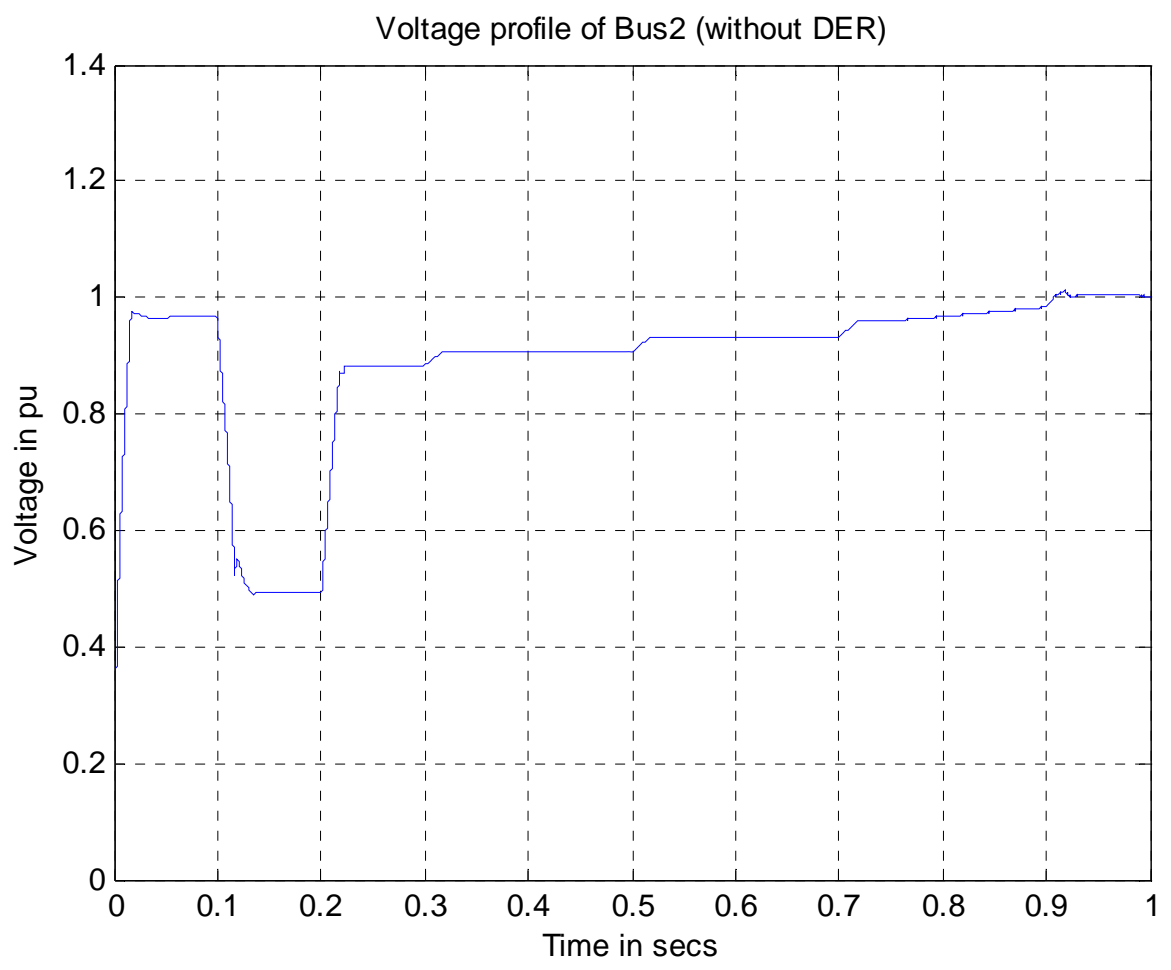

Figure 11-11. Voltage profile at bus2 without DER.

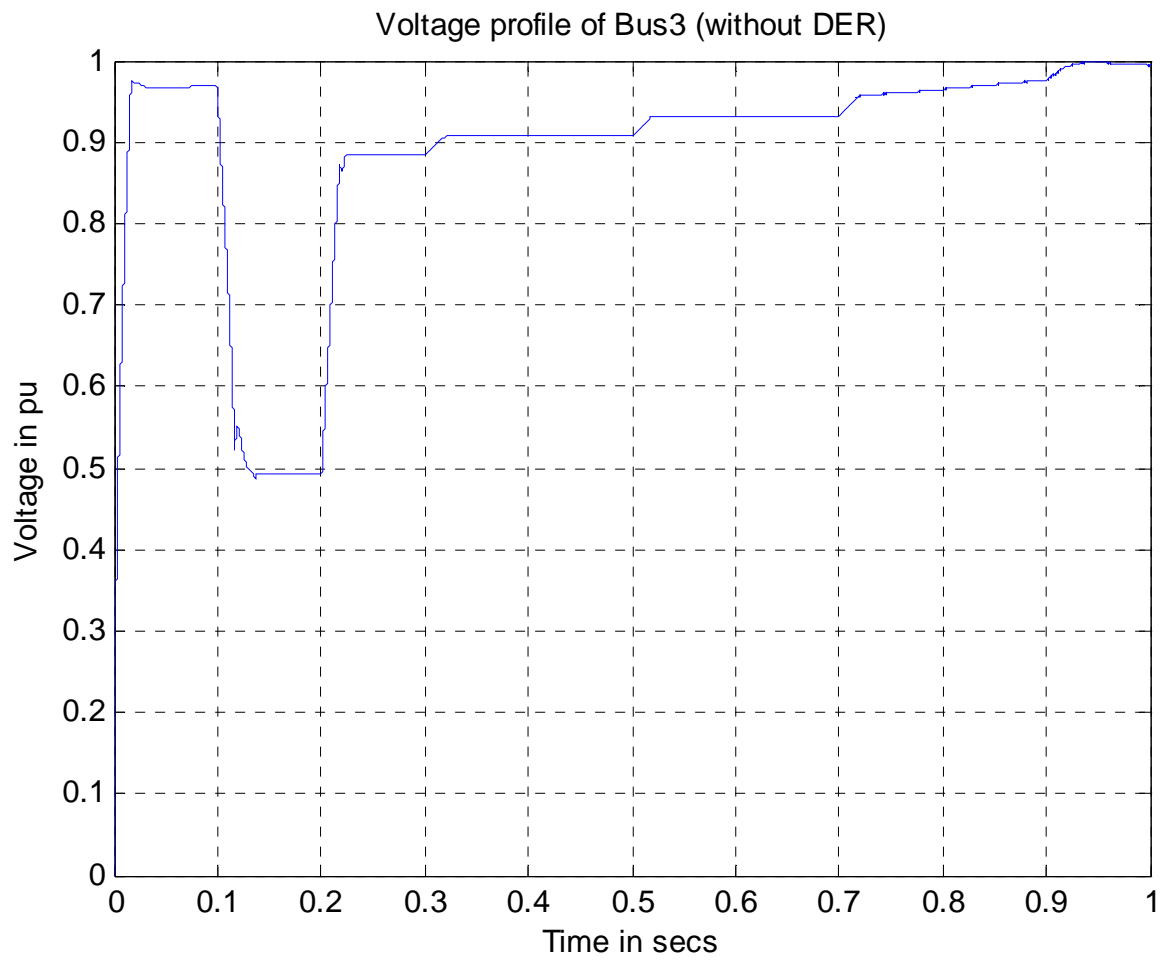

Figure 11-12. Voltage profile at bus3 without DER. 


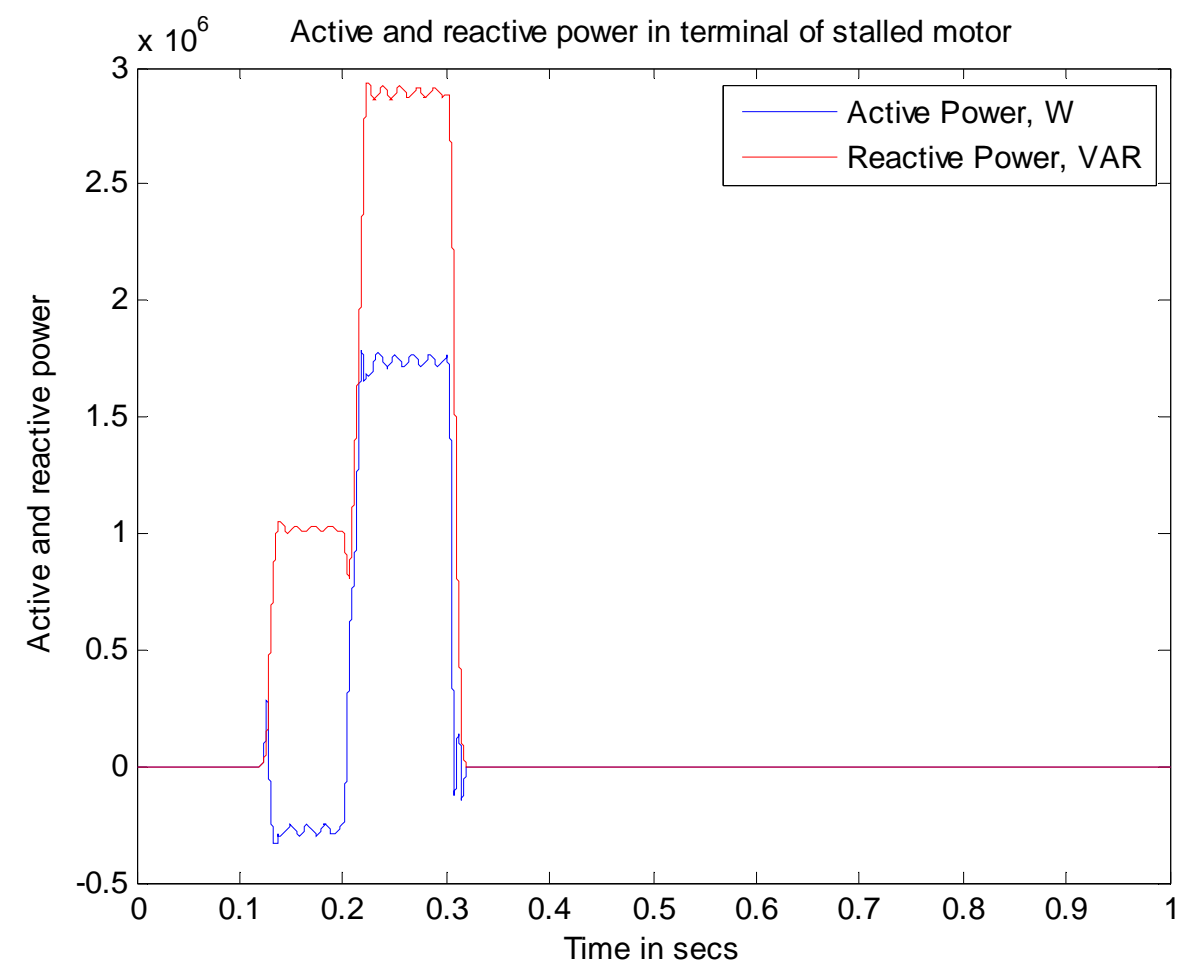

Figure 11-13. Active and reactive power in motor terminal at bus 3.

Now, the case with installation of DER at bus3 and the effect of preventing the A/C motors from stalling is observed. Figure 11-14 through Figure 11-16 show the voltage profile at bus 1, 2 and 3 after the DER is installed at bus 3. It can be observed from the graphs that after the installation of DER, the motors do not enter the stalled mode and continue to be in the running mode. While comparing the voltage profile of Figure 11-10 and Figure 11-14, it can be seen that the fault voltage of around $0.5 \mathrm{pu}$ has been boosted to above $0.6 \mathrm{pu}$ in around 3 cycles. As a result the $\mathrm{A} / \mathrm{C}$ motors do not stall in the later situation, and the voltage quickly recovers to its original value almost immediately after the fault. Some oscillations are visible in the voltage response before reaching the steady-state value, which might be a result of the induction motor dynamics. 


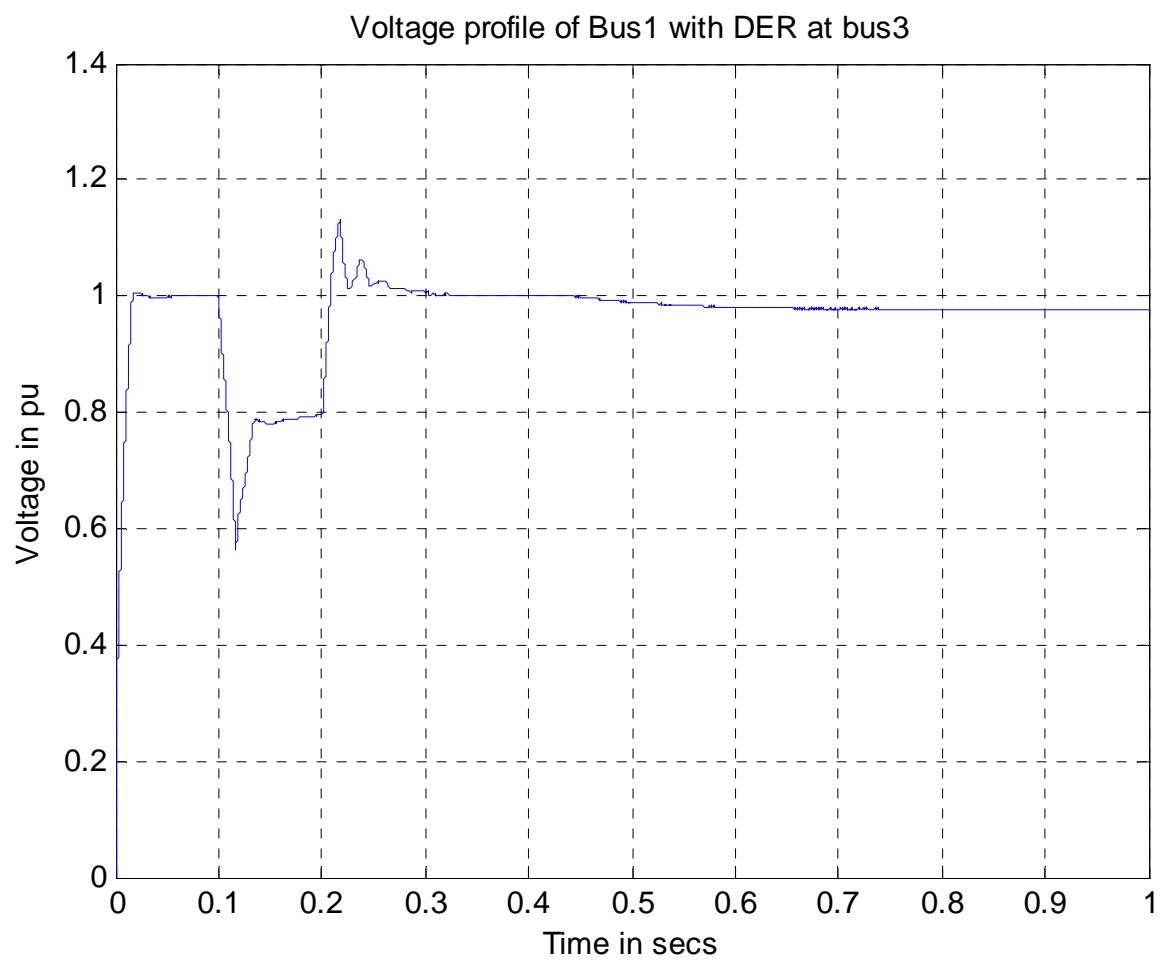

Figure 11-14. Voltage profile at bus1 with DER.

Figure 11-17 shows the reactive power injection from DER at bus 3 in order to prevent $\mathrm{A} / \mathrm{C}$ motors from stalling. It can be seen that around $20 \mathrm{MVAR}$ is required for less than $0.1 \mathrm{~s}$ duration in order to boost the voltage above $0.6 \mathrm{pu}$, which settles down to almost zero after few cycles. For a single DER, the current injection immediately after the fault and during the fault would be quite large. A future area of is the sensitivity of the inverter current versus the voltage boost requirement. Also, as mentioned above the study only considered a single DER but the current injection per DER will decrease as multiple DER is added to the feeder. This is another area of future study. 


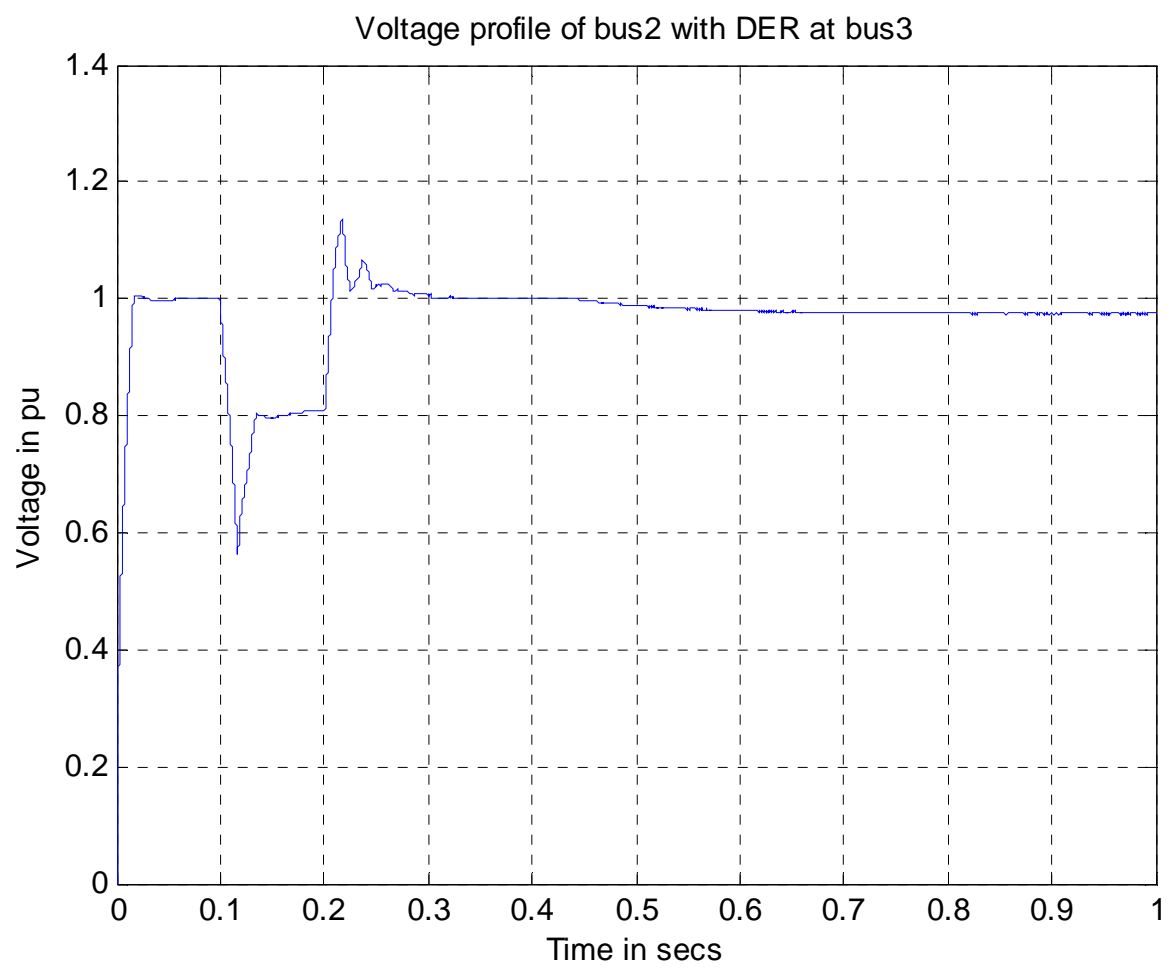

Figure 11-15. Voltage profile at bus2 with DER.

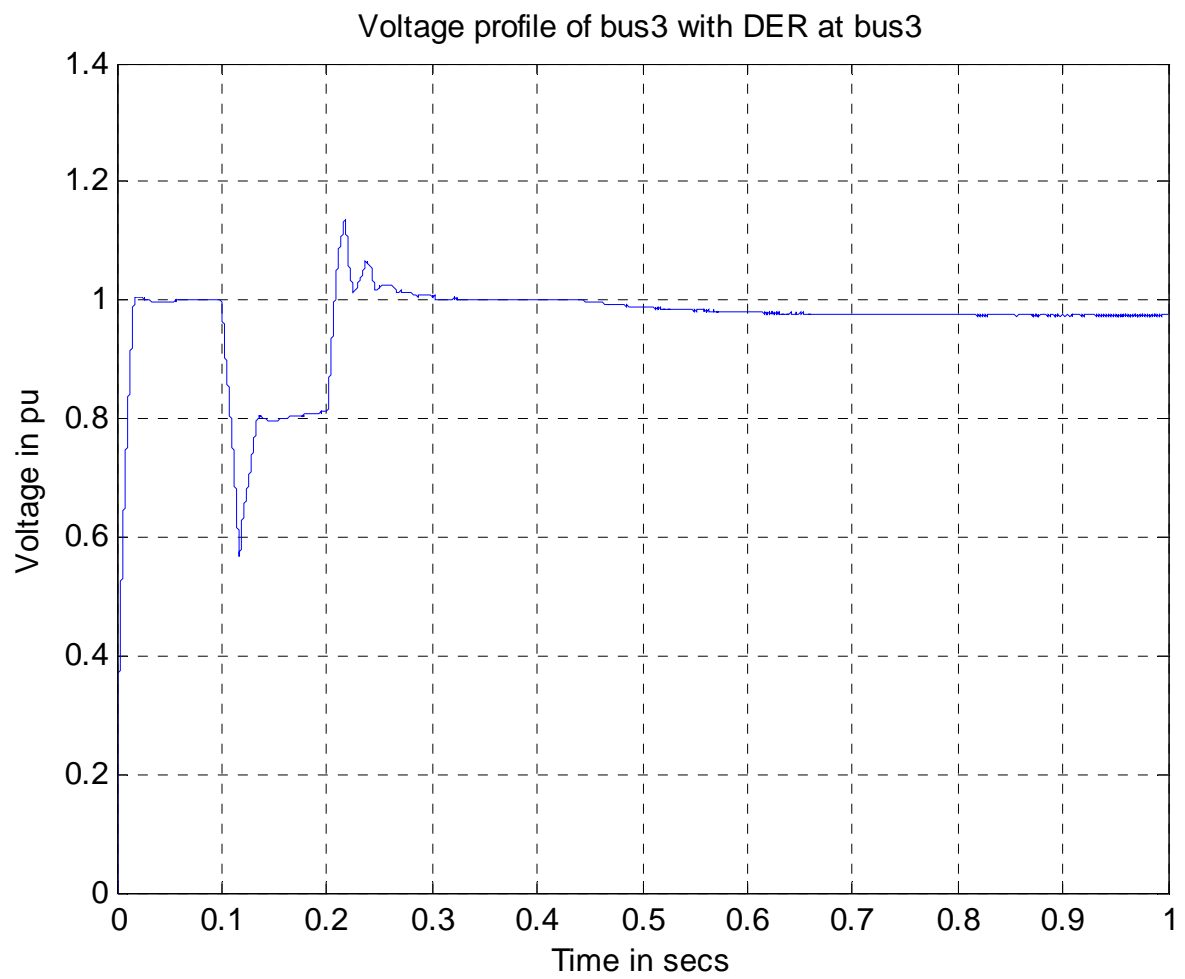

Figure 11-16. Voltage profile at bus3 with DER. 


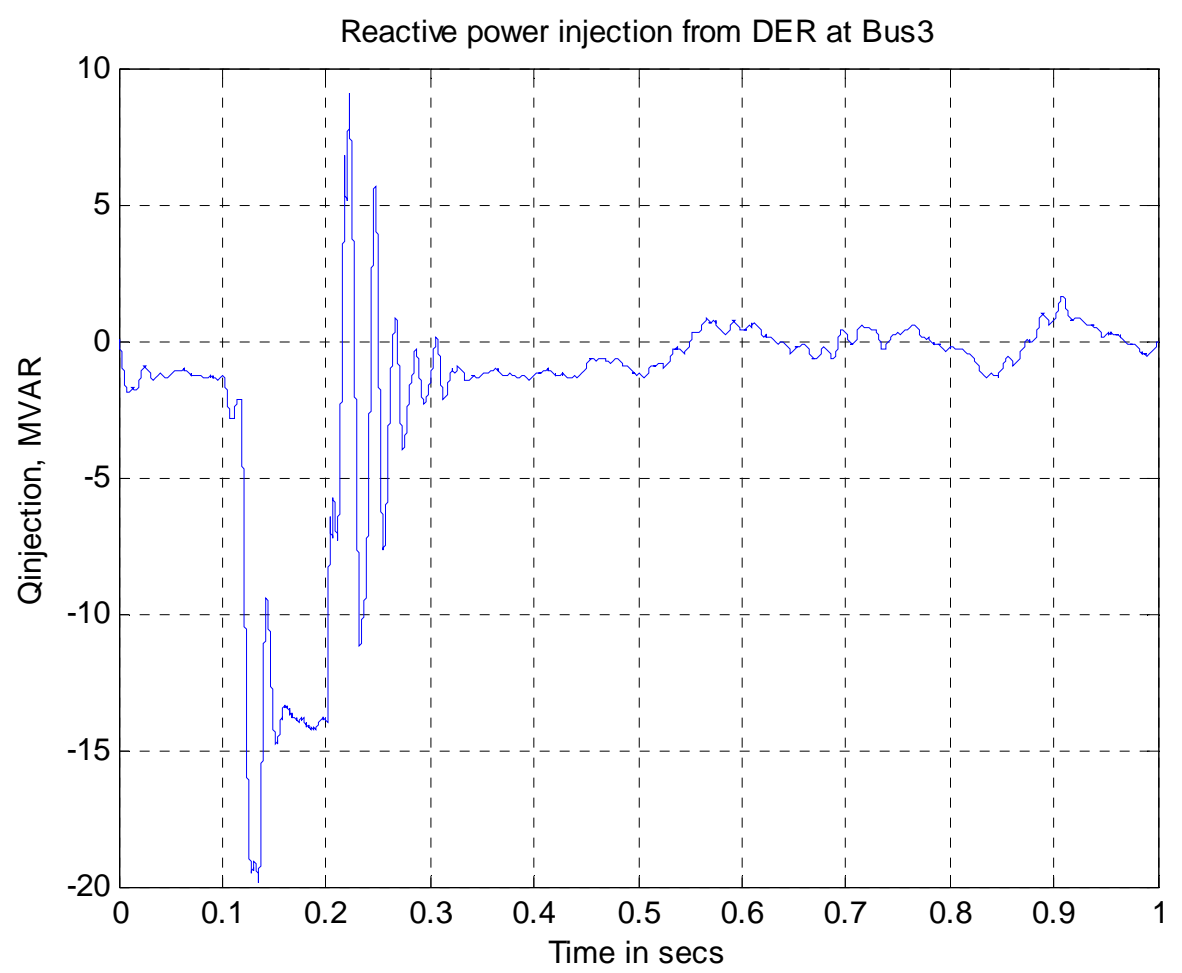

Figure 11-17. Reactive power injection from DER at bus 3.

It is clear from the simulation results that $\mathrm{DE}$ is capable of preventing the stalling of $\mathrm{A} / \mathrm{C}$ motor loads and thus can help prevent microvoltage collapse. The large amount of reactive power injection required for a short duration indicates that an inverter with a short-term overload capability would be ideal; one way to implement such a solution is perhaps to have an inverter that is electrically rated for the overload capability but thermally is not designed for continuous operation at $50 \%$ of the electrical rating. This means that the package (i.e., heat sink) would cost less, be more compact, and reduce the cost of the inverter. Presently, there is no other effective way to provide overload capability other than the use of new materials, i.e., silicon carbide, that allow the inverter to operate more efficiently and thus cooler. Another possible solution is to consider multiple smaller DER in the system. Improvement in power electronics, such as the use of silicon carbide switches to boost efficiency and reduce heating, may be a way to improve the peak performance overall — especially during a short time period such as 10 cycles - to produce an overload capability. This issue needs more investigation in the future.

\section{CONCLUSIONS}

The voltage stability of the electric power system is a complex issue with growing problems. DE can be part of the solution since DE can control local voltage if applied with the right controls and adequate capacity. The growing pressure on transmission and distribution systems to operate at lower margins, as well as the impact of new loads, is putting greater pressure on system stability. One concern is the growth in use of energy-efficient A/Cs that can stall when voltage sags (i.e., at $60 \%$ or even $70 \%$ of nominal voltage on a very hot day) as a result of a 
transmission or subtransmission system fault. Another concern is the growth of power electronics loads - such as CFL bulbs, flat panel TVs, and computers - because they may lead to harmonic, power factor, and power quality issues.

We have developed a rapid dynamic voltage regulation method for inverter and rotating DE systems using PI feedback control. The method can provide a DE system with the ability to control active and nonactive power as well as voltage, current, and power factor. We have demonstrated both in software and with testing at the DECC Lab the ability to regulate voltage using an average rms calculation at a sampling rate of $90 \mu$ s while the inverter is operated at a switching frequency of $12.5 \mathrm{kHz}$. In addition, we have demonstrated the same control methodology with an SC to show that the same method can be applied to a rotating DE system. With two-loop control, we can provide voltage regulation while controlling the current output of the inverter. This control capability is important to ensure the inverter-based DE continues to support local voltage to the extent of its capability by limiting the current to its rating.

We have shown that local voltage regulation is a practical method for expanding the margin to local voltage collapse and for providing local power quality. DE systems equipped with inverters are an excellent method of providing local regulation when the inverter is equipped with rapid, adaptive control. In the severe case of a local fault, it would be desirable for the inverter to have short-term overload capacity to be able to provide the needed reactive power (VARS) for perhaps $0.1 \mathrm{~s}$ to prevent voltage sag during faults from such loads as energy efficient $\mathrm{A} / \mathrm{C}$ compressor motors. Our simulation and test results have confirmed our findings. 


\section{References}

1. V. Stewart, "Modeling of Stalled Motor Loads for Power System Short Term Voltage Stability Analysis," IEEE, 0-7803-9156-X/05.

2. B. R. Williams, "Transmission Voltage Recovery Delayed by Stalled Air Conditioner Compressors, IEEE Trans. Power Systems, Vol. 7, No. 3, August 1992.

3. Evaluation and Modeling of Split System Air Conditioner Performance Under Extreme Ambient Temperatures with R410A Operating Up to the Refrigerant Critical Point, ARTI12CR/605-55015-01, ORNL/TM-2005/277.

4. DOE/ORNL Heat Pump Design Model on the Web, Mark VI Version, an online version of the model can be accessed at http://www.ornl.gov/ wlj/hpdm/MarkVI.shtml.

5. R. Bravo, D. Martinez, R. Yinger and L. Gaillac, "Air Conditioner Test Report”, Southern California Edision Company, November 27, 2006.

6. John DeDad, Editor-in-Chief, "Design E Motor: You May Have Problems," Electrical Construction \& Maintenance (EC\&M) Magazine, September 1, 1999, http://ecmweb.com/mag/electric_design_motor_may/.

7. "Energy Conservation Program for Consumer Products: Test Procedure for Residential Central Air Conditioners and Heat Pumps; Final Rule," Department of Energy 10CFR Part 430, Federal Register, Rules and Regulations, Vol. 72, No. 203, October 22, 2007.

8. Richard L. Nailen,"No Standards Yet for Small Motor Efficiency", Electrical Apparatus Magazine, Sept. 2004.

9. I. Boldea and S. A. Nasar, The Induction Machine Handbook, CRC Press, ISBN: 0-84930004-5, 2002

10. EPRI Power Plant Electrical Reference Series, Volume 6, Motors.

11. American National Standard for Electric Power Systems and Equipment - Voltage Ratings (60 Hertz), ANSI C84.1-2006, American National Standards Institute, Inc., approved December 6, 2006.

12. Air-Conditioning \& Refrigeration Equipment Nameplate Voltages, ARI Standard 110-2002, Air-Conditioning \& Refrigeration Institute (ARI), 2002.

13. H. Li, F. Li, Y. Xu, D. T. Rizy and J. D. Kueck, "Interaction of Multiple Distributed Energy Resources in Voltage Regulation,” IEEE PES General Meeting, Paper No. 08GM0396, Pittsburgh, PA, July 20-24, 2008.

14. Y. Xu, L.M. Tolbert, J.N. Chiasson, J.B. Campbell and F.Z. Peng, “A generalised instantaneous non-active power theory for STATCOM”, IET Electr. Power Appl., Vol. 1, No. 6, November 2007,

http://ieeexplore.ieee.org/search/srchabstract.jsp?arnumber $=4374052 \&$ isnumber $=4374051 \&$ punu

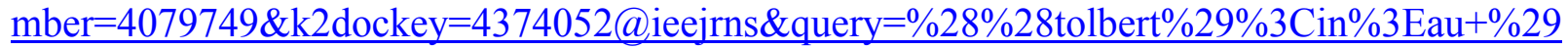
\&pos $=2 \&$ access $=$ no.

15. G. L. Chinn, "Modeling Stalled Induction Motors", 2005/2006 IEEE PES Transmission \& Distribution Conference and Exhibition, ISBN 0-7803-9194-2, August 2006. 